\title{
Equus As Client: A Biocentric Retreat
}

\author{
By
}

Stephanie Agar

A thesis submitted to the Faculty of Graduate and Postdoctoral Affairs in partial fulfillment of the requirements for the degree of

\author{
Master \\ In \\ Architecture
}

Azrieli School of Architecture \& Urbanism

Carleton University

Ottawa, Ontario

(c) 2019

Stephanie Agar 


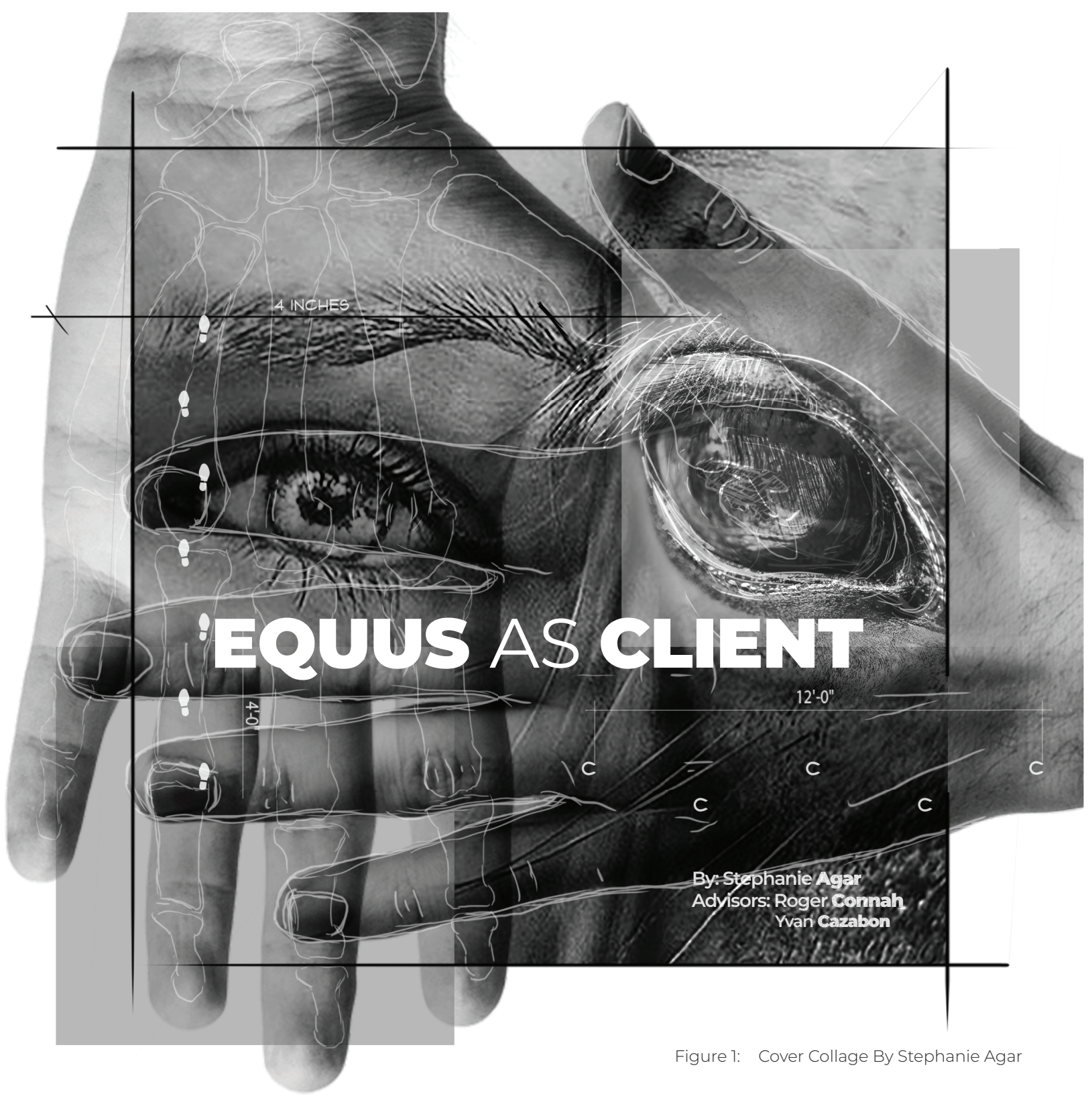




\section{Abstract}

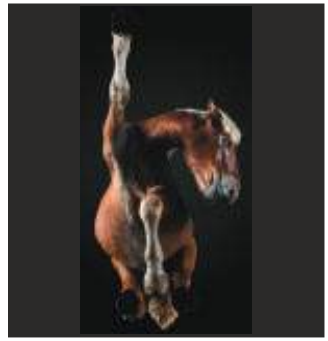

Figure 2: Under-Horse

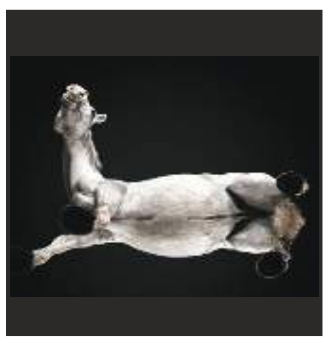

Figure 3: Under-Horse

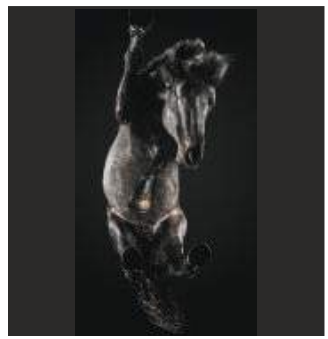

Figure 4: Under-Horse
The foundation of the built world has been acknowledged to be based on ergonomics and the study of the human scale. For architects, this often leads to manifesting a safe, comfortable and inspiring habitat for mankind. This thesis asks what would happen to architecture and design if we shift the perspective towards animals and their natural habitat, well-being and social interactions? The horse will be used as a scalar measure for a re-thinking of architecture and space. This will lead towards re-defining a program for an equestrian facility using the horse as the scale figure, with a programmatic interest in hippotherapy. An amalgamation of the horse, the site and the client/owner's requirements will be attempted with the horse as the front runner for design strategies. The thesis proposes to retrofit an existing ruin in France into a holistic design that provides therapy for the horses, humans and the ruins. 


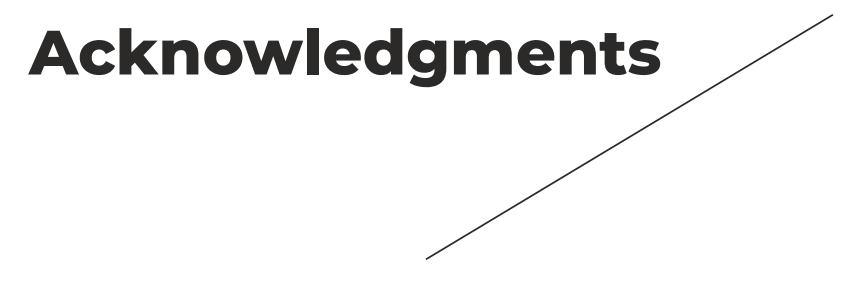

\title{
I am so grateful for the patient, supportive, and in- spiring humans + species who made this book possible.
}

\begin{abstract}
My parents, Phil and Ingrid, thank you for being my \#1 fans with your constant support throughout my education. For always being my soundboards and guiding me towards who I am today. Your hardwork has inspired me to do my best.
\end{abstract}

My brothers, Michael and Rob, thankyou for keeping me modest and grounded. You both have prepared me for the toughest of critiques. Jokes aside, thanks for being great role models growing up.

My friends / Charlie + Rooney, thank you for peeling me away from my computer and for listening to me ramble facts about horses.

My supervisor Yvan, thank you for your patience and valuable guidance which helped me complete the second half of my thesis.

My supervisor Roger, thank you for being a library of knowledge. From Baklava Beach to editing my thesis drafts, you have been a constant support towards my ideas and dreams.

Thank You 


\section{Table of Contents: Section I}

This book is divided into two sections based on the types explorations and research used. Section I: Design by Research includes a series of chapters that provide different outlooks on beneficial information about a typical horse. Section II: Research by Design introduces architecture and design to the information found in Section I. Section II will primarily focus on retrofitting a hippo-therapy center from an abandoned castle, Mothe Chandeniers in Tres Moutiers, France.

i $\quad$......... Preliminary Pages

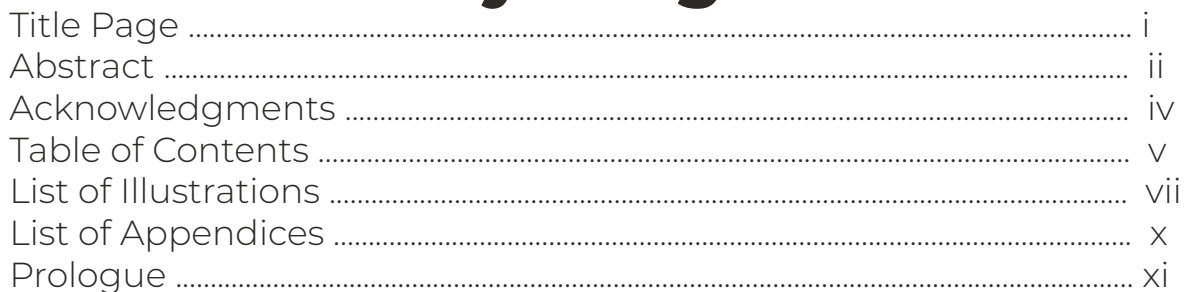

01 ......... Introduction

Introduction Design by Research ......................................................................... 01

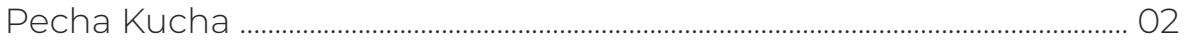

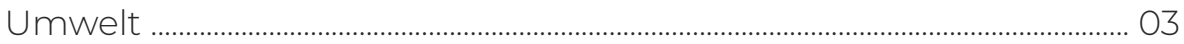

13 ......... Scale

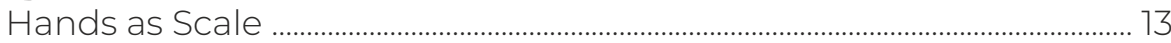

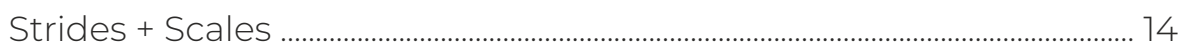

16 .......... Horsesea(er)

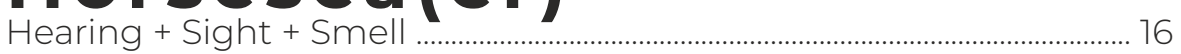

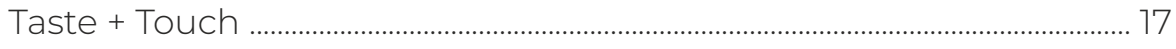

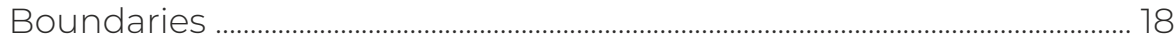

21 ......... Anthropogenic/Biocentric

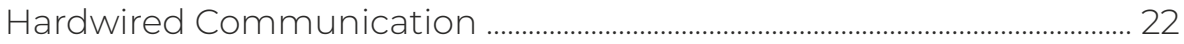

24 ......... Space, Safety, Survival

Hypervigilance .................................................................................................................... 24

Hypersensitive Architecture ................................................................................................. 25

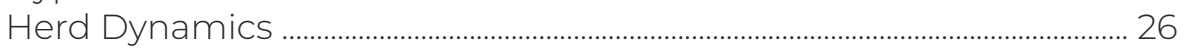

28 ......... The Container / The Barn Detrimental Design ........................................................................................... 28

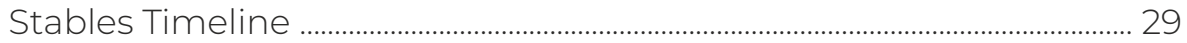

32 ......... Stereotype

Stable Silhouettes 


\section{Table of Contents: Section II}

By collecting the following information, this thesis analyzes areas where architecture can relate, benefit or develop conditions in a space. Architecture can be a mechanism that mirrors and influences one's inner self. In order to fully grasp the intent of the subject, the horse, we must take a less anthropogenic perspective. By doing so, one will gain a better understanding of a horse's actions.

\section{6}

\section{7 .......... Strategics}

\section{1 ......... Program}

\section{5 ......... Site Studies \\ France ... Stu Moutier}

\section{6 ......... Tres Moutiers, France}

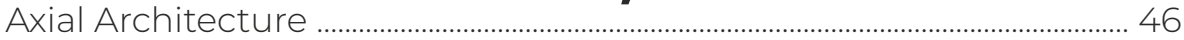

Mothe Chandeniers ................................................................................. 49

Storyline

\section{3 ......... Common Ruins}

Site Context Study

Ruins Floor Plan

61 ......... Design Development

Proposed Drawings

\section{6}

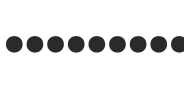

The Zones

Visitors Centre

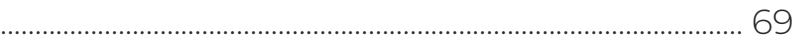

Accommodation Zone .................................................................................. 72

Equestrian Zone ......................................................................................... 74

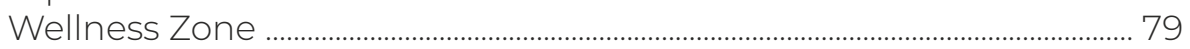

Social Zone

$81 \ldots . . . . . .$. Experience

Multiple Perspective Design

Anamorphic Images

Endnotes

Works Cited 


\section{List of Illustrations}

Figure 1: Cover Collage by Stephanie Agar............................................. pg. ii

Figure 2: Under-Horse Photograph by Andrius Burba ............................. pg. iii

Figure 3: Under-Horse Photograph by Andrius Burba............................... pg. iii

Figure 4: Under-Horse Photograph by Andrius Burba............................... pg. iii

Figure 5: Equestrian Site Plan by Moss Sund Architects ........................... pg. $\mathrm{xi}$

Figure 6: Matrix by Stephanie Agar............................................................. pg. 2

Figure 7: Horse Build Study by Stephanie Agar......................................... pg. 13

Figure 8: Comparing Strides by Stephanie Agar..................................... pg. 14

Figure 9: Road + Railway Scales by Stephanie Agar.............................. pg. 15

Figure 10: Standard Doors by Stephanie Agar......................................... pg. 15

Figure 11: Standard Bathroom by Stephanie Agar..................................... pg. 15

Figure 12: Standard Bedroom by Stephanie Agar..................................... pg. 15

Figure 13: Standard Wash Stall by Stephanie Agar...................................... pg. 15

Figure 14: Standard Horse Stall by Stephanie Agar................................... pg. 15

Figure 15: Horse Sense by Stephanie Agar..................................................... pg. 16

Figure 16: Horse Sense by Stephanie Agar................................................. pg. 17

Figure 17: Horse Vision by Stephanie Agar................................................ pg. 18

Figure 18: 360 Riding Arena Photograph by Stephanie Agar..................... pg. 19

Figure 19: 360 Horse Stable Photograph by Stephanie Agar....................... pg. 19

Figure 20: Horse-Human Bonds by Stephanie Agar.................................. pg. 21

Figure 21: Claustrophobia Photograph by Nicholas Oen ......................... pg. 25

Figure 22: Germaphobia Photograph by Sertaneojo Bruto ...................... pg. 25

Figure 23: Isolophobia Photograph by Donna Caterick .......................... pg. 25

Figure 24: Nyctophobia Photograph by Wayne Tilcock .......................... p 25

Figure 25: (Non)Domesticated Stats by Stephanie Agar............................ pg. 28

Figure 26: Stables throughout time by Stephanie Agar............................ pg. 30

Figure 27: Stable Stereotypes by Stephanie Agar..................................... pg. 33

Figure 28: Healthy Stables by Design by John Blackburn Architects ......... pg. 34

Figure 29: Design Strategies by Stephanie Agar....................................... pg. 40

Figure 30: Program Footprints by Stephanie Agar...................................... pg. 42

Figure 31: Land Use in France by Stephanie Agar...................................... pg. 45

Figure 32: Axis at Versailles Photograph by Norman K Booth.................. pg. 46

Figure 33: Vegetable Rows Photograph by "Lets Talk Business ............... p p. 47

Figure 34: Tree Rows Photograph by Unknown ..................................... pg. 47

Figure 35: Road Blasted Through Rock Photograph by Bryce Canyon.... p p. 47

Figure 36: Mothe Chandeniers Aerial Photograph by YAC....................... pg. 49 
Figure 37: Mothe Chandeniers Interior Photograph by YAC …................ pg. 49

Figure 38: Mothe Chandeniers Openings Photograph by YAC …............ pg. 52

Figure 39: Mothe Chandeniers Portico Photograph by YAC ..................... pg. 52

Figure 40: Bridge Towards Entrance Photograph by YAC ........................ pg. 52

Figure 41: Mothe Chandeniers Exterior Photograph by YAC ................... pg. 52

Figure 42: Mothe Chandeniers Aerial Photograph by YAC ..................... pg. 52

Figure 43: Common Ruins Equus Cover by Stephanie Agar ........................ pg. 53

Figure 44: Context Study by Stephanie Agar …........................................ pg. 56

Figure 45: Front Elevation by Stephanie Agar........................................... pg. 57

Figure 46: Floor Plan by Stephanie Agar................................................. pg. 57

Figure 47: Site Plan by Stephanie Agar................................................... pg. 57

Figure 48: Mothe Chandeniers Axo by Stephanie Agar ............................. pg. 58

Figure 49: Mothe Chandeniers Sketch by Stephanie Agar ......................... pg. 59

Figure 50: Proposed Floor Plan by Stephanie Agar..................................... pg. 60

Figure 51: Program Cycle by Stephanie Agar ........................................... pg. 61

Figure 52: Strategy by Stephanie Agar................................................. pg. 62

Figure 53: Exploded Axonometric by Stephanie Agar............................... pg. 63

Figure 54: Site Plan 1:1500 by Stephanie Agar........................................ pg. 65

Figure 55: Historic Rear Exterior Render by Stephanie Agar...................... pg. 66

Figure 56: Historic Key Plan by Stephanie Agar...................................... pg. 66

Figure 57: Historic Axonometric by Stephanie Agar................................. pg. 66

Figure 58: Thermal Bath Render by Stephanie Agar................................. pg. 67

Figure 59: Cafe Render by Stephanie Agar............................................... pg. 67

Figure 60: Courtyard Render by Stephanie Agar....................................... pg. 68

Figure 61: Aerial Render by Stephanie Agar ............................................ pg. 68

Figure 62: Visitors Centre Render by Stephanie Agar................................ pg. 69

Figure 63: Visitors Centre Render by Stephanie Agar................................. pg. 69

Figure 64: Visitors Centre Key Plan by Stephanie Agar.............................. pg. 69

Figure 65: Visitors Centre Axo by Stephanie Agar...................................... pg. 69

Figure 66: Castle Ruins Section by Stephanie Agar ................................... pg. 70

Figure 67: Accommodation Render by Stephanie Agar .............................. pg. 72

Figure 68: Accommodation Key Plan by Stephanie Agar............................ pg. 72

Figure 69: Accommodation Axo by Stephanie Agar .................................... pg. 72

Figure 70: Accommodation Render by Stephanie Agar ............................. pg. 72

Figure 71: Villa Section Render by Stephanie Agar .................................... pg. 73

Figure 72: Villa Interior Render by Stephanie Agar..................................... pg. 73

Figure 73: Equestrian Key Plan by Stephanie Agar ..................................... pg. 74

Figure 74: Equestrian Axonometric by Stephanie Agar ............................. pg. 74

Figure 75: Equestrian Rooftop by Stephanie Agar ....................................... pg. 74

Figure 76: Equestrian Floor Plan by Stephanie Agar .................................. pg. 75

Figure 77: Equestrian North-South Section by Stephanie Agar .................. pg. 76 
Figure 78: Equestrian East-West Section by Stephanie Agar …….............. pg. 76

Figure 79: Equestrian West-East Section by Stephanie Agar ..................... pg. 76

Figure 80: Horse Stall Render by Stephanie Agar.................................... pg. 77

Figure 81: Equestrian Interior by Stephanie Agar ................................... pg. 77

Figure 82: Stable Corridor Render by Stephanie Agar ............................... pg. 77

Figure 83: Wellness Below Grade by Stephanie Agar ............................... pg. 79

Figure 84: Wellness at Grade by Stephanie Agar .................................... pg. 79

Figure 85: Wellness Key Plan by Stephanie Agar........................................ pg. 79

Figure 86: Wellness Axo by Stephanie Agar ............................................ pg. 79

Figure 87: Social Exterior Seating by Stephanie Agar ................................ pg. 80

Figure 88: Social Fire Pit by Stephanie Agar .............................................. pg. 80

Figure 89: Social Key Plan by Stephanie Agar .......................................... pg. 80

Figure 90: Social Axo by Stephanie Agar.................................................. pg. 80

Figure 91: Co-Habitation Render by Stephanie Agar.................................. pg. 81

Figure 92: Multi-Perspective Catalogue by Stephanie Agar ....................... pg. 82

Figure 93: Physical Model Photograph by Stephanie Agar ......................... pg. 83

Figure 94: Physical Model Photograph by Stephanie Agar ......................... pg. 83

Figure 95: Physical Model Photograph by Stephanie Agar ......................... pg. 84

Figure 96: Physical Model Photograph by Stephanie Agar ........................ pg. 84

Figure 97: Physical Model Photograph by Stephanie Agar ........................ pg. 84

Figure 98: Physical Model Photograph by Stephanie Agar ........................ pg. 84

Figure 99: Physical Model Photograph by Stephanie Agar ......................... pg. 84

Figure 100: Physical Model Photograph by Stephanie Agar ......................... pg. 84

Figure 101: Physical Model Photograph by Stephanie Agar ........................ pg. 84

Figure 102: Equestrian Anamorphic by Stephanie Agar............................... pg. 85

Figure 103: Wellness Anamorphic by Stephanie Agar................................. pg. 86

Figure 104: Historic Anamorphic by Stephanie Agar .................................... pg. 87

Figure 105: Equestrian Anamorphic by Stephanie Agar ............................. pg. 88

Figure 106: Wellness Anamorphic by Stephanie Agar ................................. pg. 89

Figure 107: Canada's Horse Statistics by Stephanie Agar.............................. pg. 101

Figure 108: Hanna, Alberta Aerial Photograph by Calgary Herald ........... p p. 102

Figure 109: Hanna Roundhouse Interior Photograph by This Place Matters. pg. 102

Figure 110: Hanna, Alberta Site Plan by Stephanie Agar............................. pg. 103

Figure 111: Hanna, Alberta Axo by Stephanie Agar .................................. pg. 104

Figure 112: Hanna, Alberta Sketch by Stephanie Agar .............................. pg. 105

Figure 113: Bat Tower Sketch by Ants of the Prairie ................................ pg. 106

Figure 114: Bat Tower Render by Ants of the Prairie ................................. pg. 106

Figure 115: Co-Habitat Diagram by Ants of the Prairie .............................. pg. 106

Figure 116: Co-Habitat Render by Ants of the Prairie ................................. pg. 106

Figure 117: Working with Farm Animals Book Cover by Temple Grandin ... pg. 107

Figure 118: Amphibious Architecture by The Expanded Environment ........ pg. 107 


\section{List of Appendices}

\section{1 ........... Appendix A: canada site study}

Canada Horse Statistics ................................................................................................ 101

Hanna Alberta Roundhouse Site Study ......................................................... 102

\section{$106 \ldots . . . . . .$. Appendix B: precedent Biocentric Projects}

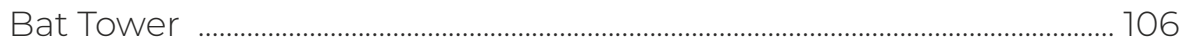

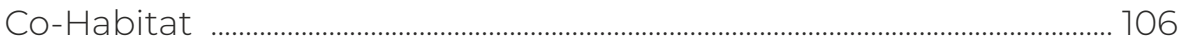

Temple Grandin Working With Farm Animals ............................................ 107

Amphibious Architecture ............................................................................................ 107 


\section{Prologue}

In 2016, I began working for Moss Sund Architects in Toronto, Ontario. I was inspired by the firm's environmentally conscious approach to architecture, and their dedication towards incorporating passive design and net-zero strategies in their projects. During my tenure, the principle architect, Carolyn Moss and I worked on a design proposal for a private equestrian center located in King City, Ontario. The project consisted of an indoor riding arena, a barn with 10 horse stalls, an indoor $25 \mathrm{~m}$ racing pool, a $400 \mathrm{~m}$ running track, and a new residence for the two clients and their three children. The clients wished to have a close living quarters and viewing relationship with the horses. The design was a unique facility that not only achieved the typical sustainability requirements but was also customized to the horses and their well-being. The clients reasoning was simple: the horses gave so much to them that they wanted to do the same by customizing their barn while breaking away from the traditional barnyard design. Essentially, the horses became our client. The final proposal included natural ventilation to reduce airborne dust and bacteria in the air, a manure and hay storage which naturally heats the facility and a strategic design focusing on the horse's psyche. Interested in providing a secondary program, we began researching the benefits of hippo-therapy; the practice of horseback riding as rehabilitative treatment for people who are suffering from PTSD, cerebral palsy, and anxiety. Horses have proven to be extremely successful resources for treating wounded soldiers, people with cognitive and physical disabilities, drug addicts, and convicts.

During this thesis, I came across an international competition. I chose to transfer this background research to a different site in order to deepen the research and test the programmatic principles of hippotherapy.

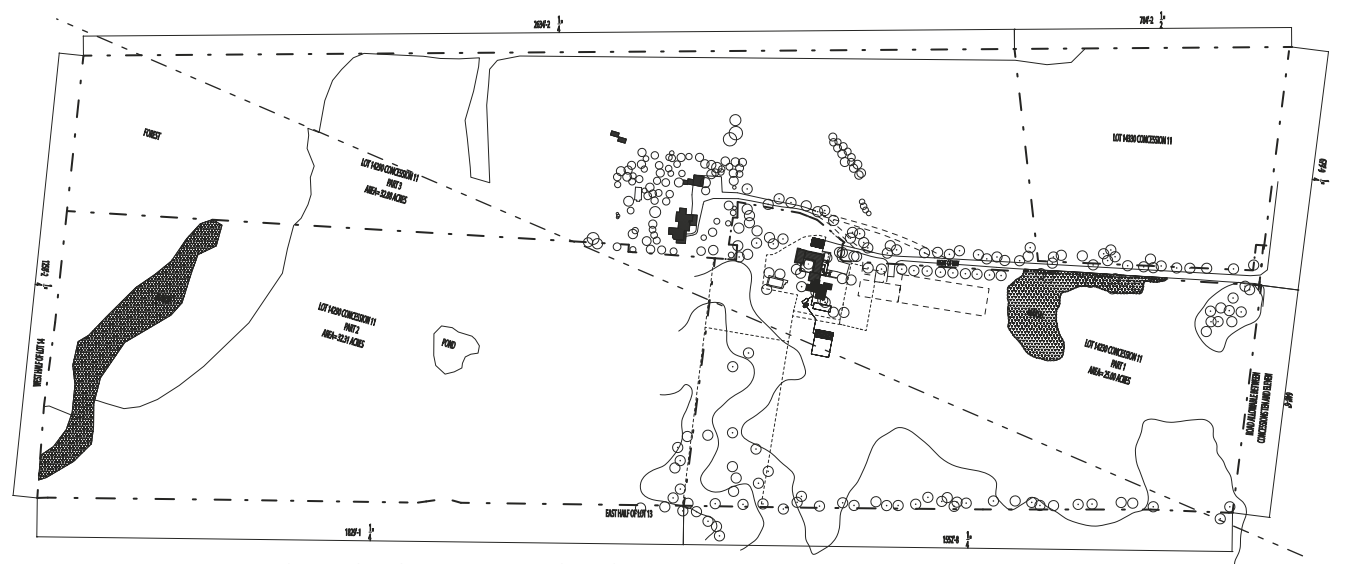

Figure 5: Equestrian Centre Floor Plan by Moss Sund Architects

Equus As Client: A Biocentric Retreat 


\section{Introduction}

Regardless of the environment, each species or subject exists in it's own realm. Depending on the subject, the objects within its realm are entirely dependent what is relevant to the subject. Their differences in size, appearance, requisites, and perspective justify that all subjects have their own "umwelt" or surrounding environment.?

It is not uncommon for a human to anthromorphize their interpretation of other animals intentions and their realms. As a prey animal, the horse has survived on this earth for 55 million years, co-existing with other animals in the wild and within the last 1.5 to 2.5 million years has coexisted with the genus homo sapiens, humans. During this relatively "short" time, humans have domesticated all of the species of horses with the exception of two, the Tarpan and the Przewalski. ${ }^{2}$

Throughout this time, horses and humans have formed an unlikely relationship that has progressed society in agriculture, defense, transportation, entertainment and more recently, in therapy. ${ }^{3}$ This human - horse connection will be embodied in the architectural discoveries in this thesis. Exploring how consciously and subconsciously, the built environment affects one's mental state. Mechanisms such as light, scale, form, material, and even aroma will be studied in the project's design. Experiential qualities in architecture will be essential in creating a comfortable environment for all inhabitants. ${ }^{4}$

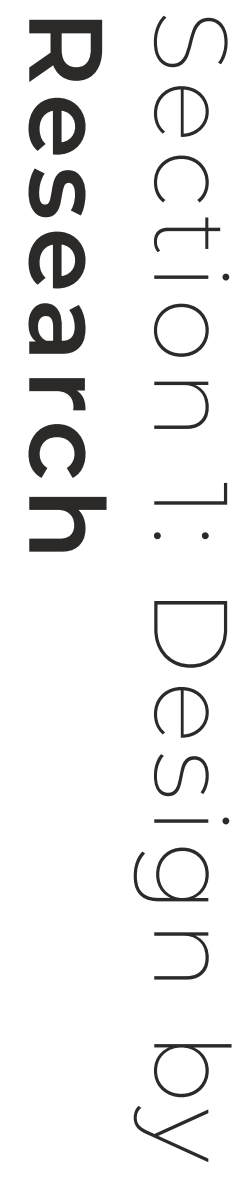

**One meaning both horse, human and all living things in general. 


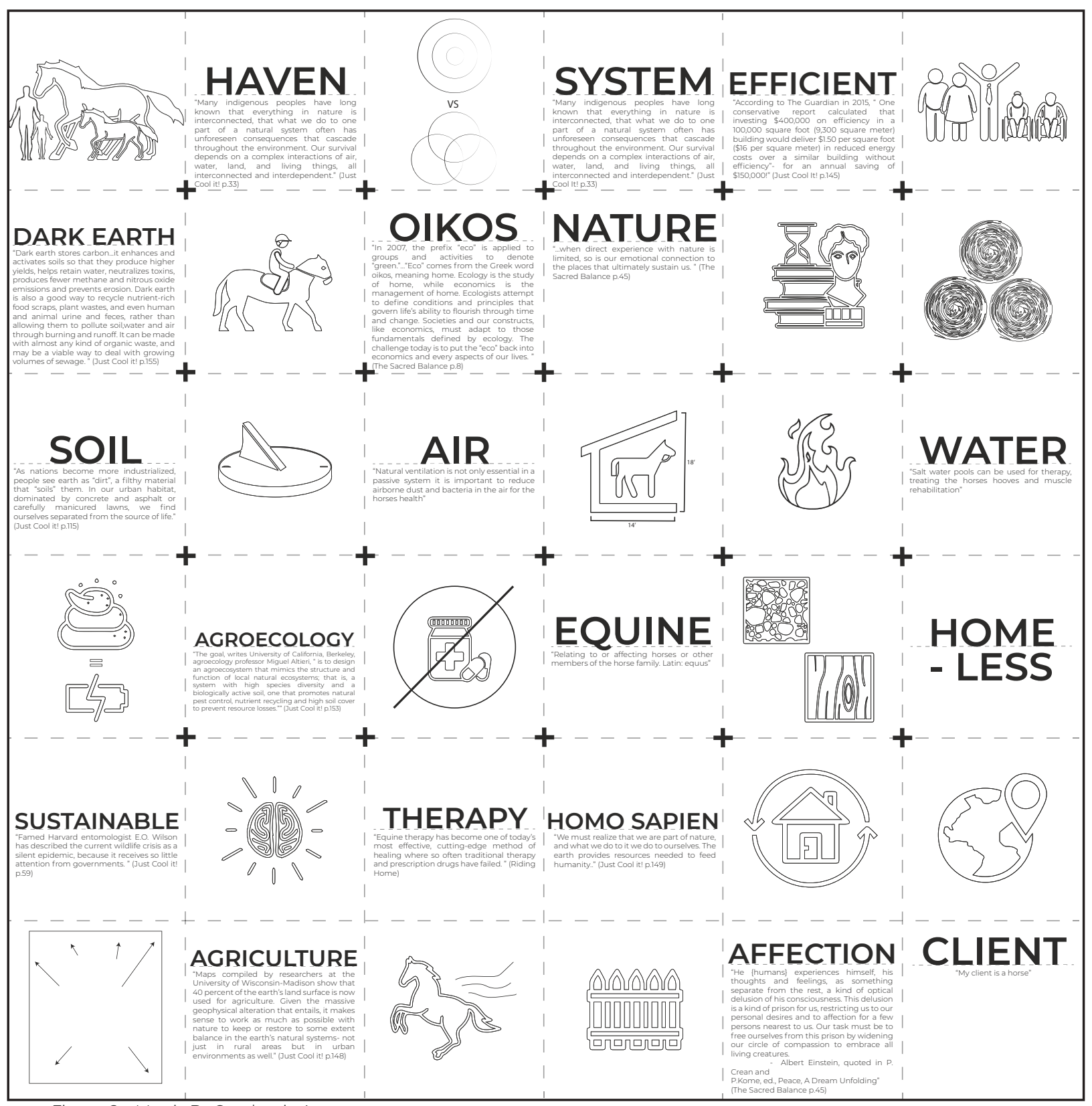

Figure 6: Matrix By Stephanie Agar 


\section{Umwelt}

Literature, philosophy, technology, and science have always considered the non-human perception. Such perspectives include other species, the built environment, plants, and more recently technological objects. An individual's perspective of space or an object varies depending on the subject's own bodily form, senses, emotion, memory, methods, and intent with the space or object. ${ }^{5}$ One can gain a richer understanding of the subject's actions when distanced from our own skewed impressions. The experiences humans have versus what non-humans have during the same moment are different. What is consistent throughout the study of all non-human perspectives is the pivot from an anthropocentric mindset, which privileges the human actors, to a biocentric mindset that considers the human actor as an equal among an entire ecological system. Biocentric individualism is understood as the "belief that all living things deserve some moral respect, and the ecological ethic, the belief that ecosystems deserve moral respect as wholes." 6 This non-anthropocentric perspective involves relations and interactions between humans and non-humans in a non-categorical manner. What is important is how the capabilities and limitations of all the subjects work against or compliment each other in any given moment.?

The biocentric perspective is often considered a view in favor of animals, excluding the human species. It is essential however to understand that the human does not disappear in a non-anthropocentric perspective, rather it becomes an individual entity in an amalgamation of entities. All entities are legitimate and equal in this mix of "radical pluralism". ${ }^{8}$ Examples of theoretical and built projects will be analyzed to allow us to comprehend how literature, architecture and technology

Equus As Client: A Biocentric Retreat 
may incorporate an other-than human perspective. Such examples highlight the potential design possibilities, material agency considerations, analysis of forms, and the exploration of the engagement of all potential senses.

Jakob von Uexküll describes a subject's "umwelt" or unique environment as follows "...for everything a subject perceives belongs to its perception world [Merkwelt], and everything it produces, to its effect world [Wirkwelt]. These two worlds, of perception and production of effects, form one closed unit, the environment... These environments, which are as diverse as the animals themselves, offer every nature lover new land of such richness and beauty that stroll through them will surely be rewarding, even though they are revealed only to our mind's eye and not our body's." 9

Although there seems to be development in non-anthropocentric perspectives, human-centeredness continues to dominate literature, science, and especially design projects. There are obvious implications and hurdles involved when shifting away from a human perspective. This thesis provides an argument for the non-human perspective and the rewards for exercising this alternative perspective. Concepts may be discounted when implementing only a human-centered perspective. A non-human approach expands the scope requirements of the project and it's research as it incorporates humans needs and wishes as well as other subjects involved. By realigning one's perspective, new opportunities for a phenomenological experience in design, literature and research are created. ${ }^{10}$

The human perception is our most relatable and automatic form of perception when manifesting art for humans to enjoy within their own culture. The rapid development of humans over time has created built-environments, social realms, 
measurements, and material indulgences that non-domesticated species do not perceive as important." A simple exercise of comparing a horse interacting with its environment to a human interacting with its environment illustrates this. There is a clear difference in an "other-centered" perspective to a generally "self-centered" perspective. As a prey animal, a horse's senses and awareness to its surrounding environment are extremely acute in comparison to a predator such as a human. Physically, a horse's eyes are farther apart than a human, creating a different range of vision and perception of depth. What may be left, right, up, down, forwards, and backwards to a human is different to a horse. ${ }^{12}$ A human may determine a chair as an object to sit on, where a horse may think it's a predator. A human may use a fence or signage as a boundary line to express their territory, where a horse may use scents and body language to demonstrate their territory. A subject's level of interaction with their surroundings depends entirely on whether they have had a previous encounter or a hardwired connection within the space. ${ }^{13}$ Jakob von Uexküll justifies this idea in the following: "With the number of actions available to an animal, the number of objects in its environment also increases. It increases as well in the individual life of any animal capable of accumulating experiences, for each new experience conditions a new attitude toward new impressions." 14

Humans are imprinted with the belief that our species is at the top of a scala naturae. It is a myth that has been contrived and widely understood by humans that we are superior in all ways to other animals and that our perception is the most interesting and important. ${ }^{15}$ This quotation by Jakob von Uexküll illustrates this myth humans collude with, "... it begins to look increasingly ridiculous for us to indulge our delusions of possessing a radical cleverness, some sort of un-Umwelt that would separate us as if by an "abyss" (as Heidegger puts it) from other ani-

mals." 16 To overcome this position, one can start with exploring non-humans and their abilities to express themselves. Another way to shift one's perspective would 
be to visit, meditate or inhabit the natural environment. Returning the roots of all species' initial "home" provokes one's imagination to recollect a perspective before there was differentiation from other forms of life. ${ }^{17}$

"In Tibetan Buddhism lojong is the art of putting yourself in another's shoes. Thus, while assuming the sensorium of other organisms has long been claimed in shamanic circles, and has been explored in fiction... such explorations, such as "embodiments" remain rare in scientific literature." 18

Eileen Scarry writes with passion for both the natural world, specifically flowers, and the world of literature. She discusses how flowers are uniquely attuned to human perception and how the phenomena which is most evocative in literary language, to describe space, shares qualities with flowers. Scarry explains that just as architects understand how to manipulate buildings, writers understand how words are their material palette to influence the human brain. ${ }^{19}$ Scarry explores the world from all perspectives and uses this as a tool to enhance writing, theories and the built environment.

In The Spell of the Sensuous, David Abrams divides his explanation for his studies into a personal and scientific chapter. His main argument is that "we are human only in contact, and conviviality, with what is not human." 20 In other words, consciousness and mindedness emerge from environmental attunement. He argues that our present society participates almost exclusively with other humans and with our own human-made technologies. Abrams is shifting this attention back to non-human nature and through his surroundings, specifically to the organic world. His spatial recognition depends entirely on the relationship to the landscape and our ability to engage, participate, and sense the surrounding world. 
He defines the act of perception of being seen and seeing others. To Abrams, participation is being in one another's existence, influencing each other and being influenced in turn. ${ }^{21}$ The Spell of the Sensuous has a vivid descriptive writing style that eloquently relates and contrasts nature from a non-human and human perspective. Real life experiences are shared explaining how he truly attuned himself to animal perception and constantly compared structured opinions or built surroundings to something more organic.

During a night in Bali, as Abrams was walking alongside the fireflies and stars in the rice fields, he has a bodily experience with the landscape. "I was no longer beneath the nights sky but also above it - the immediate impression was of weightlessness" 22 In this experience, Abrams exclaims that he was a part of a systematic whole in his surroundings. Mirroring Jakob von Uexküll's attitude towards a biocentric perspective, Abrams explains that if we shut ourselves off from the other voices like the landscape and other animals, we are robbing ourselves of humanity. ${ }^{23}$

Architects have a responsibility to design spaces that are experiential, enlightening and engaging to the subject inhabiting it. In order to do so, designs are strategically thought through based on the target occupant. The objects and attributes within the designed space must resonate with the subjects. ${ }^{24}$ James Gibson's definition of 'affordance' explains the concept further as "a combination of physical properties of the environment that is uniquely suited to a given animal-to his nutritive system or his action system or his locomotor system." 25 Carl DiSalvo and Johnathan Lukens reflect on Gibson's definition of design.

"As is commonly held, then, the space of possibilities and limitations within any 
design context includes all of the affordances in an environment....By cataloging and considering the affordances of the multiplicity of actors in the environment-and, by way of ANT [Actor-Network Theory], extending the role of "actor" to all of the entities in the environment, both human and nonhuman-we can imagine, and design for and with, a much broader range of action." 26

For example, a city park may have many affordances that different subjects may engage with. An adult may walk along the asphalt pathways and sit on benches while watching a child play in the pond, where a squirrel does not perceive the asphalt from the grass but responds to the benches as "feeding" zones; the pond as a bath and trees as seating platforms for viewing other subjects.

A non-anthropocentric perspective provides new opportunities for experience and design as it involves looking at the appropriation of non-human form, construction, or material of a space. Biomimetic architecture is becoming increasingly popular and is developing as technology evolves. Prototypes, where qualities of a plant or other organic subject are being studied for their shape and function and are applied to potential architectural structures and facades. Sensors and other technologies are often incorporated as new materials and structural properties are intended to be a bio-animate environmental participant and sensor. By shifting the perspective of the human towards the perspective of the morphology of plants, one achieves new forms to investigate. ${ }^{27}$

Ethical organizations in architectural practice are providing motivation for design that considers a better environment for all subjects. Precedents may include the birdhouse, salmon runs built into dams, and artificial reefs. Although these examples are largely for human benefit, there are marginal hints towards possibilities 
for nature-restoring architecture and architecture that serves other than-human interests. ${ }^{28}$ This concept advances the notion of environmental remediation by introducing non-humans as the client for the design.

In 2007, Natalie Jeremijenko's project called OOZ exhibited this thought. The project consisted of spaces where humans and willing animal participants would interact. The sites of the interactions were to be designed to attract and accommodate the animal's interests before the humans. Jeremijenko listed several design goals for the sites of interaction that included providing shelter, food, species-specific comforts and conveniences, and technologies that the animals could master. Carl DiSalvo and Johnathan Lukens justify this project as a non-anthropocentric design perspective.

"Interspecies interaction at these sites is intended to be reciprocal-for example, "the light switch in the preliminary beaver home would be operable by both the beavers and the humans, such that humans may turn the light on to better observe the beaver, however the beaver could turn it off again, or vice versa" (Jeremijenko 2007). This allows conditioning, traditionally performed on animals by humans, to be performed on humans by animals as well." ${ }^{29}$

To acknowledge a multi-perspective space, architects can use design as a tool in providing individual accommodation spaces for the species, joined spaces for bonding, and zones in between. Architecture can respond to this non-verbal communication between all living things. An example would be the creation of a space to promote the use of body language for the equally anxious horse and human. Perhaps architecture could reflect the same honest intentions that a horse 
has. Design could then be used as a tool to mirror the characteristics of the inhabitant. ${ }^{30}$ Depending on the purpose of the space, the design could influence the occupant's inner self. Experiential qualities that trigger the imagination would welcome this potential phenomenon, while exploring how consciously and subconsciously, the built environment affects one's mental state. ${ }^{31}$ Mechanisms such as light, scale, form, material, and the senses including aroma are essential. Experiential qualities in architecture will be crucial in creating a comfortable environment for all inhabitants.

If one is unable to fully understand the perspective of another subject, technology could be the compliment supplement. For example, The Animal Superpowers project created a line of sensory-enhancing toys that allow a human user to experience a non-human perspective that is visible and tangible. ${ }^{32}$ All of the explorations demonstrate a consideration for the subject of study, not for the human using it. Some examples include: "an ant costume, which comes with hand-mounted microscope antennas to see the world from the perspective of an ant as you crawl along the ground; a bird costume that provides the wearer with a physical sense of magnetic fields; a giraffe costume that changes the wearer's voice; elephant shoes that which receive vibrations from other nearby "elephants"; and a helmet that provides children with spatial vision similar to that of an electric eel." 33

As Carl DiSalvo and Johnathan Lukens believe, "a move toward more astute recognition of non-humans and the interplay between humans and non-humans would be, from that perspective, a move toward a more sustainable society and future. Shifting from a human-centered to a non-anthropocentric approach and granting legitimacy, if not equivalency, to plants, animals, and other biomass, would draw heightened attention to the need to understand and account for 
the systemic effects of design across species and throughout the environment." 34

By overcoming anthropocentrism, we are able to view that world outside of our own daily subconscious patterns, like breathing in air, binocular vision or being bipedal. "It involves imagining the perception of wavelengths outside of those visible and audible to us. It involves imagining devices other than the opposable thumb. It involves the recognition that our perceptions of causality, history, morals, and agency all too often assume that they are reciprocated in kind by agents incapable of reciprocation. Ultimately, it involves our overcoming the narrative fallacies and rationalizations that we use to place ourselves at the top of a chain, and instead placing ourselves in a web in which the components are impossible to isolate from the whole." 35

A biocentric perspective would allow one to see understand, and manifest architecture, literature and technology in new ways. The point is to decenter the human from it's presumptuous position of importance in contemporary design. However, there seems to be a paradox in creating a non-anthropocentric perspective for something that is deemed important in purely human terms. Many explorations are to benefit the human for adopting such a perspective. The human is not abandoned, as illustrated in the examples above, a non-anthropocentric perspective is however also a means to an end of some human benefit. ${ }^{36}$

Equus As Client: A Biocentric Retreat 
“...there is a continuous communication not only between living things and their environment, but among all things living in that environment. An intricate web of interaction connects all life into one vast, self-maintaining system. Each part is related to every other part and we are all part of the whole, part of Supernature. ${ }^{n 37}$ 


\section{Hands as Scale}
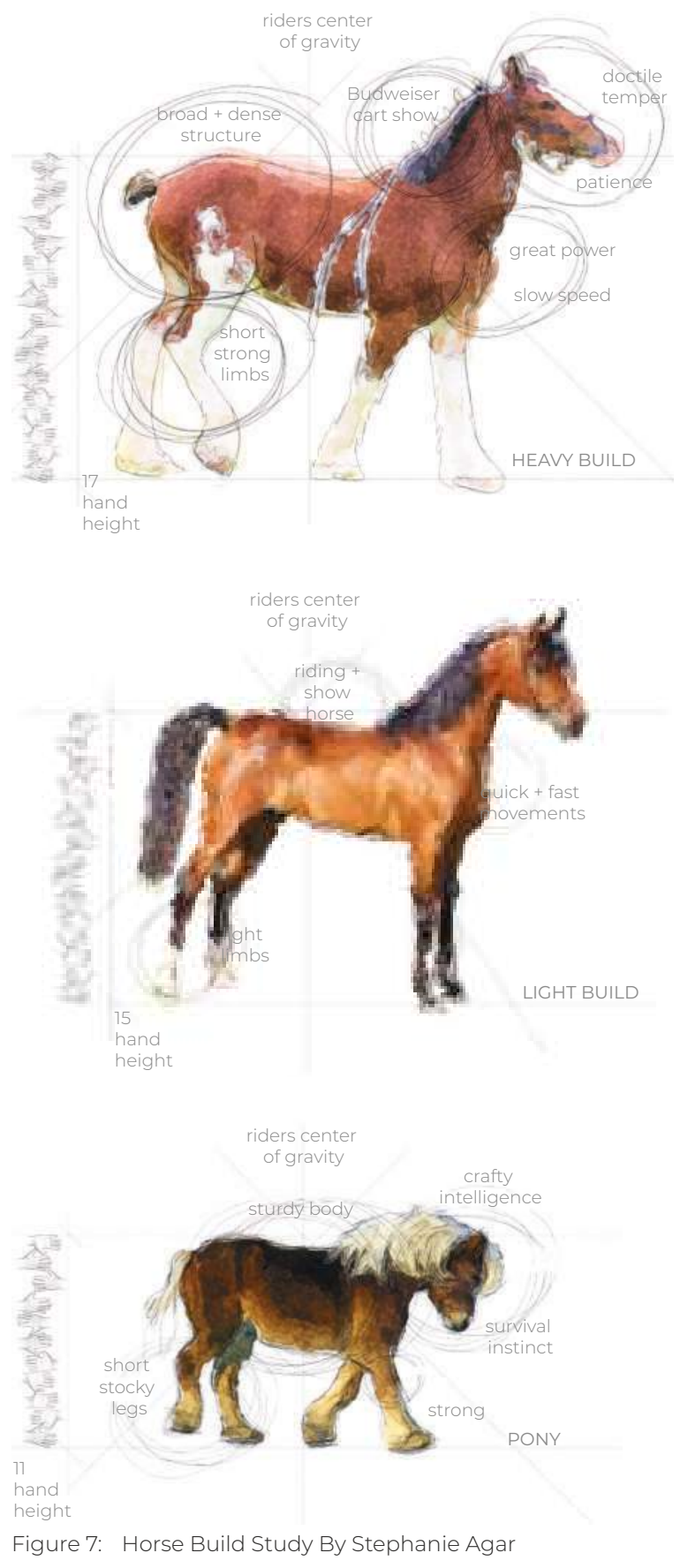

Horses have had a substantial impact in the development of our society while experiencing conditions varying from military battles to towing bricks in harsh weather. ${ }^{38}$ Throughout this duration, the species have been bred by humans to become increasingly stronger, faster and more powerful.

But first let us turn to 'horse build'. In comparison to a human, the scale of the horse is large as it is generally 8 times the weight and 1.5 times the height. When referring to a horse's height, humans use their hands as a common measuring guide and measure from the withers (back of neck) to the ground. For example, a heavy build horse averages 17 hands, a light build averages 15 hands and a pony averages 11 hands in height. It is understood that the width of a hand is about 4 inches. ${ }^{39}$ This is a qualitative approach, where typically a quantitative approach is used for other species. Is there an easier way for humans to grasp the height of a horse, identifying with the size of a hand better than the inch. As we proceed, "hands" will be used as a scalar tool to help to develop and shift the way we might represent architecture in relation to the horse.

Equus As Client: A Biocentric Retreat 


\section{Strides + Scales}

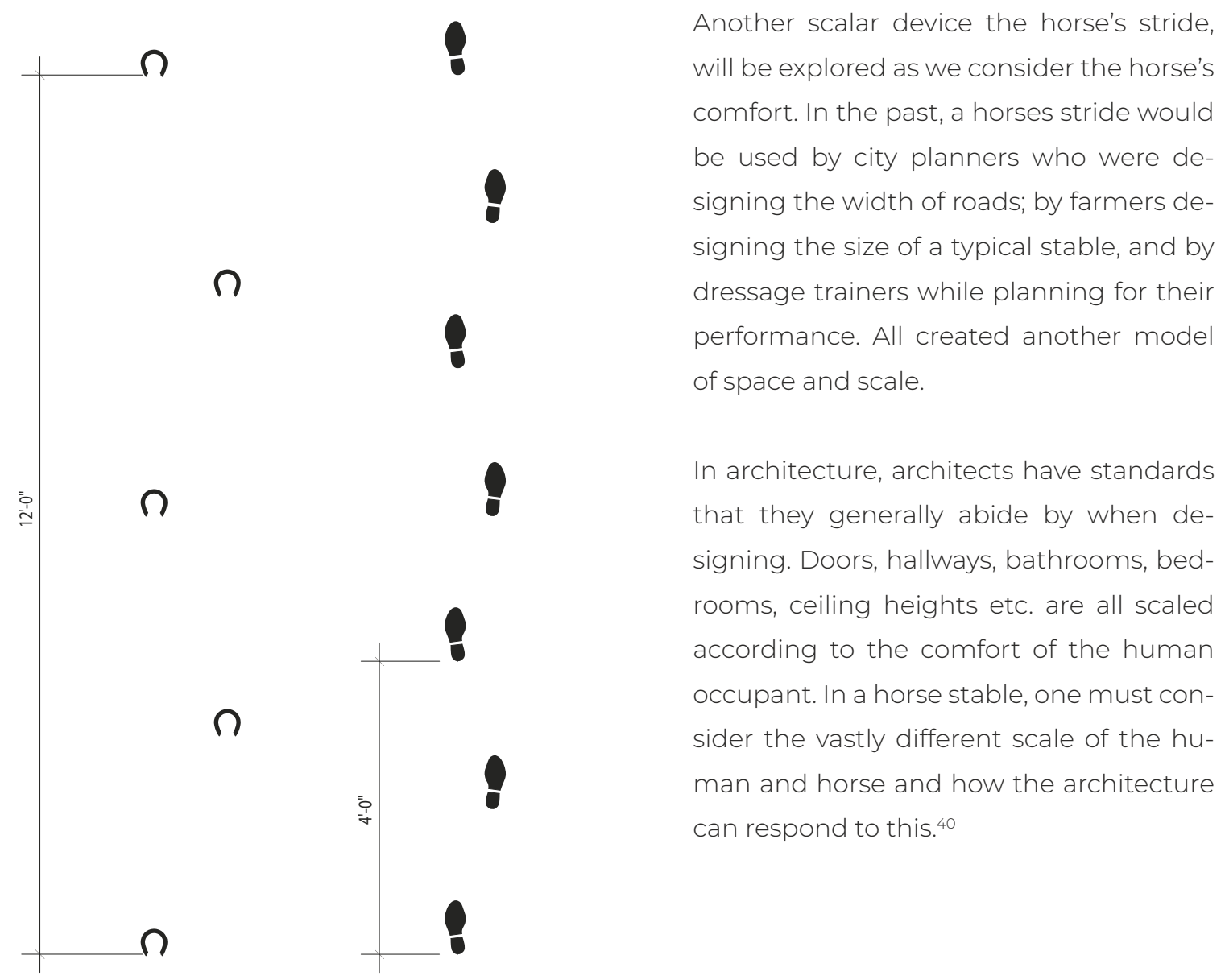

Figure 8: Comparing Strides By Stephanie Agar 

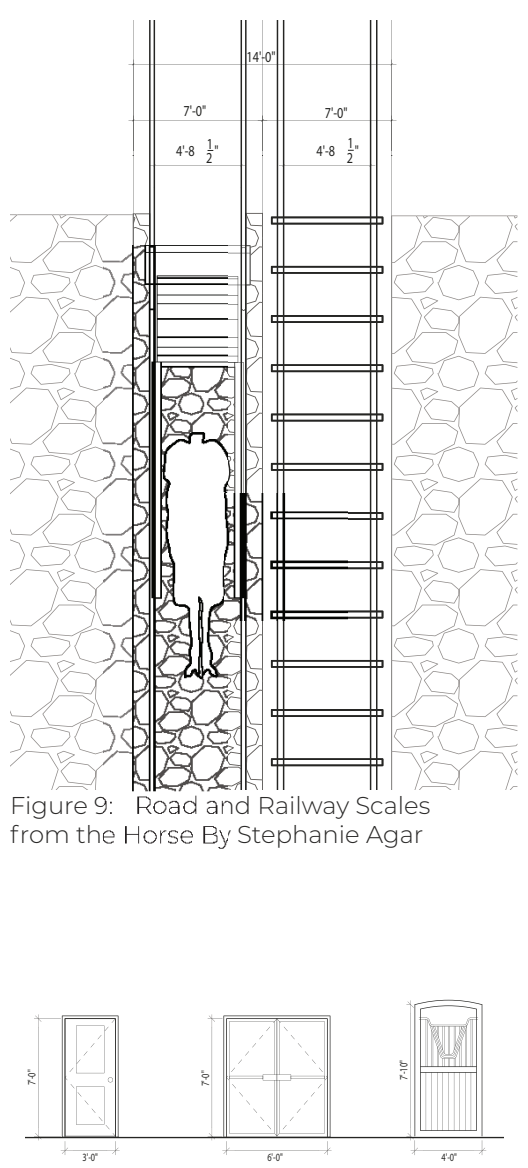

Figure 10: Standard Doors vs Stable Door By Stephanie Agar
Comparing and contrasting a horse's living space to a human's gives one a better understanding of the different requirements, or the minimum dimensions a horse needs in comparison to a human. Door openings, bathrooms, and bedrooms all have a standard base size in the human realm of architecture. In stable design, there are also standards based on the horse's scale; the bare minimum they require leads to a building footprint that can be quite large. ${ }^{41}$

Used as a common method of transportation in the past, the horse's body, stride and overall scale have greatly influenced the city's common roads and railways. Old 7 foot roads were once used by horse and buggies, where there was a rivet for the wheels to travel in. Once the machine era arrived, trains took over the roads. The train tracks standard size is 4' 8-7/2" because that is the same width as the rivets in the roads they were placed in..$^{42}$ These standards will be used as a guideline for the design. Where appropriate new scales and spaces will be introduced in order to form a desired experiential quality.

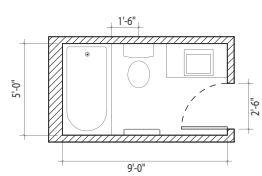

Figure 11: Standard Bathroom By Stephanie Agar

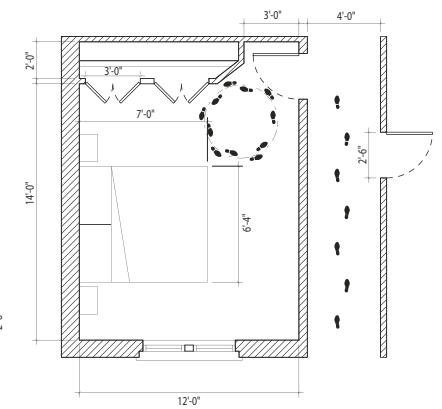

Figure 12: Standard Bedroom By Stephanie Agar

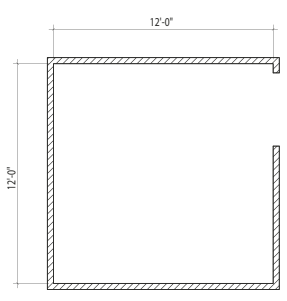

Figure 13: Standard Wash Stall By Stephanie Agar

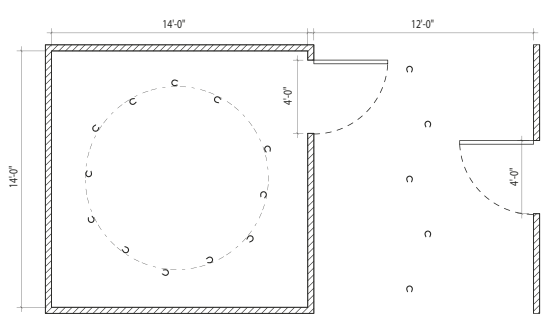

Figure 14: Standard Horse Stall By Stephanie Agar 


\title{
Senses: A Comparison
}

\author{
HEARING
}

A horse's hearing is far more sensitive than a human's. The heightened hearing may be due to their extremely mobile ears. The ears can be rotated in any direction, independently of one-another. The horse can lift its head, listen without turning and run if there is danger. Alert to all sounds, a horse is particularly responsive to human voices, making the ears a valuable, calming, training aid. 43

\section{SIGHT}

Larger in comparison to other animals, the horse's eyes have a 350 degree vision. As a flight-risk animal, they rely heavily on their vision to observe their environment for danger and to ready for flight. Sensitive to movement, a horses eyes are naturally focused on distance in order to look out for predators. To focus on a particular object, the horse will lower and raise its head instead of altering the shape of the eye lens. ${ }^{44}$

\section{SME L L}

Similar to its hearing, the horse's sense of smell is acute as it plays an important role in its day to day life. They rely on their smell to recognize others and their surroundings. Their acute sense of smell may be related to their pronounced homing instinct. Used in concert with their memory, horses use smells as landmarks to navigate home. Their smell is also used to avoid undesirable items in their food. Horses are particularly sensitive and repulsed by the smell of blood. ${ }^{45}$

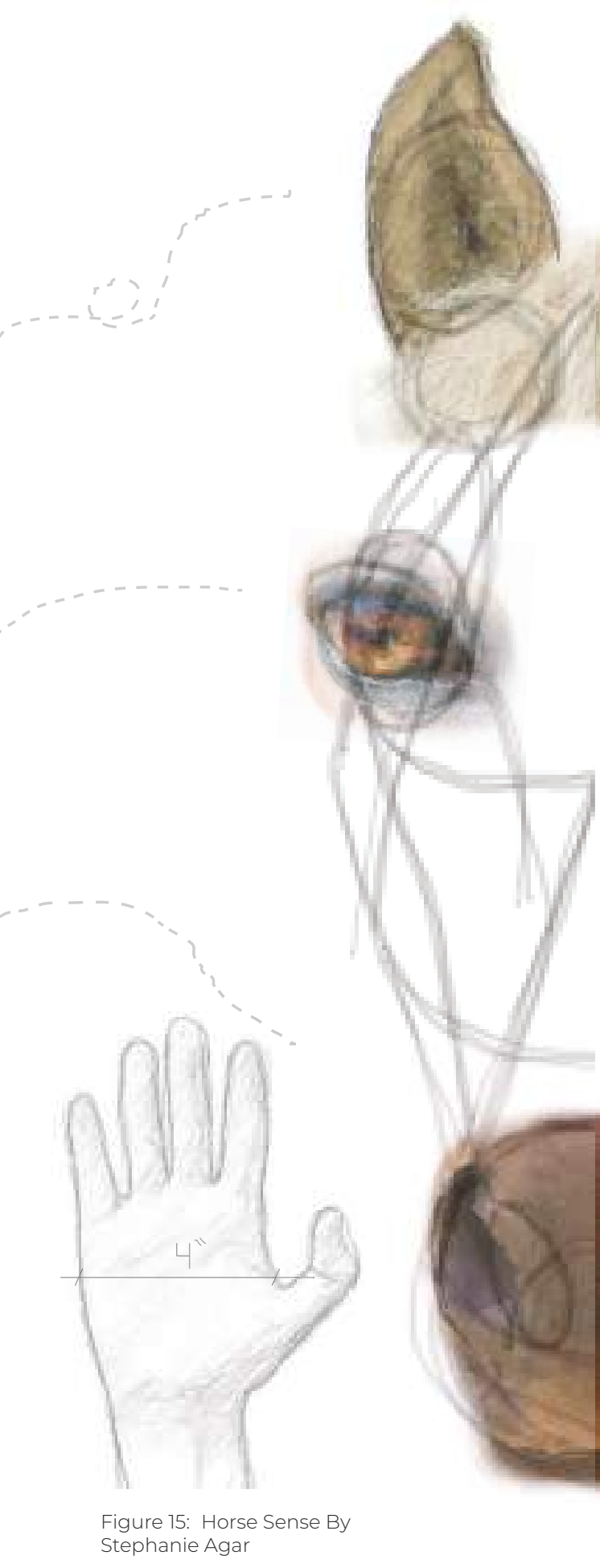

Figure 15: Horse Sense By 


\section{TA ST E}

Little is known about a horse's taste. Taste is associated with touch and is important in mutual grooming. It is presumed that horses like sweet things, however they also like bitter plants like tree bark. Horse riding relies on the horse's extreme sensitivity in its mouth as the rider uses the rein and bit in the mouth to give direction. ${ }^{46}$

\section{$\mathrm{TO} \cup \mathrm{CH}$}

The sense of touch is an important means of communicating with other horses and with humans. Whiskers on the muzzle and hairs around the eyes sense nearby objects. The withers are the most comforting place to touch for a horse. Receptor cells on a horse's sides allows the rider to communicate what movements it wants the horse to do. Horses have an acute sense of touch all over their bodies, allowing them to sense the slightest pressure and react to it. ${ }^{47}$

The size of the horse's head can also be understood by all when it is put beside the human hand. This 8 inch $\times 8$ inch book provides a reference to relate the 4 " increment based on the human hand. As one is comfortably palming it in both hands, he/ she will be able to confirm that one hand is about 4 inches. ${ }^{48}$

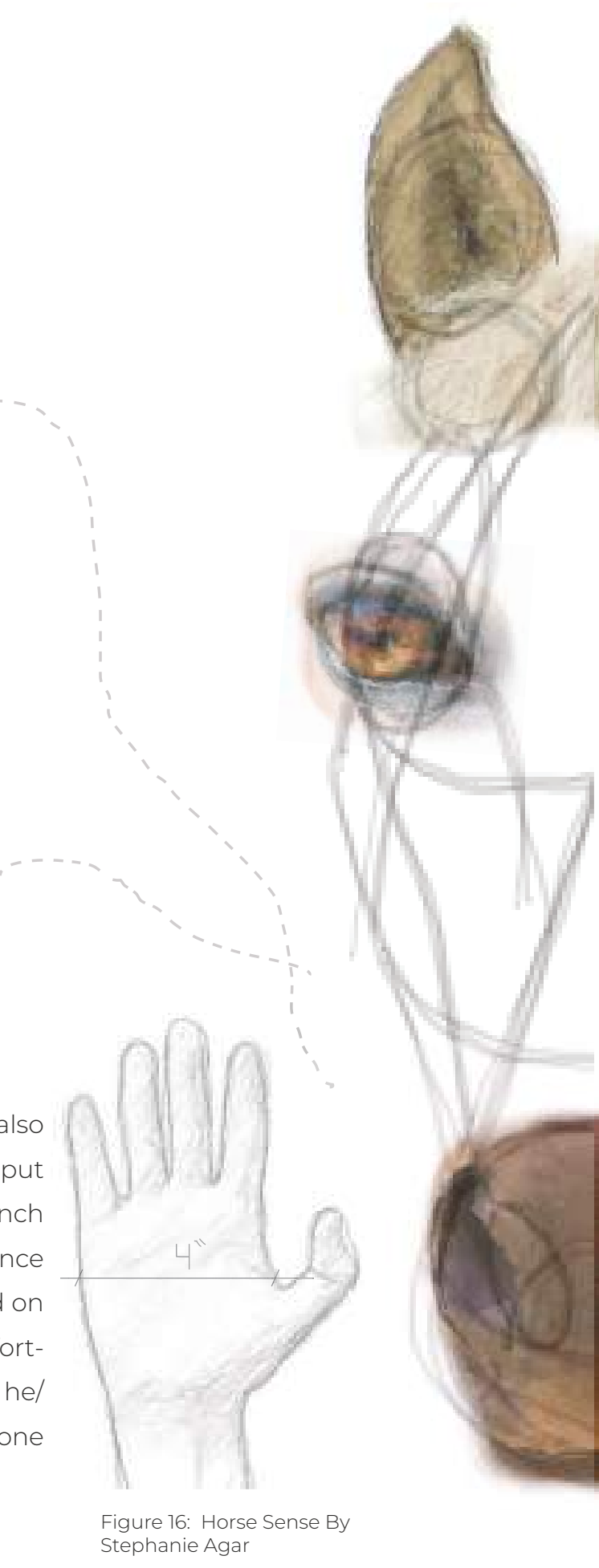

Figure 16: Horse Sense By Stephanie Agar 


\section{Boundaries}

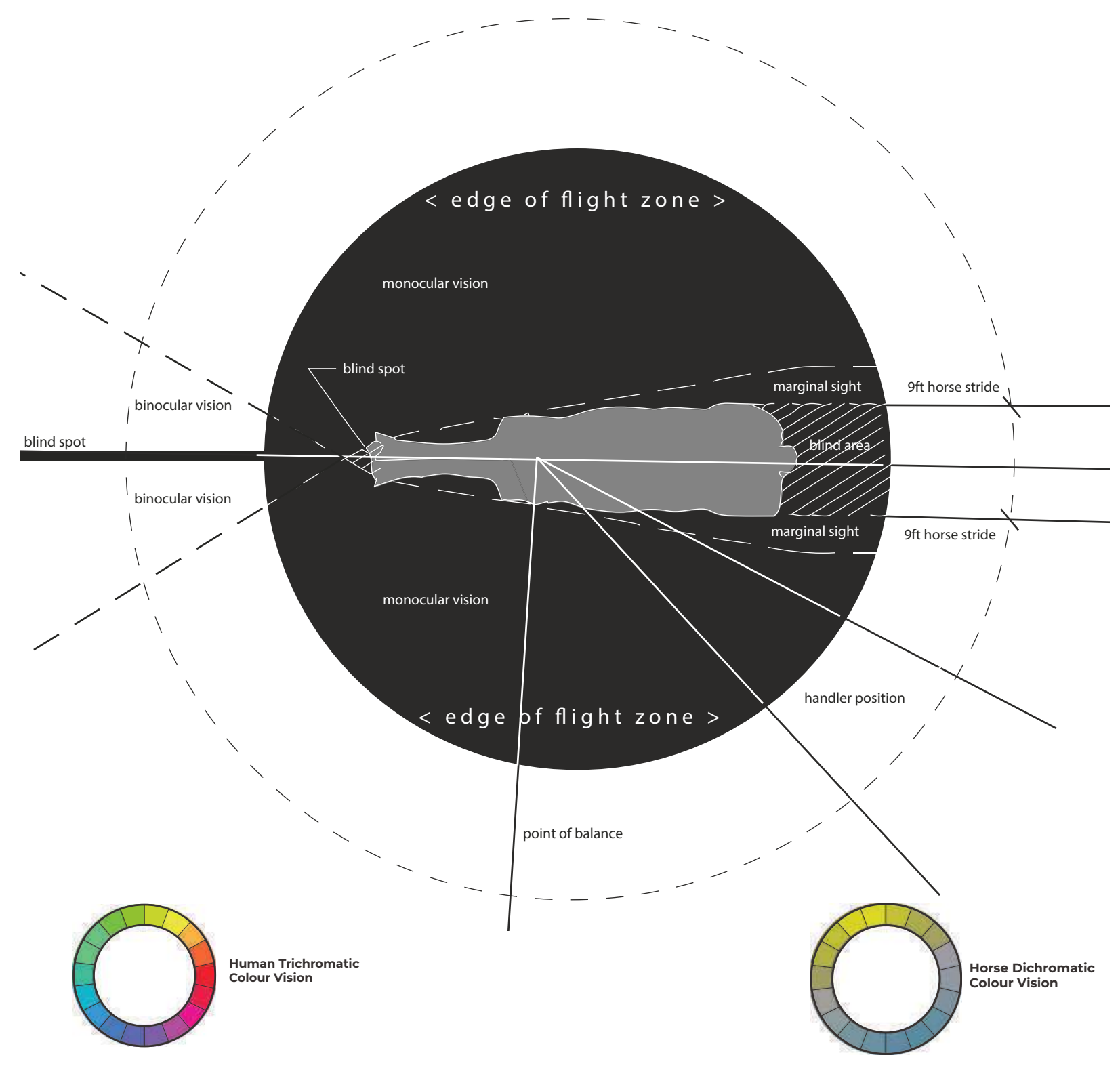

Figure 17: Horse Vision By Stephanie Agar 


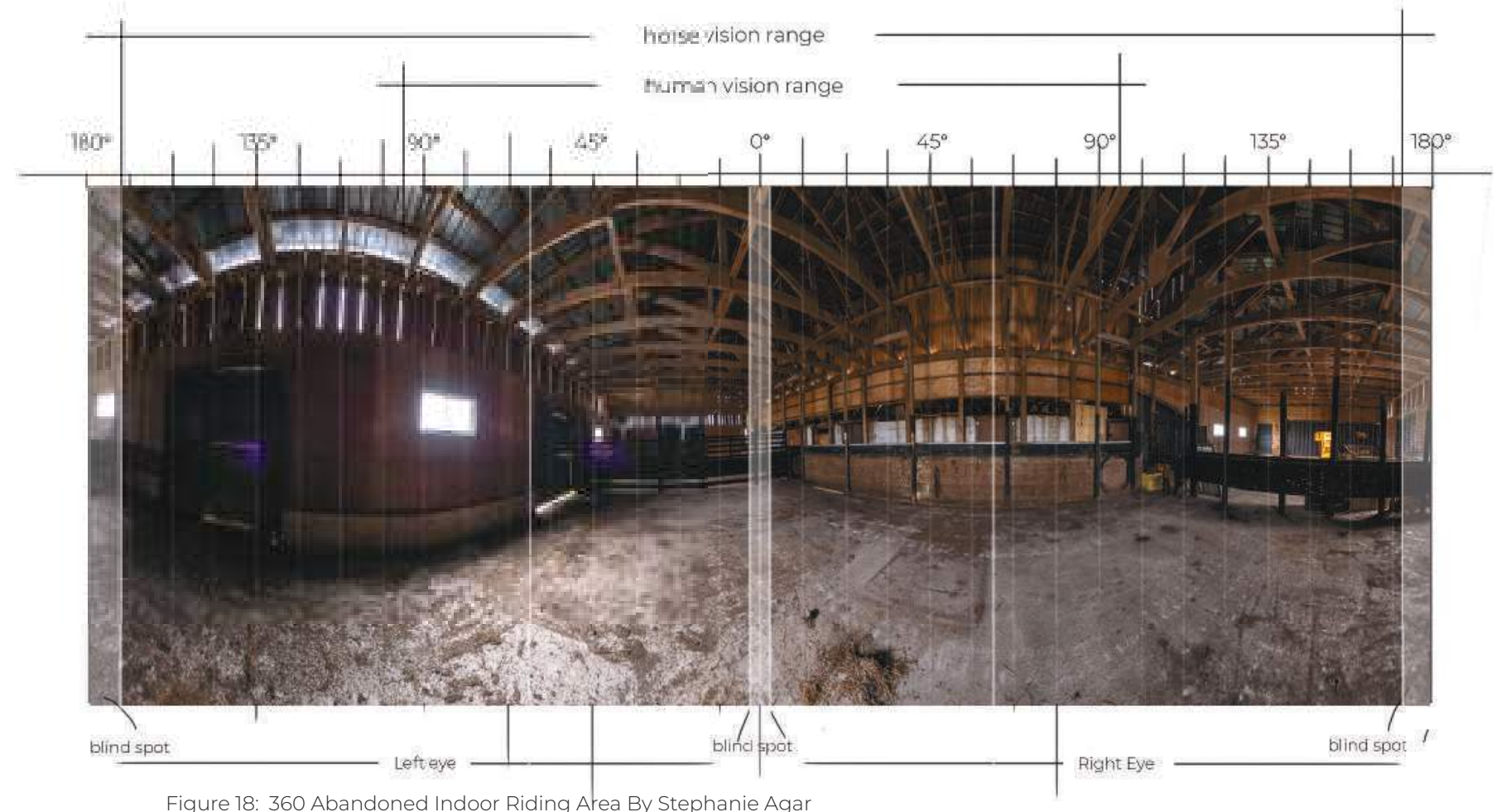

Figure 18: 360 Abandoned Indoor Riding Area By Stephanie Agar

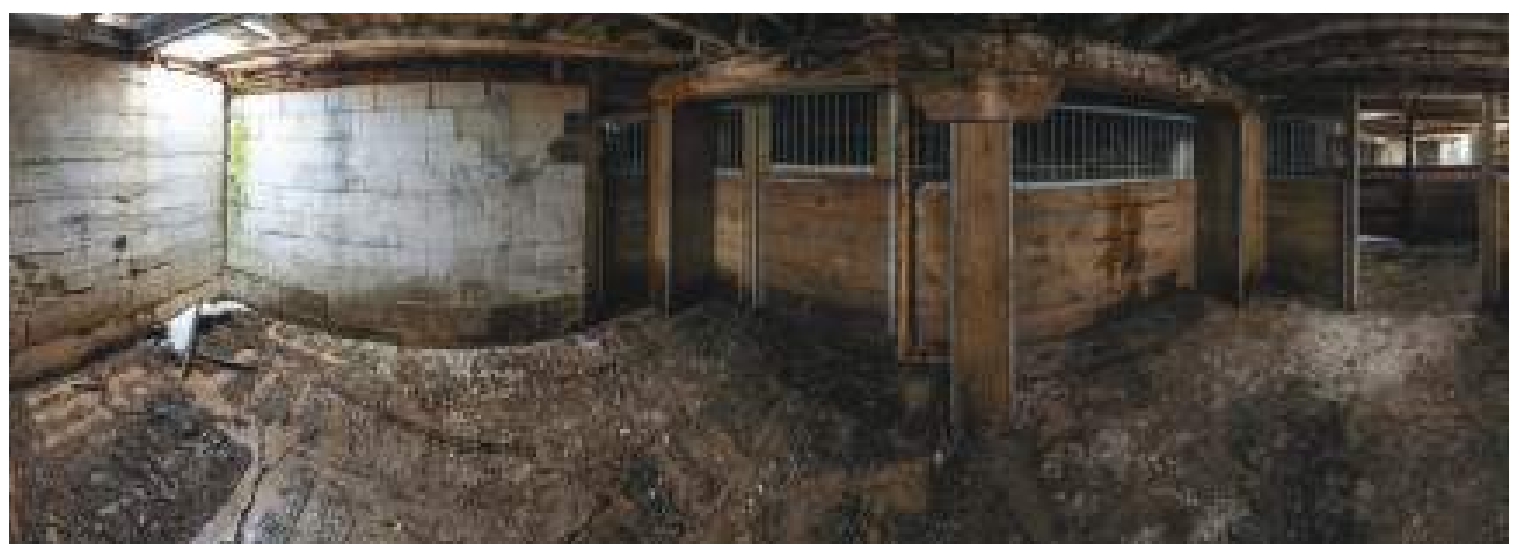

Figure 19: 360 Abandoned Horse Stable By Stephanie Agar 
"A human being is part of the whole, called by us, the universe. A part limited in time and space. He experiences himself, his thoughts and feelings, as something separate from the rest, a kind of optical delusion of his consciousness. This delusion is a kind of prison for us, restricting us to our personal desires and to affection for a few persons nearest to us. Our task must be to free ourselves from this prison by widening our circle of compassion to embrace all living creatures." 49

- Albert Einstein, Quoted in P. Crean and P.Kome, ed, Peace, A Dream Unfolding 


\section{Relationship}

It is not uncommon for a person to see, judge, misinterpret and anthromorphize everything a horse does. ${ }^{50}$ The present-day horse's superior size, power and speed have been enhanced through natural selection over time; as a prey animal they rely on these three survival characteristics. According to the pioneer of natural horsemanship, Tim Hayes, predatory humans and prey horses are genetical- ly hardwired to not get along, so he is astonished that these two species have such a deep history of partnership. ${ }^{51}$ Individually, the horse and human each have potential strengths, together they unleash a powerful dynamic. The proposed project will acknowledge this, providing individual accommodation spaces for the species, joined spaces for bonding, and zones in between.

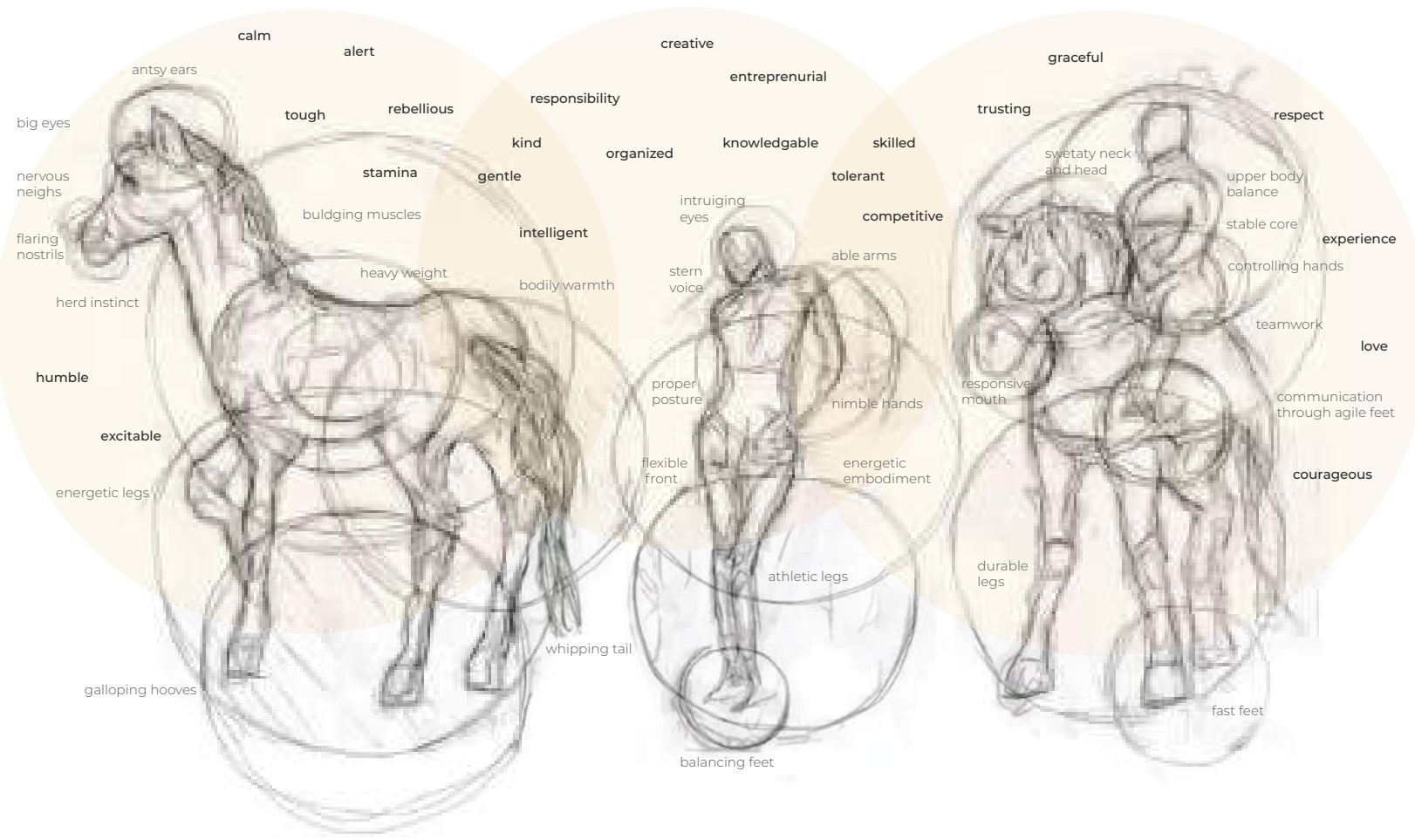

Figure 20: Horse-Human Bonds + Power By Stephanie Agar 


\section{Hardwired Communication}

Their hardwired equine survival capabilities give them the fastest reaction time and memory of any other land animal. Horses store their memories in two categories; things that will prey on them and things that won't. Historically, the human species would fall under the first category, things that prey on, and thus by nature a horse's first reaction when interacting with a human is to run. They rely heavily on their non-verbal body language to communicate with their own and with humans. ${ }^{52}$

Likewise, before verbal language was developed, humans would communicate through body language like horses do. So, how do humans form such a deep bond with horses? Scientists, farmers, and patients interested in hippo-therapy believe it is their hyper-vigilance and herd dynamics that make them ideal therapists, this idea will be developed later in the project. ${ }^{53}$

Architecture can respond to this non-verbal communication by creating a space that promotes the use of body language for the equally anxious horse and human. Some strategies may be designing an open space to play, this allows the horse and human to see the entire area, putting their mind at ease knowing that they are safe. Some areas for activities such as grooming or feeding may be more enclosed and private, allowing the attention to be drawn to the horse with no distractions. ${ }^{54}$

Grooming stations are an essential part of forming a known bond with a horse. After a horse has established that there is no prey animals threating them, the horse's next priority is to groom its mates. ${ }^{55}$ Grooming stations may be indoor 12'x 12' wash stalls or outdoor showers that often include tools to clean the hooves, brushes for their coats and picks to clean off mud. Higher-end grooming stalls may have heaters or drying stations that blow hot air to dry the horse during the colder seasons. This is important not only for the physical health of the horse, to avoid illnesses, but also for the psychological and social aspect. ${ }^{56}$ 


\section{"Who you are speaks so loudly \\ I cannot hear what you say ${ }^{2057}$}

- Ralph Waldo Emmerson 


\section{Hypervigilance}

According to Tim Hayes, hyper-vigilance in horses is thought to be rooted in their superhuman senses; as they mastered all they could to keep them from being eaten. ${ }^{58} \mathrm{Com}$ paring a horse interacting with its environment to a human interacting with its environment would be comparing a "other-centered" perspective with a generally "self-centered" perspective..$^{59}$

A horse's reaction towards something is 100\% honest in how they are thinking and feeling during that moment; they have no shame in the truth of their emotions. Riding Home: Horses To Heal by Tim Hayes explains this notion. He compares how when a human is smiling they seem content to other humans, while to a horse who sees their facial muscles slightly tense up and the pulse in their temples beat, they know something is wrong and walk away. ${ }^{60}$ Their acute senses allow them to read and diagnose a situation quickly. The design proposed within this document aims at creating a space that welcomes a hypervigilant horse and makes them feel safe and relaxed in order to establish a bond with visiting human patients. This may be difficult as there is the unexpected and the unexplained that can cause chaos within the horse or the human. The architecture must be used as a biocentric retreat.

"This evolutionary survival ability to read with flawless accuracy not just the behavior of others but their silent intentions is what gives the horse the psychological mirroring expertise of the most gifted human therapist... Psychologists define "mirroring" as the phenomenon that enables a person to see himself represented by his behavior as a reflection, or mirror image, in the eyes and or behavior of another person with whom he in interacting." 67

- Tim Hayes in Riding Home

Perhaps the proposed architecture could reflect this intention. Design should be used as a tool to mirrors the characteristics of the inhabitant. Depending on the purpose of the space, the design should influence the occupant's inner self. Experiential qualities that trigger the imagination and satisfies human comforts would welcome this potential phenomena. ${ }^{62}$ 


\section{Hypersensitive Architecture}

The constant external awareness that the horse has of its environment, and the triggers they may encompass, are similar to the symptoms a human has when they experience PTSD. ${ }^{63}$

"Brilliantly designed for instantaneous escape, the horse is a hyper-vigilant walking time bomb wrapped in a defensive shield of sophisticated sensory radar, forever ready to explode into a run with the fastest reaction time of any animal on the planet." ${ }^{64}$

- Tim Hayes in Riding Home

Essentially, this thesis proposes a project that responds to the whole of the beings needs and creates a hypersensitive space. The five senses of vision, hearing, taste, and touch must be compassionately rooted in the architecture. ${ }^{65}$

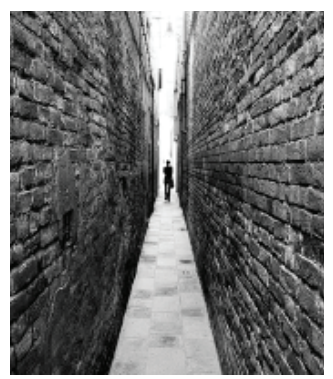

Figure 21: Claustrophobia

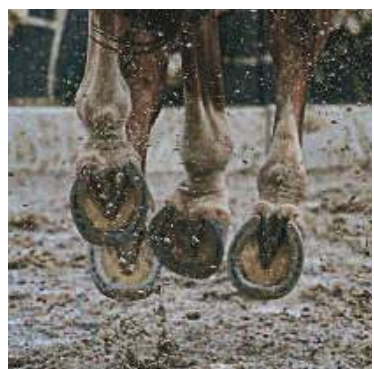

Figure 22: Germaphobia

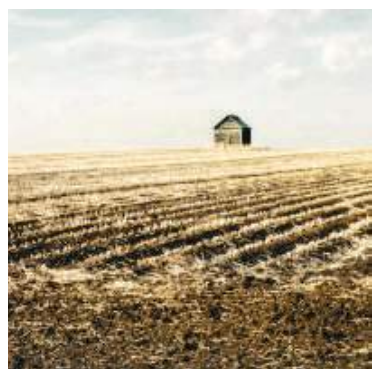

Figure 23: Isolophobia

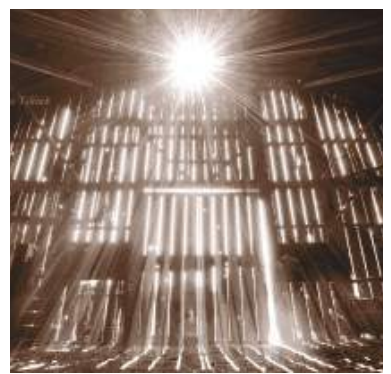

Figure 24: Nyctophobia 


\section{Herd Dynamics}

If a horse has reached its desired comfort level and feels safe, its next behavioral motivator is to seek comfort physically and emotionally. Generally, a horse's favorite thing to do is to rest. To mutually groom one another is to love. Horses have great social skills; they are the ideal examples of what getting along looks like. Tim Hayes defines a horse's persona as being accepting, tolerant, kind, respectful, honest, fair, nonjudgmental, compassionate and forgiving. ${ }^{66}$ Oscar Gleason says "the two controlling passions of a horse's nature are love and fear." ${ }^{\prime 67}$ These traits are the main reason horses travel in herds and are socially curious with humans. Once familiar with a person, the horse can often become a person's tool for self-discovery and personal development, resulting in healing one's emotional distress.

"...horses think in pictures and communicate in nonverbal body language, their mirror neurons are naturally able to read the unconscious body language of humans, which reflects a person's true feelings, regardless what they say or do." 68

- Tim Hayes in Riding Home
As herd animals, horses have a hierarchy leadership, within their social sphere there is only one alpha. The alpha is usually an elder mare who has established her position through experience and strength. When an alpha is being determined or tested, there is a pecking order that occurs physically. This is often displayed as playful, rough behavior as one claims it's territory. The same situation occurs when a horse and human are first introduced, which could seem frightening to someone who has not had experience with herd dynamics in horses. ${ }^{69} \mathrm{~A}$ master must be determined. Modern horse whispering takes a different approach than the traditional aggressive and dominant cowboy approach to "break the horse". A horse whisperer may use ropes and a confined pen to physically manipulate the horses footwork and behavior, acting similar to how a elder mare would in a pecking match. From an architectural approach, it would be essential to design the stable layout according to the horses social needs an introductory space where the horse meets the patient is important. 
The health of the horse can be affected by every aspect of the form from the layout of the roads and paddocks down to the selection and placement of the buckets in the stall. ${ }^{70}$

-John Blackburn 


\section{Detrimental Design}

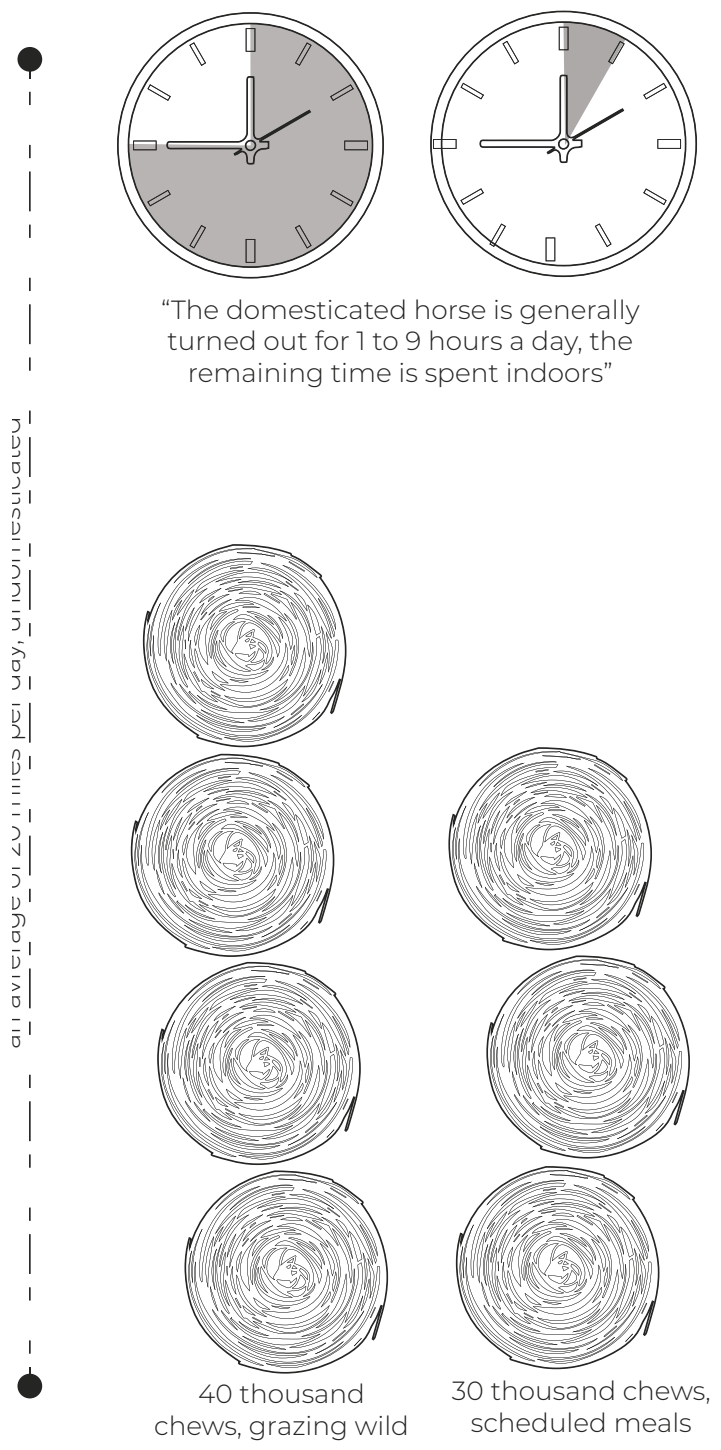

Figure 25: (Non) Domesticated Horse Statistics by Stephanie Agar
It has been found that when horses are stored in their stalls for long periods of time they are restricted mentally as well as physically. Undomesticated, the horse species thrive on traveling distances of over 20 miles while eating vegetation throughout the day. ${ }^{71}$

Undomesticated a horse chews 40 thousand times per day, domesticated it chews 10 thousand fewer. This results in regular equine dental work made necessary from painful sharp unworn teeth, and the lacerations they create in their mouth. The horse's natural ability to maintain healthy, worn in hooves is also compromised. ${ }^{72}$

Horses who are enclosed in unhealthy space develop stable vices such as chewing, bucking, rocking back and forth, and cribbing that could lead to the horse to colic. This frustration is similar to humans who have been incarcerated as they often turn to drugs, alcohol and in extreme cases, suicide. Design could prevent this by introducing 24/7 turnout pens attached to the stables. A thoughtful paddock layout is key. Proper gates, drainage, topography, and planning are all components of a successful paddock. ${ }^{73}$ 


\section{Stables Timeline}

Horses originally resided in the wild and were hunted for their meat. The first known horse stable was constructed in Ancient Egypt in 1237-1304 BCE. Excavations suggest that this stable was a massive facility for over 450 horses. It was comprised of a series of sloped floors and rows of stalls around the perimeter with a courtyard in the middle, perhaps designed for entertainment or militia practice. ${ }^{74}$

100AD ancient Rome stables featured developments such as limestone blocks with curved window openings and feeding troughs built in the walls of the openings. ${ }^{75}$

The 5th to 15th century Middle Ages era saw an increase in housing horses for defense use, often called the bastlehouse.

The Golden Age during the 16th to 19th century saw the most development for stable design. The house barn is one of the first forms of farmhouses. This building provided shelter for its animals on the ground or basement level with the human living spaces above. This was a strategy used by farmers as the animals' body heat generated warmth for the house. ${ }^{76}$

The connected farmhouse separated the building into a more elaborate form of four rectangles in a line. The four sections of the architecture were connected yet provided separate spaces often called the barn, back house, little house and house (in that order). ${ }^{77}$

The multi-programmatic house began to sever, creating distinct living quarters for humans and another for their animals. Stalls and stables were initially invented to quarantine the "sick" horses from the herd. ${ }^{78}$

It was not until the Victorian Golden Age in the 1830s that horse's quarters were provided with sufficient drainage, lighting and ventilation supporting better hygiene. This advancement initiated the beginning of showcasing wealth through stable design. ${ }^{79}$

Since the decline in societies interest in horses, there has been a decline in the development of horse stables. 


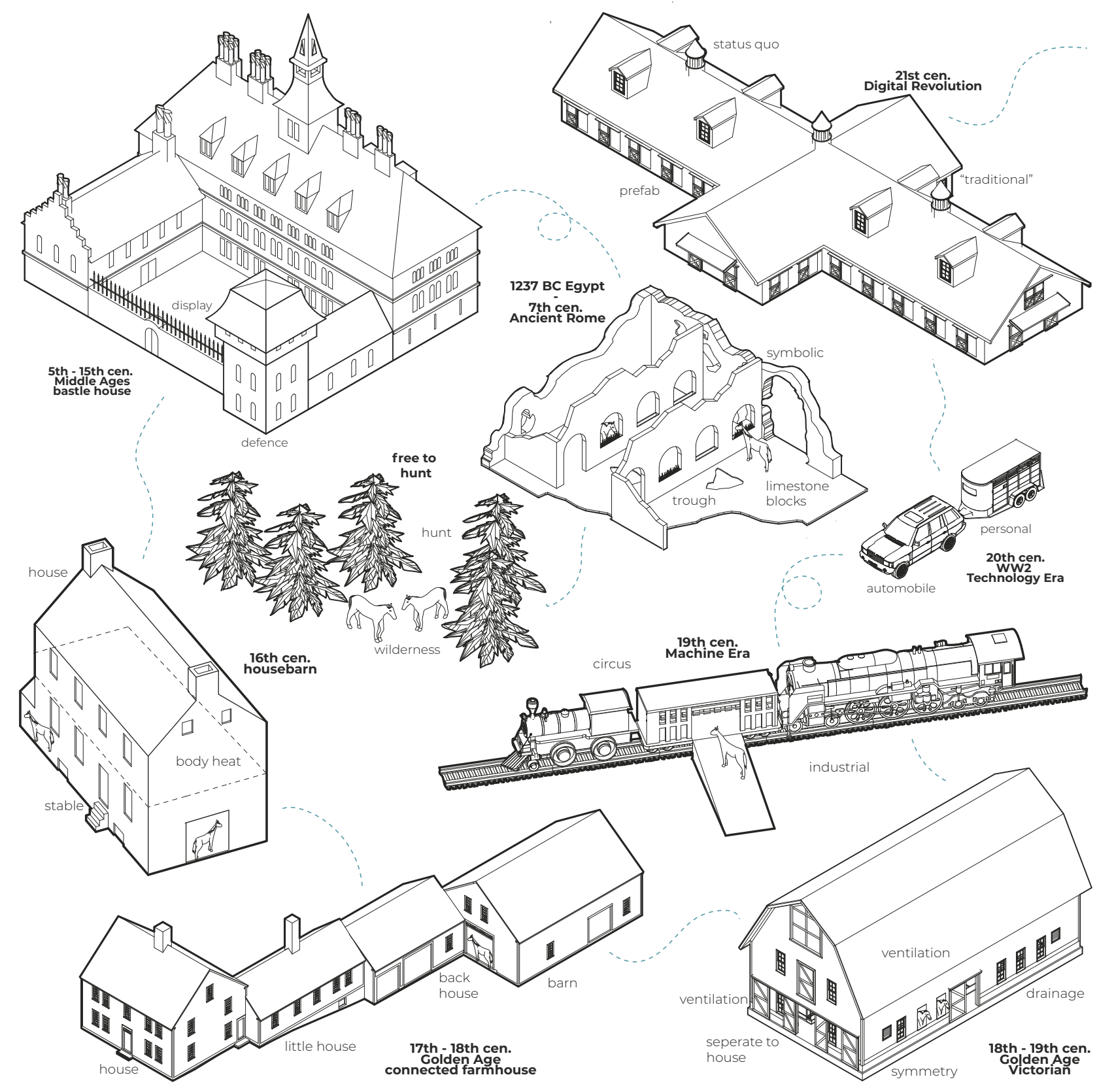

Figure 26: Stables throughout the centuries by Stephanie Agar 
“We design barns of all types, high end to very basic. A healthy barn does not necessarily require high end finishes. I never had a horse ask for oak paneled tack rooms or heayy timber framing" so 


\section{Stereotypes}

Negative connotations associated with stables come from different extremes of either abandoned barns or elaborate estates. Abandoned, they are often described as foul smelling, dark, dusty wooden shacks. A high end horse stable may showcase wealth, royalty, competition and specialization. The traditional horse stable has a 7:12 roof pitch, symmetrical windows, a bell tower, and red paint with white trim. ${ }^{81}$

The typical silhouettes are illustrated on the following page. Opinions from architecture colleagues, friends and authors of what they think best describes a barn is also recorded. With all of the opinions listed on the illustration in the clouds on the next page, the question "Is there a reason why barns are designed like this?" arose. Looking through books such as The Horse Encyclopedia and John Blackburn's Healthy Stables by Design, it was clear that the designs were evolved either for the horse's health and/or for the efficiency of the farmer.

Horse stalls are typically arranged in rows with a corridor on the outside. Although there are several typical arrangements, there is evidence or a preferred way. While laying out stalls in the floor plan, one must understand the prevailing winds and ventilation of the stable. This affects the horse's health greatly as improper ventilation may carry bacteria or illnesses down the row of stalls and to each horse. The key is to work with Bernoulli's principle and have the row of horse stalls perpendicular to the prevailing winds. The pitched roof aids the flow pathway of a passive ventilation system. Cold air closer to the ground pushes the warm air up towards to clerestories and out the vents or skylights, creating a stack effect. ${ }^{82}$

A plan for drainage in and around the stable is essential to keep the stables clean and the horse's hooves healthy. This is generally done with 2-5\% slopes in the interior floors, draining to the outside and away from the building. Paddock drainage is done through landscape design and is important as the fields need to be properly drained to reduce the tracking of mud and damage to the fields. ${ }^{83}$

The proposed design has acknowledged this research and the benefits they produce. The objective is to incorporate these strategies but dissect the negative stereotypes that come with them. 


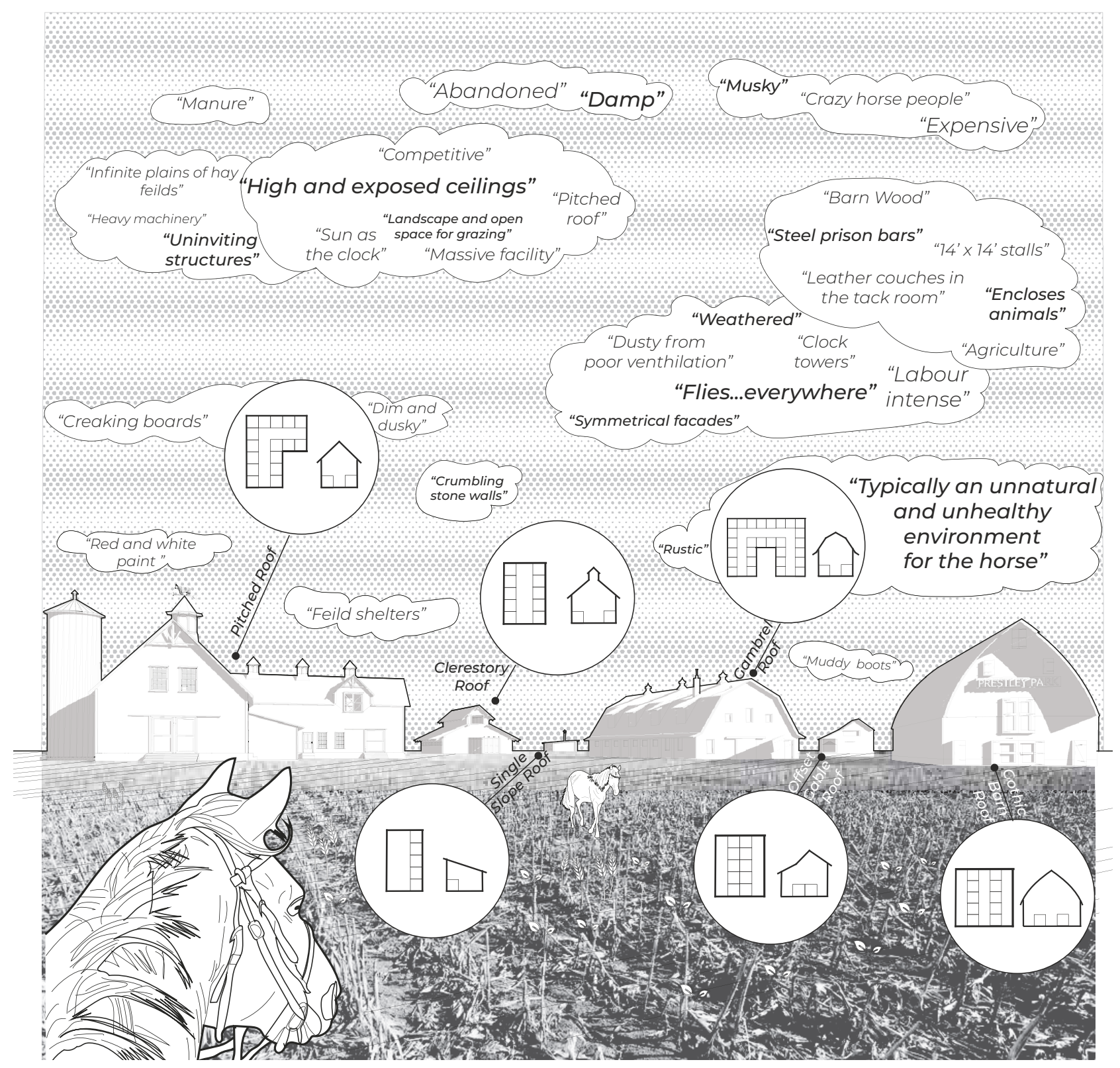

Figure 27: Stable Stereotypes by Stephanie Agar 


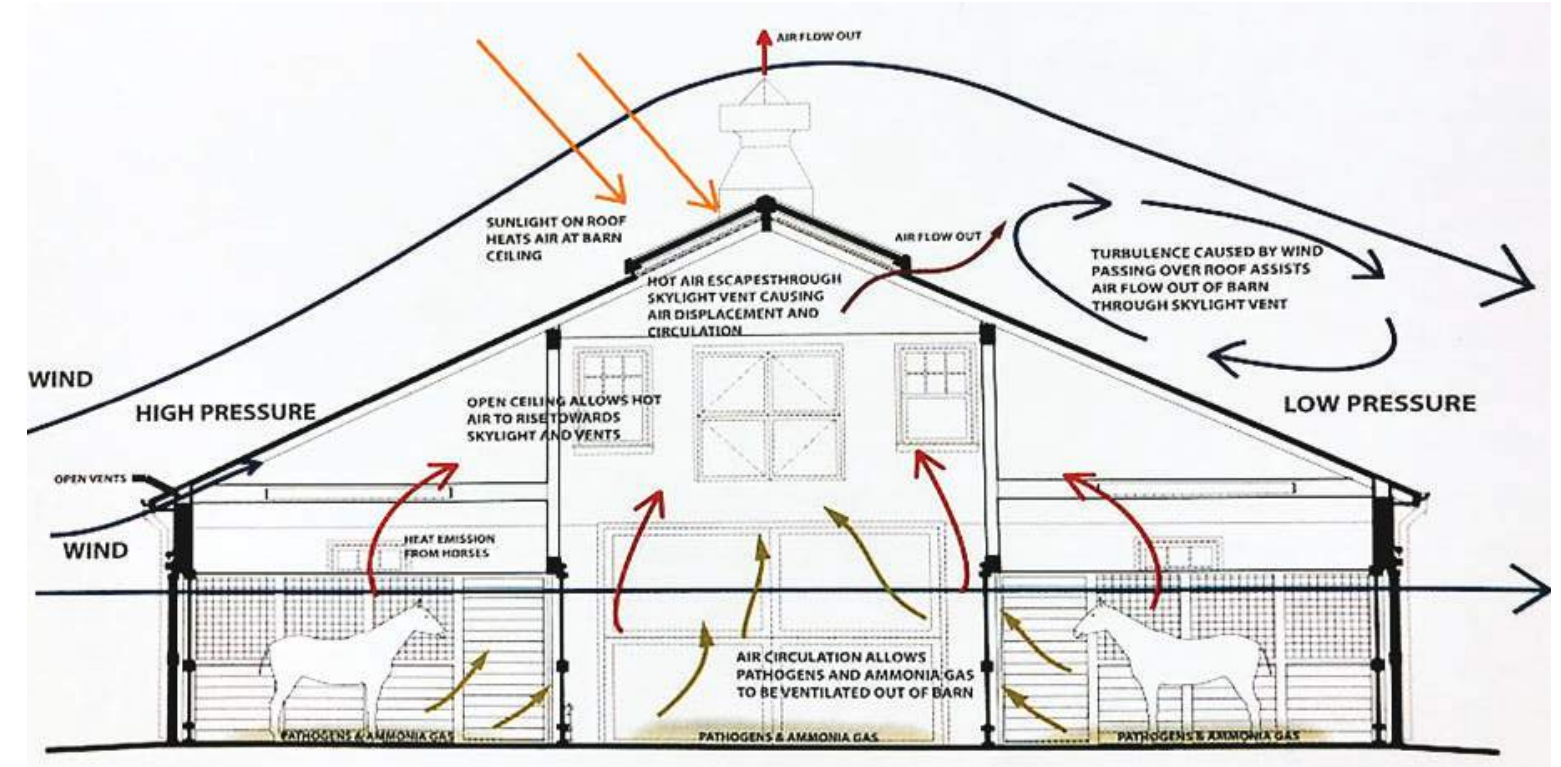

Figure 28: Healthy Stables by Design Diagram 
"One conservative report calculated that investing $\$ 400,000$ on efficiency in a 100,000 square foot ( 9,300 square meter) building would deliver $\$ 1.50$ per square foot (\$16 per square meter) in reduced energy costs over a similar building without efficiency"- for an annual saving of $\$ 150,000 !^{m 84}$

- The Guardian, 2015 


\section{Design Preamble}

The second part of the thesis proposes research through design. The proposed intervention shows how architecture and design can incorporate a biocentric perspective, specifically aligned with a horse's umwelt. The proposed program is a hippotherapy center for a wide range of visitors; at risk youth, addicts, brave veterans with PTSD, locals, or simply those who are seeking a retreat. The objective of the design is to manifest a safe and tranquil experiential space. Understanding the senses and how they (re)act is an essential mechanism used in the design. By doing so, the subjects who are usually in a hypervigilant state, the visitors and horses, are able to release their busy minds and focus on healing.

Canada and France were initially chosen as potential site studies to house the hippotherapy program. Each location revealed different benefits, showing strong potentials as sites. Canada is growing in the hippotherapy market while France is well acquainted with the practice. France has an outstanding number of valued abandoned ruins that are in dire need of conservation and architectural 'therapy'. In the end, France was explored further as an adaptive reuse project through an international competition. The existing site itself, and the whole of humans, horses and architecture would undergo 'therapy' through design.

This section focuses on developing a retrofit design for a castle in Les Trois Moutiers, France, Mothe Chandeniers. The site was brought forward by Young Architects Competitions, a foundation in Bologna that organizes international competitions. The competition, Common Ruins, provided a framework which assisted the development in a productive direction. The competition called for "designing a visitors' center aiming at ensuring a unique, spiritual and regenerating hospitality experience". 85 With the competition's guidelines in mind, this thesis proposed a hippotherapy center.

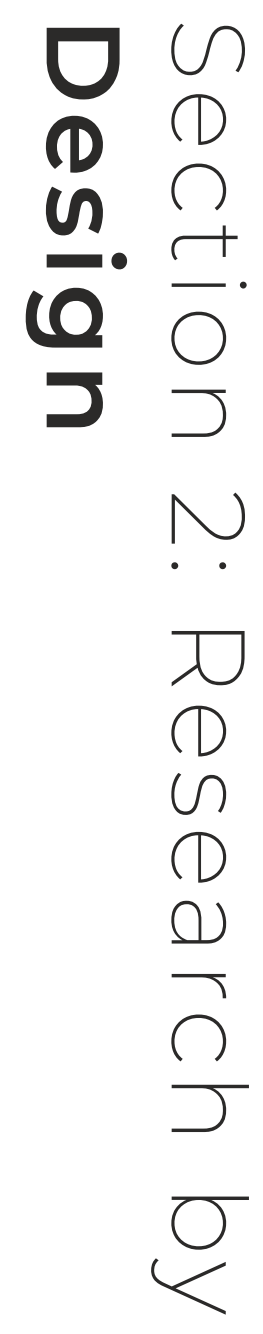




\section{Essential Design}

Design strategies are proposed as a way to benefit the horse first. Cowboys have followed this ideology before the general public was aware of it. From their wide brim Stetson hats to their laceless shoes, design matters not only for practicality but more importantly for the horse's survival.

A Stetson hat, arguably the symbol of the cowboy, is known for protecting the rider from the harsh sun. However, when the horse and rider are unable to obtain water in the middle of the fields, the rider can drink from his/her canteen while the horse does not know how to drink from a bottle. The rider may let his parched horse drink by pouring water from his canteen into the bucket-like bowl of his Stetson.

Another strategic design for the cowboy prevents him from "getting hung up". A cowboy's boots have no laces so their boots fall off when the saddle falls loose and slips around the torso of the horse, the rider is able to fall off and be free from the panicked horse. ${ }^{86}$ 
"Essentially the horses

became our client" 


\section{Design Strategies}

Architectural strategies include orientating and manipulating the site to create an advantageous design. This may be through burming the earth against the perimeter of the architecture to conceal it within the landscape, working with prevailing winds, or understanding the sun exposure.

Another strategy focuses on the scale of the project, as it could easily get out of hand and take over the entire site or be conversely confined into a single space and lead to claustrophobia. The scale of the site, a human and their limitations, and most importantly the horse are all contributing factors in the design strategy.

Lastly, the overall health that the built environment provides is an essential product of the design. This thesis aims to manifest a safe, healthy, happy project for an existing site, the owners, visitors and the horses. Essentially, the project focuses on using design as a form of therapy for the rehabilitation of the site's ruins,as well as for the well-being of humans and horses.

Sustainable design which considers employing: natural light, ventilation such as vented skylights, Daniel Bernoulli's equation of vertical lift, chimney effect and storage are all important factors when constructing a stable that is supporting the horse's mental and physical health. ${ }^{87}$

The lack of urban animal habitats can be seen as "gaps in the logic of sustainability.. When we think about sustainable design, we think of renewable energy, green infrastructure, solar panels. But there's a lot missing in thinking about how the world is not purely anthropocentric." 88 By taking this sustainable view point further, this research adopts an animal-centric approach; including all of the actors that are affected in the process of creating a built environment. 

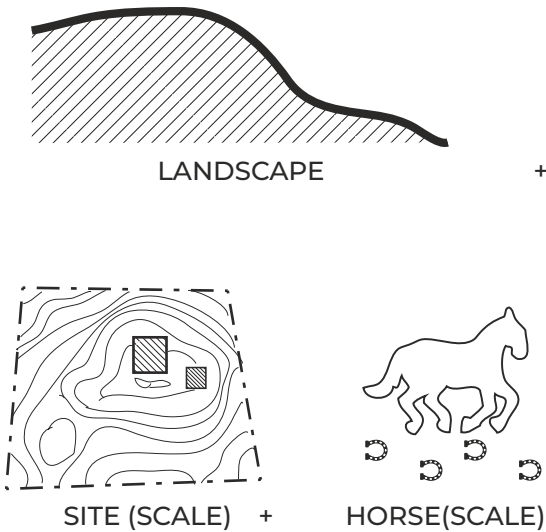

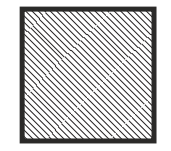

SHELTER

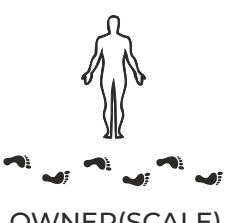

OWNER(SCALE)

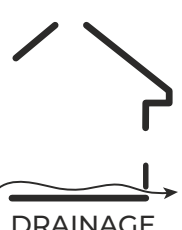

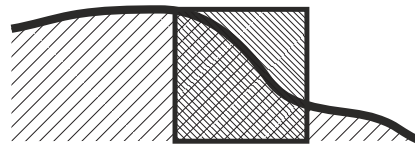

STABLE DESIGN

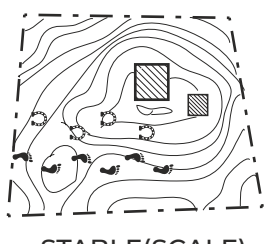

STABLE(SCALE)

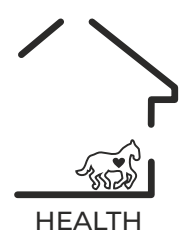

Figure 29: Design Strategies by Stephanie Agar 


\section{Hippotherapy}

Hippotherapy, equine therapy, therapeutic horseback riding and natural horsemanship are different types of treatment that involve humans forming a healing connection with a horse. "It is a methodology that involves looking at the horse-human relationship from the horse's point of view." ${ }^{\prime \prime 9}$ The person can vary from at risk youth, autistic children, brave veterans, PTSD, paralysis, prisoners and addicts. Hippos comes from the ancient Greek word for horse. Hippotherapy was developed during the mid $20^{\text {th }}$ century in Germany. From success stories, with almost instantaneous results compared to traditional therapy, hippotherapy facilities spread across the world. PATH is the Professional Association of Therapeutic Horsemanship International. ${ }^{90}$

Tim Hayes in his novel, Riding Home: The Power of Horses to Heal, writes;

"A horse can often become one of a person's greatest teachers for self-discovery and personal development and, remarkably, a source of healing one's emotional wounds." ${ }^{9}$ "For someone with physical needs, sitting on a horse as she/he slowly walks can move the riders body in a way that partially replicates the healthy muscle movements of a person who is able to walk naturally." 92

The Wild Horse Inmate Program in Colorado has a incarceration rate that is half the national rate of Colorado (67\%). The prisoners have tamed the overpopulated and dangerous wild mustangs, that were otherwise sent for slaughter. Consequently, the inmates were 'tamed' by the horses. ${ }^{93}$

Horses for Heroes is a therapeutic center for brave veterans suffering from PTSD, physical injuries or combat trauma. During their visitations, the clients bond with the horses through grooming and riding. It is an alternative method from the typical Western solution, prescription drugs and sit-down therapy talk sessions. 


\section{Hippotherapy Spatial Programming}

1. Sustainable features (approx. 40' $\times 20^{\prime}$ ): Equipment for PV panels, space for passive design such as operable windows, large glazing and trombe walls, water and energy harvesting and storing.

2. Horse stable (approx. $\left.32^{\prime} \times 120^{\prime}\right)$ : Including horse stalls for individual and foal use $\left(14^{\prime} \times 14^{\prime}\right)$.

3. $10 \times$ Villas (approx. $20^{\prime} \times 20^{\prime}$ ): Accommodation for retreat visitors that are both private and public, allowing one to seek isolation and social space. The villas are minimalistic and airy, allowing one to experience the landscape. The architecture is burmed into the ground to prevent any discontinuation in the site's vistas.

4. Indoor riding arena (approx. $142^{\prime} \times 66^{\prime}$ ): During the colder months, an indoor riding arena would be benefi-

cial. Rehabilitation Spa (approx. 24'x 32'): For horses and humans, a rehabilitation spa would be a space for physical restoration. Working horses look powerful and indestructible, however like humans, their bodies are actually prone to several types of injuries. Ponds for horses to soak in have been proven to be beneficial for their hooves, muscles and joints. This space will feature modules of open plan spaces where humans can also interact and improve their physicality.

5. Mindful Wellness (approx. $24^{\prime} \times 32^{\prime}$ ): Similar to the rehabilitation

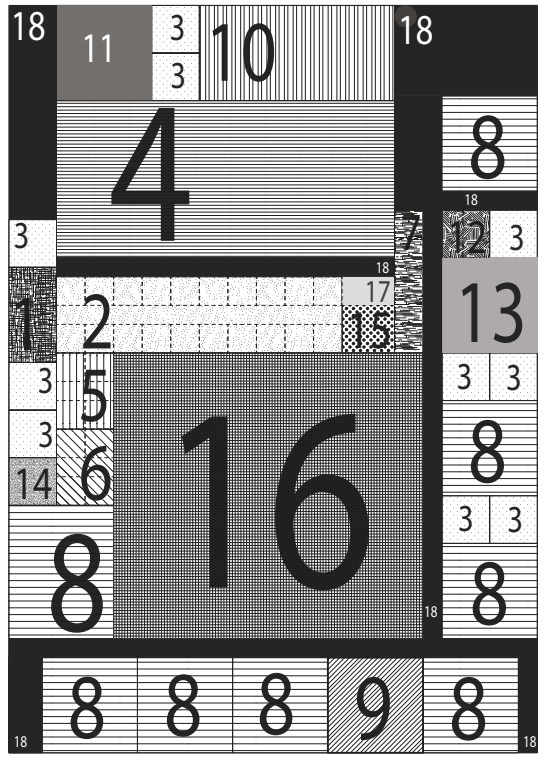
spa, the mindful wellness area will feature modules of open plan spaces where humans and horses can interact. This space focuses on psychological therapy. Bonding areas and meditation spaces will be essential.

6. Wash Stalls (approx. 60' $\left.\times 12^{\prime}\right)$ : Rows of outdoor and indoor wash stalls for the horses is essential in maintaining a healthy, hygienic stable.

7. Outdoor paddocks (approx. $84^{\prime} \times 175^{\prime}$ ): Fenced off grazing spaces

8. Turnout space (approx 40' $\times$ 40'): Turn out pens are important for the horses freedom and overall health. It allows them to graze outdoors in a designated paddock and return to their stalls as they wish. It also orchestrates which paddock the horses are directed to, limiting over grazing and preserving the landscape.

Figure 30: Program Footprints by Stephanie Agar

Equus As Client: A Biocentric Retreat 
9. Machinery storage (approx 40' 80'): The machinery storage must be located away from the horse stables, yet close enough to the stable for efficiency. Horse's are known to startle and run into the machinery with devastating consequences. This space requires a lot of space as it will hold all of the equipment required to maintain the site and its programs.

10. Hay storage (approx $40^{\prime} \times 40^{\prime}$ ): As a fire hazard, hay must be stored properly and in two locations (a smaller portion in the stable and the larger part in its own building). If there is too much moisture in the building/ hay, a chemical reaction will occur, causing a fire. Ventilation is one solution to heat and moisture build-up and must be anticipated in the design.

11. Accessory Storage (approx 20' $\left.\times 20^{\prime}\right)$ : A space for horse bedding, blankets, saddles etc.

12. Visitors center (approx 40' $\times 40^{\prime}$ ): Strictly for the humans use as horses do not require or feel the urge to sign in as they visit the site.

13. Tack room (approx $\left.20^{\prime} \times 20^{\prime}\right)$ : Attached to the horse stable, the tack room is a traditional space in a horse stable. This space will be a seating area where they can observe the horses.

14. Café / Harvest (approx $20^{\prime} \times 20^{\prime}$ ): The food supply required to fuel all of the inhabitants on the site is immense. Fortunately, the chosen site has 36 acres of fertile land. For efficiency and sustainability reasons, the design incorporates a harvesting - café space. Lemon and orange trees exist on the site.

15. Ruins (approx 130' $\left.\times 120^{\prime}\right)$ : The existing castle ruins will act as the main entrance and threshold to the site.

Filled with history and splendor, this fortress will require conserving and interventions in order to enhance the hippo-therapy program. Ideally, the interventions will be minimal; adding a roof and suspended pathways. To maintain the evocative nature that is currently taking over the ruins, the center of the castle will be used as a courtyard with no roof, allowing the existing trees to grow.

16. Shop (approx $\left.24^{\prime} \times 10^{\prime}\right)$ : A requirement for the YAC competition, this shop has been interpreted as an information center supporting hippo-therapy education.

17. Circulation (approx $25 \%=16,000 \mathrm{sf}$ ): The scale of the circulation in the buildings are essential as some corridors will need to fit humans and horses.

Equus As Client: A Biocentric Retreat 
Maps compiled by researchers at the University of Wisconsin-Madison show that 40 percent of the earth's land surface is now used for agriculture. Given the massive geophysical alteration that entails, it makes sense to work as much as possible with nature to keep or restore to some extent balance in the earth's natural systems- not just in rural areas but in urban environments as well.94 


\section{Site Study: France}

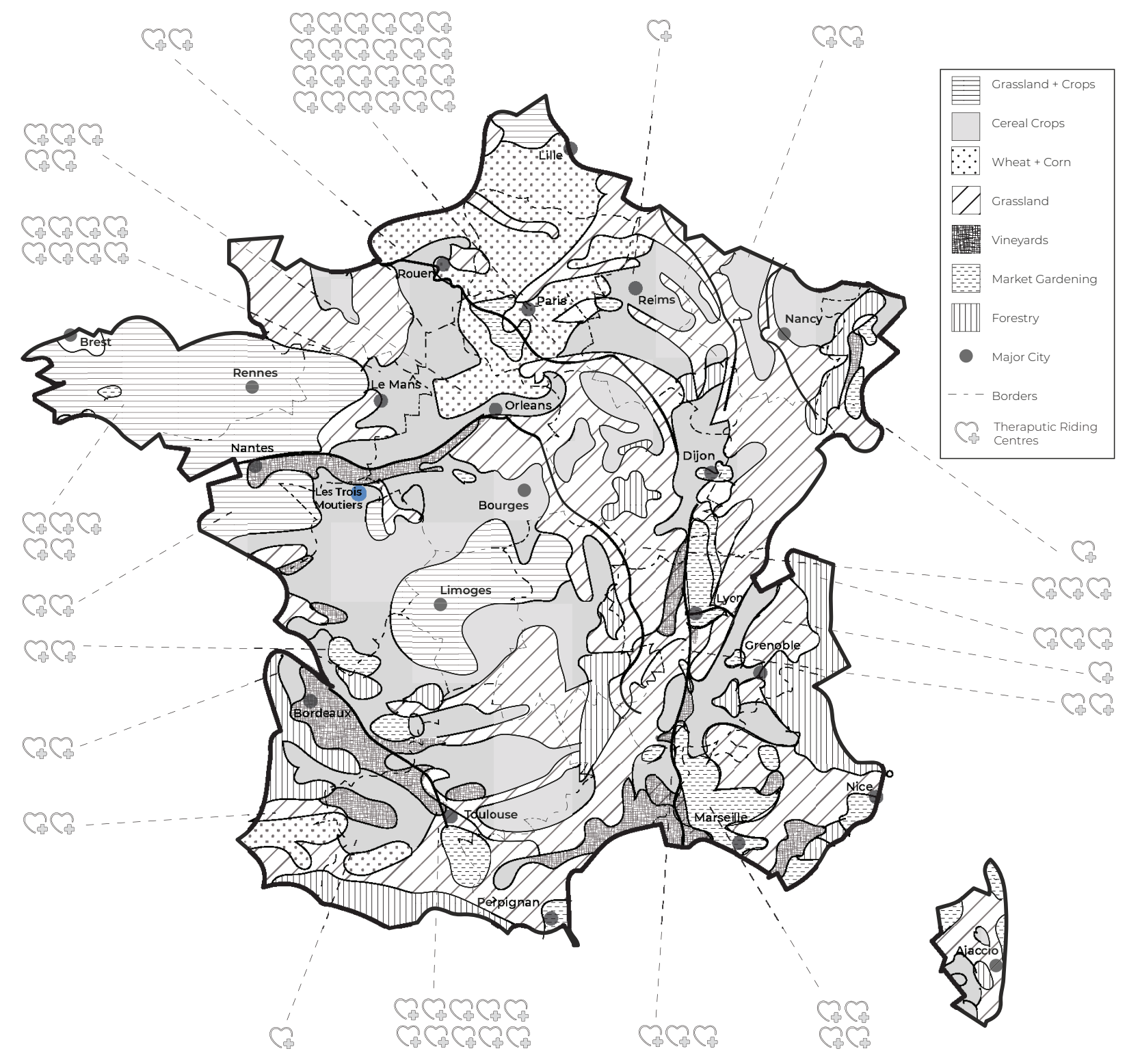




\section{Human Control: Axial Architecture}

French architecture has been influenced by several period styles over the centuries; including the Romanesque, Gothic, Baroque. It would be an injustice to generalize French architecture as it has a deep history. For the purpose of this thesis, the French Baroque ideology that "symmetry and order take over nature" will be studied. Specifically, analyzing the French Formal Garden and the human instinct of mastering total control through severing the landscape with an axis. ${ }^{95}$ This concept of using a direct, continuous vector as a landscape tool in site design serves many purposes. According to Foundations of Landscape Architecture: Integrating Form and Space Using the Language of Site Design, a straight line can direct the eye, accommodate movement, establish a datum, establish a dividing edge, provide and architectural extension, imply human control and to create rhythm. ${ }^{96}$

Perhaps the most notable example of the garden axis in French architecture is at Versailles. The site plan for Versailles draws a straight vector from King Louis XIV's bedroom and through the entire site and to infinity to the Nouvelle France West, symbolizing the King's dominion over all.97 The straight line as an architectural extension is used in gardens as a central axis that guides one from the built environment to the landscape. This joins and

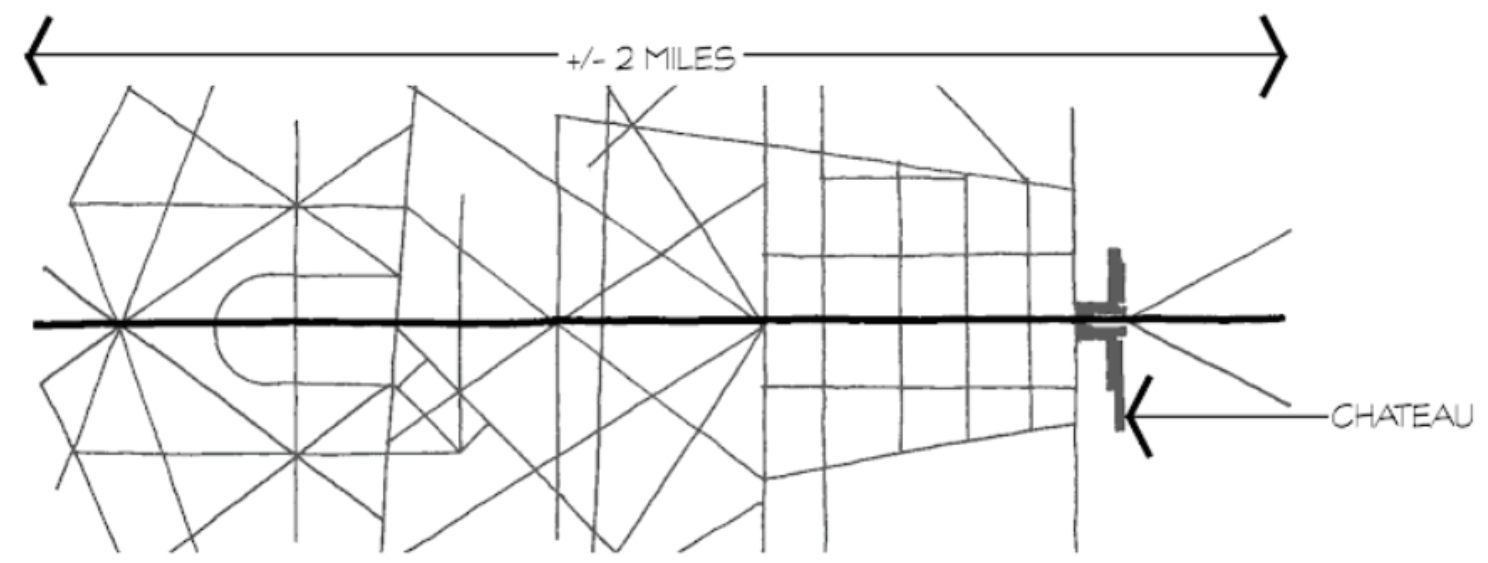

Figure 32: Axis and Avenues at Versailles 
unifies the building to it's surroundings. There is a purity in the clear distinction between what is simple and man-made and what is complex and organic. The axis undeniably symbolizes the human re-imagination and management over the landscape. It is no mistake that the practice of planting in straight rows is the common method in agriculture. ${ }^{98}$

How does one respect the traditional controlling French Baroque axis in a romanticized ruin which aims to give way to nature?

The main focus of this thesis project is to pivot the human centeredness in design towards a more biocentric influence. It is possible to re-imagine the common function of the controlling human-made vectors. What if this "invisible" two-dimensional vector was used as an alternative boundary line which guides the inhabitants? Traditionally, horse paddocks are fenced in order to prevent over-grazing and run-away horses. Shift this into a vector design and use a different material such as water or topography. Instead of the typical fence, water or a sudden topography change could act as a boundary line, yet still provide the desirable natural views and open plan.

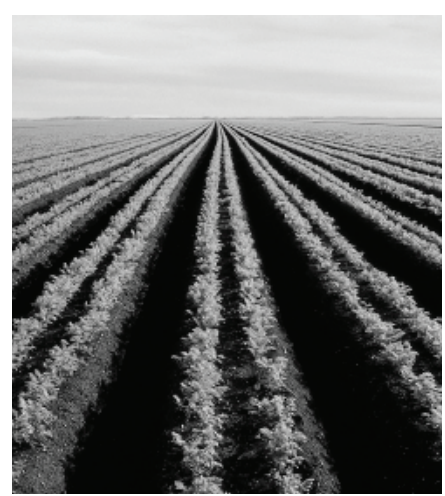

Figure 33: Vegetable Rows

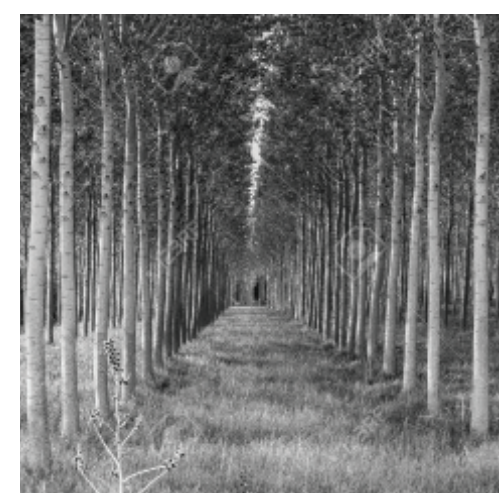

Figure 34: Tree Rows

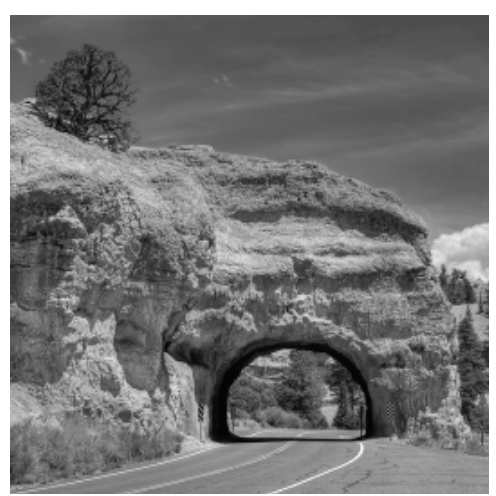

Figure 35: Road blasted through rock 
"The equine architect must "ulisten" to the site the same way an equestrian listens to his horse. Much like a horse with his individual demands and personality, a site contains its own demands and personalfty. You must find and work with them for the project to be successfulpm99

-John Blackburn 


\section{Mothe Chandeniers, Les Trois-Moutiers}

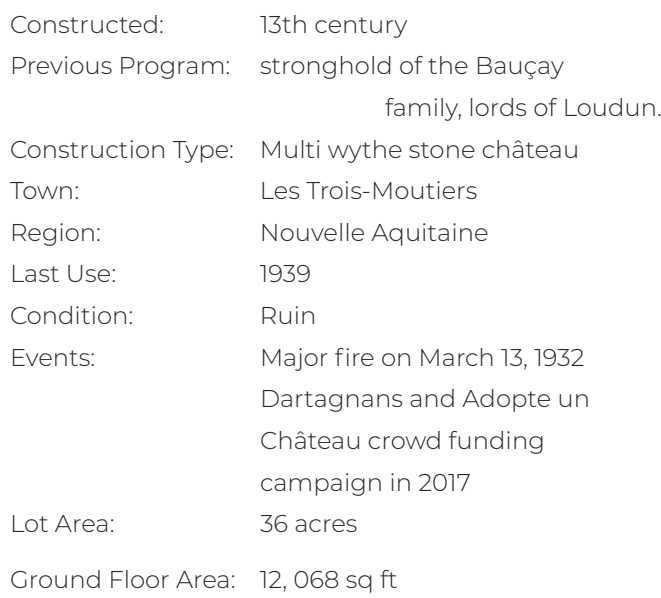

"It is lost in the French countryside. It is a Gothic lace embroidered in stone. It is an enchanted mirage fluctuating on a calm lake. It is embraced by jealous vegetation that has been twining its bastions and architectures as a greedy lover. The castle evokes an intimate embrace between history, architecture and nature. Faraway from mankind, this place has achieved its most resplendent beauty. However, now it needs mankind in order to forestall its ultimate destruction ... At the sunset of a building, architecture itself has to protect the remarkable combination of human action and natural activity that is the fascination of Mothe Chandeniers. Architecture has to save the castle from the erosion of time in order to give it back to the community that purchased it. It is an unprecedented challenge that invites designers to deal with a place with a surreal beauty able to create oneiric and refined holidayscenarios." 100

-YAC Competition Brief
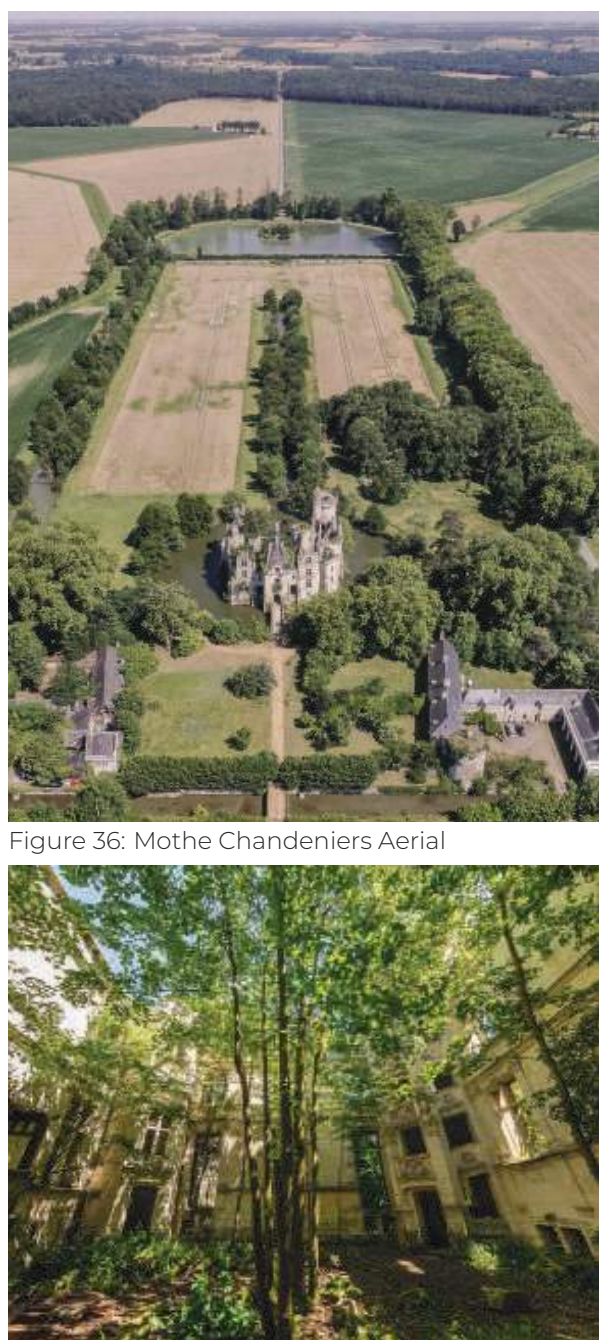

Figure 37: Mothe Chandeniers Interior 


\section{Mothe Chandeniers Storyline}

The Mothe Chandeniers castle sits on a 36 acre plot of agricultural land. The site includes a moat that acts like an axis as it surrounds the castle and branches off into three different directions. The three water channels sever and segregate the site. The ruined castle is in a state of ruin as it is being reclaimed by vegetation that enters and exits the architecture at nature's disposal. Pinnacles, ribbings, Gothic statues, double arched windows and porticoes are all sewed together forming an intricate workmanship of embroidered-like ivy. The original rooftops covering the labyrinth halls are now sheltered by tree canopies. There is a sense of security in the density in the solid stone walls, yet they are riddled with cracks and crevasses that create a porosity of light and air. ${ }^{101}$

Renovated during the Romantic Age, Mothe Chandeniers is an embodiment of architectural romanticism.

\begin{abstract}
"This artifact evokes emotions, cherishes and enhances imagination and spirituality, makes visitors live a Gothic past where mystery is possible and magic is real." ${ }^{\text {"102 }}$
\end{abstract}

-Young Architects Competitions

\section{Timeline \\ $13^{\text {th }}$ century: castle origins}

$15^{\text {th }}$ century: Property of Mothe Chandeniers family

$1^{\text {th }}$ century: Marquis Francois de Rochechouart-Chandeniers's house. He was banned from Loius VIII's court and was to live in exile. His wife, Maria Loup de Bellenave, died in labor in May 1649. Her remains were guarded in the castle. The fortress hosted symposia for intellectuals and artists. Leonard Frizon, a poet, wrote many descriptions of the castle in his work. He raved about the $300+$ lemon and orange trees around the open-air theatre..$^{103}$ 
$17^{\text {th }}-18^{\text {th }}$ century: abandoned for two centuries after the death of Marquis Francois de Rochechouart-Chandeniers. ${ }^{104}$

19 ${ }^{\text {th }}$ century - 1809: Francois Fidèle Hennecart, a wealthy textile tradesman, purchased the castle. Hennecart restored the 17th century architecture prestige in the building by adding the existing channels and moat around the castle. The Hennecart family was buried on site. Francois Fidèle Hennecart's daughter Aimèe Alexandrine Hennecart and niece Marie Ardoin, are responsible for the interventions that were manifested into the castle that it is today. ${ }^{105}$

1858: Marie Ardoin married baron Lejene; they lived in the castle and used it as a hunting lodge. The surrounding properties of the castle were once included in the hunting lodge. Over time it was severed and used as arable land. ${ }^{106}$
13 March 1932: Originating in the East wing, a massive fire destroyed most of the building. Until 1950, Lejene's descendants lived in the West wing of the castle as it was not completely destroyed. ${ }^{107}$

Present: Currently, fire and weathering have affected the structural system in the castle. The castle has remained abandoned until recently, when the Dartagnans Foundation bought it. "Dartagnans is a fund aiming at protecting and safeguard-ing the international artistic heritage. Recently, it has purchased the castle thanks to more than 27910 shareholders' donations. Today, through YAC, Mothe Chandeniers invites designers to highlight the natural fascination of the castle in order to transform it into a destination of contemplation and relaxation for tourists and visitors from all over the world." "nos 


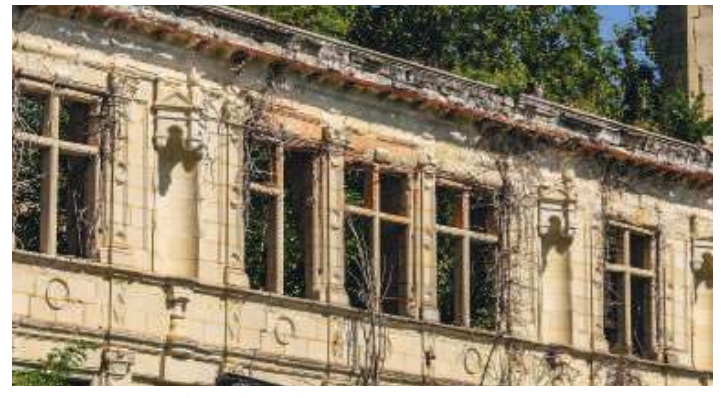

Figure 38: Mothe Chandeniers Openings

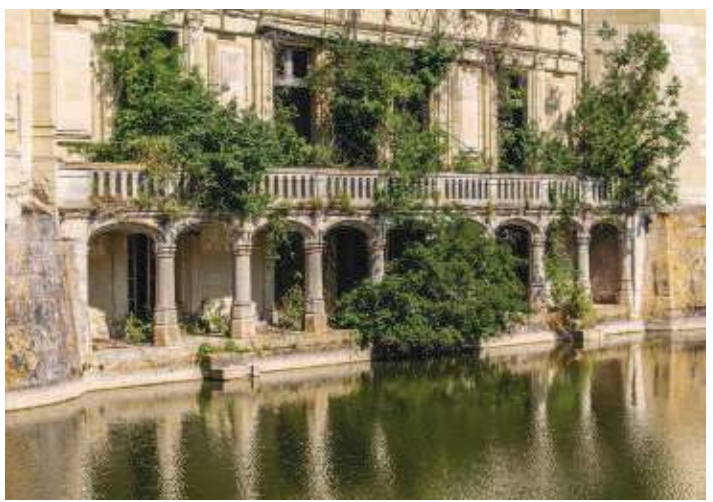

Figure 39: Mothe Chandeniers Portico

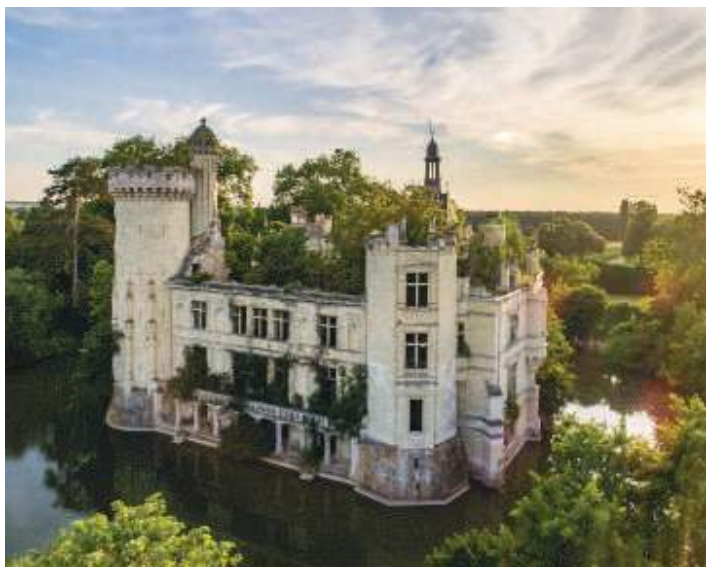

Figure 41: Mothe Chandeniers Exterior

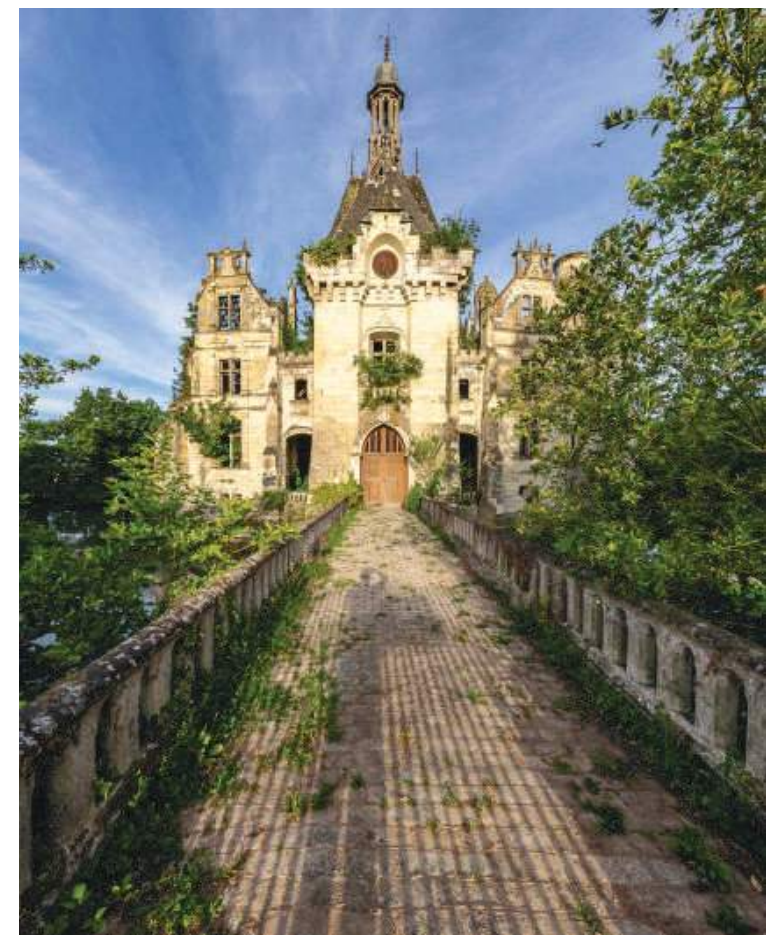

Figure 40: Mothe Chandeniers Bridge towards Entrance

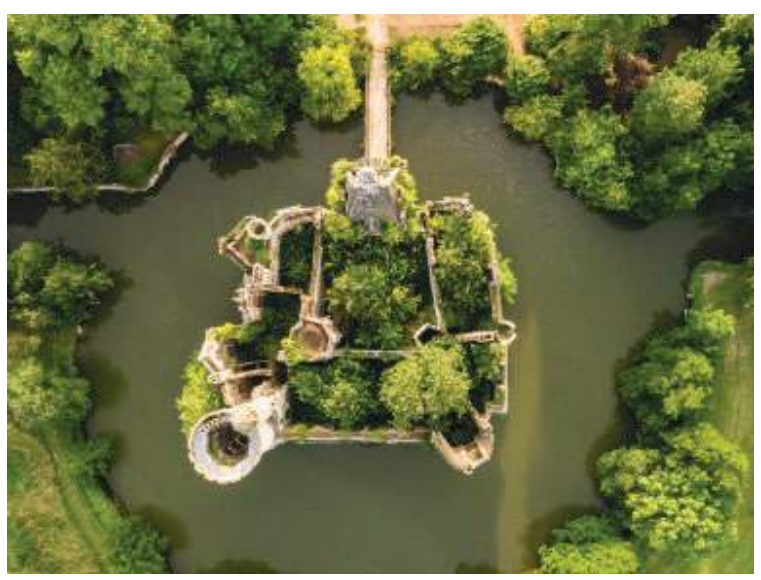

Figure 42: Mothe Chandeniers Aeria 


\section{Ranked: International Finalist Mention}

This project will be transmitted to architectural magazines and websites and will be hosted in international exhibitions. It is published on www.youngarchitectscompetitions.com ..........

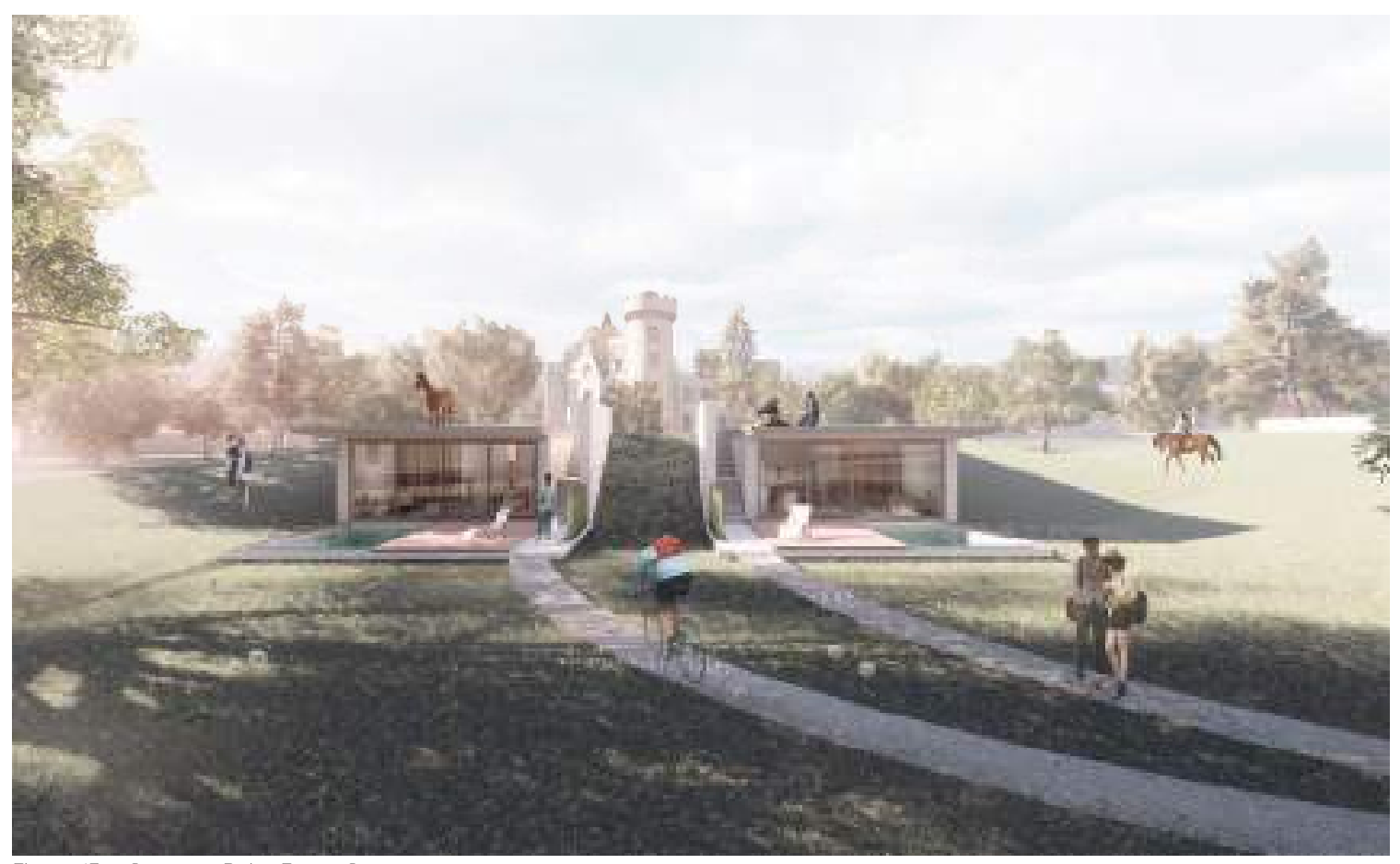

Team Name: Equus

Jury

Marco Amosso | Lombardiniz2

Aldo Cibic | Cibicworkshop

Olivier de Chabot I Groupe Mercure

Romain Delaume | Dartagnans

Luca Dolmetta | LD+SR architett

Dagur Eggertsson | Rintala Eggertsson Architects
Team Members: Stephanie Agar

Alfonso Femia | Atelier(s) Alfonso Femia AF517 Anish Kapoor

Julien Marquis | Adopte un Château

Rudy Ricciotti | Rudy Ricciotti Architects

Edoardo Tresoldi
A. roups compermids.

presents...

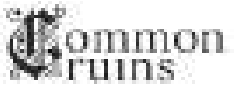




\section{Ukiyo [u - key-yo] - Japanese}

\section{(n.) Living in the moment, de- tached from the bothers of life.}

"The Floating World" 


\section{Site Context Study}

Understanding the realm in which the built environment lies is essential when approaching the design in a biocentric manner. It would be inefficient to ignore the vegetation, natural resources and existing inhabitants while designing. All of these aspects on the site provide a certain potential that can be highlighted through strategic architectural design.109 The existing landscape's earth and water and bountiful vegetation have potential to supply the demands of the program for both horses and humans.

As a large-scale production, the amount of produce needed would be immense. The 36 -acre site is able to provide for the production; however, studies and a plan must be implemented in order to take full advantage of the agriculture. As mentioned in Section I, the landscape requires segregation into paddocks to prevent over-grazing and flooding. ${ }^{110}$ Sudden topographical changes and water channels may serve the agriculture while defining a boundary or 'zone'. The existing topography on the site has slight variations and contours. The proposed site will alternatively subtract and add the excavated earth in strategic locations in order to enhance the site's natural resources. No earth is added or removed from the site. The existing moat and water channels continue to serve as a main axis on the site. Due to the mild weather and precipitative climate, the site's channels are prone to flooding. Thus, a series of elevated boardwalks are proposed. The pathways material consists of perforated mesh, to eliminated any disruptions for vegetation and water flow.

The landscape has beautiful vistas of the countryside."1 The proposed built environment does not hinder the views, it enhances them. Throughout the site, the design frames views and provides thresholds that connect the interior to the exterior. The majority of the glazing on the site is facing towards the southern sun. Portions of operable glazing allow for passive heating, cooling and ventilation. As the designated program is high-maintenance, the passive systems will lower the required work load of the occupants and their equipment. Having proper heating, cooling and ventilation is important for both horses and humans. For horses, it may mean life or death as airborne bacteria and heat stress may greatly affect the horse's health. ${ }^{112}$ 
Understanding the scale of the site and the number of occupants inhabiting it requires looking at the site plan in a numerical fashion. Essentially, the 36 acre site's proposed pathways can be cantered through by a horse in 35 minutes and walked through by a human in 45 minutes. Along the way one may find other species that co-exist in the site's ecosystem. Co-habitation within the ecosystem allows for natural growth and balance within the site. ${ }^{113}$

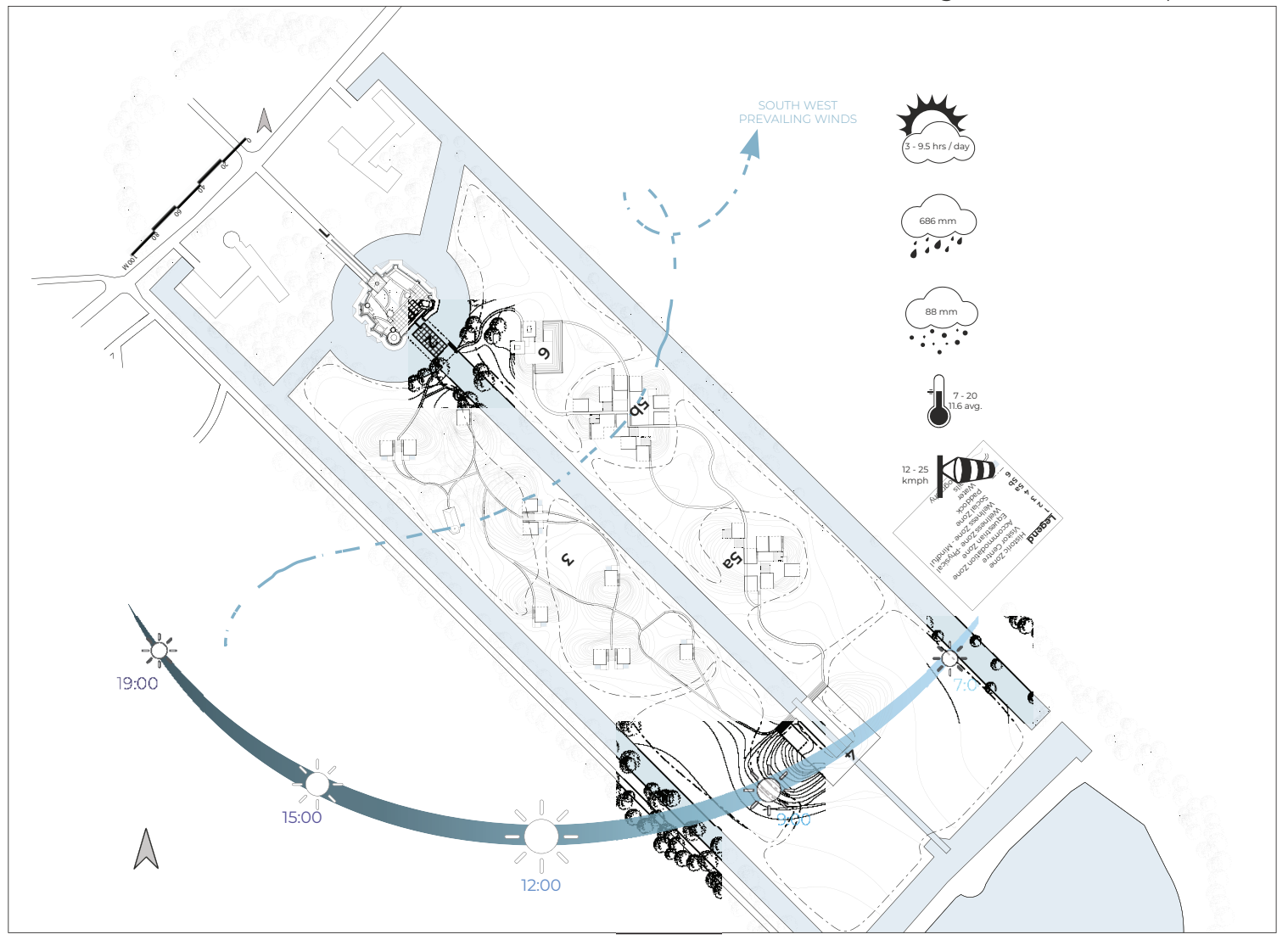

Figure 44: Mothe Chandeniers Context Study
"Scattered towers covered in ivy overlook lavender and wheat fields. Roses, lilies and petunias embellish vegetable gardens and porticoes. Ancient agricultural vehicles rust under a warm and generous sky. Every element contributes to suggest a sense of conciliation evoked by the smell of hay and the quiet dance of the fronds of willow trees. The ancient Aquitaine region is truly an oasis of peace." 774

-Young Architects Competitions 


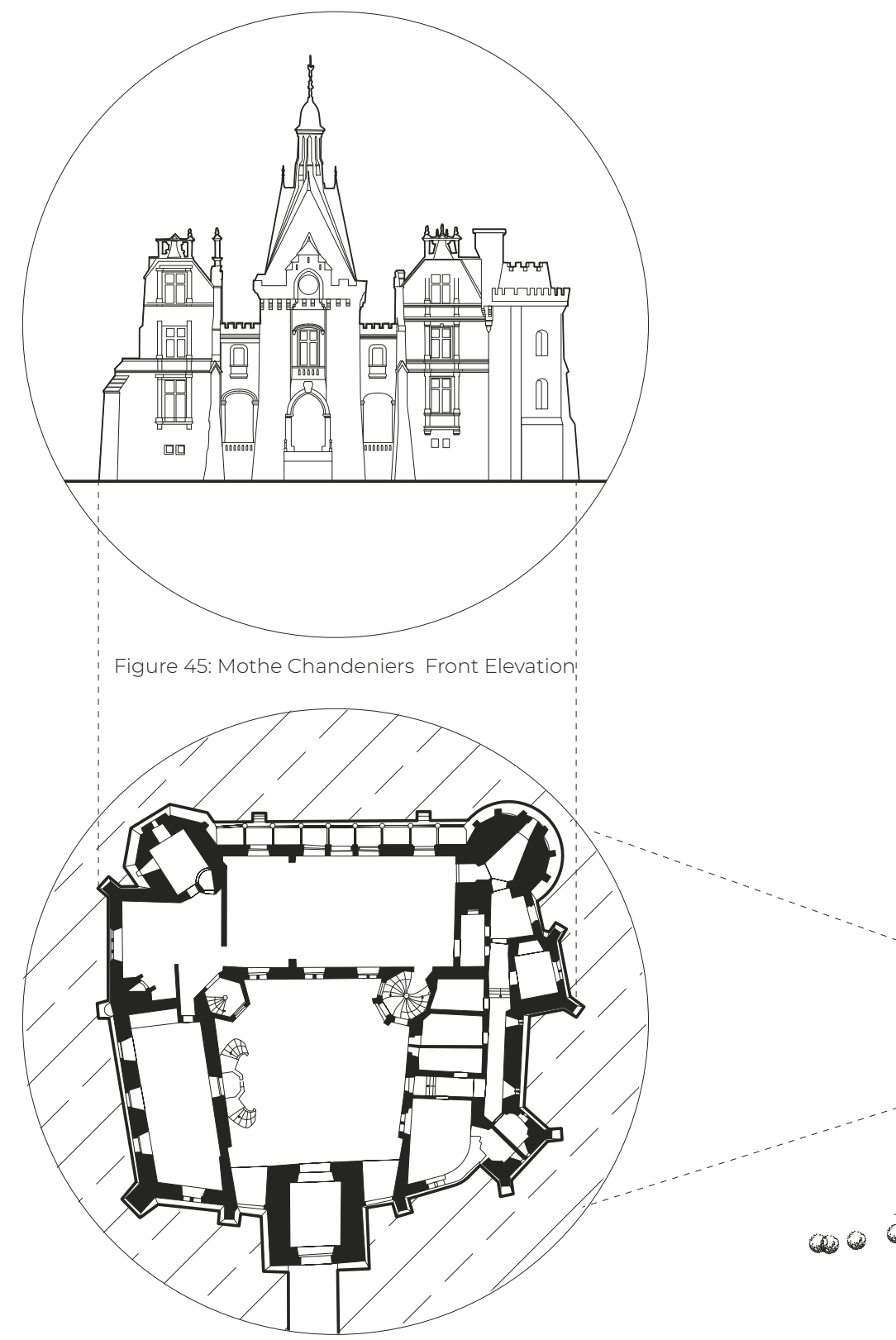

Figure 46: Mothe Chandeniers Floor Plan

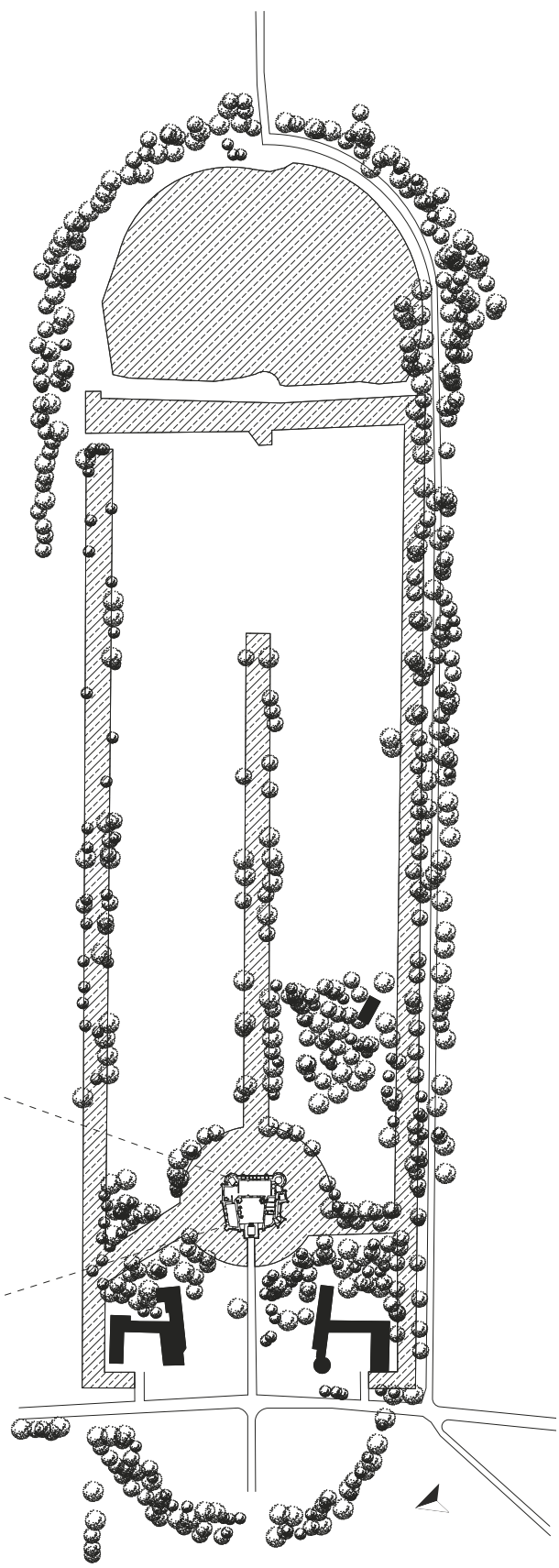

Figure 47: Mothe Chandeniers Site Plan 


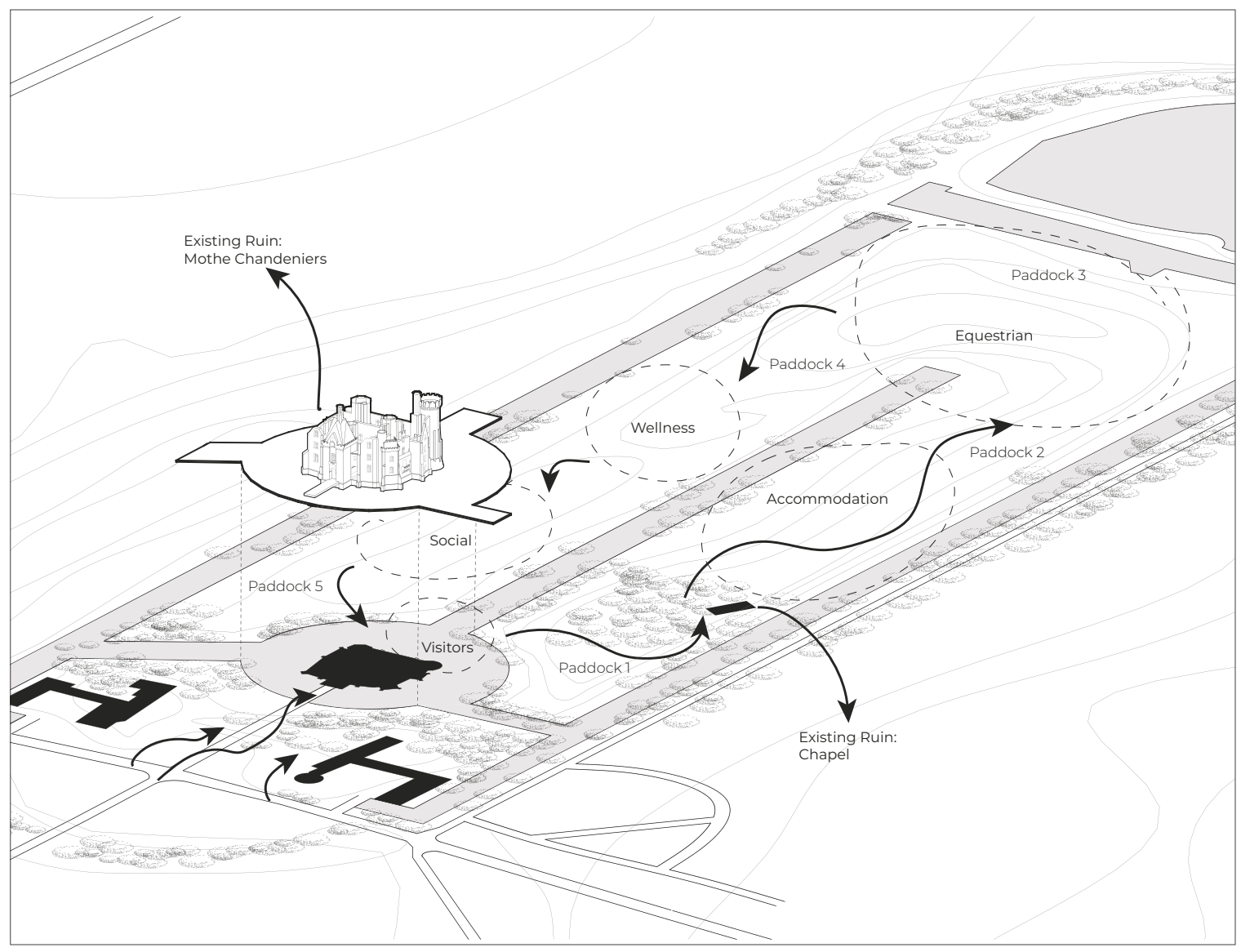

Figure 48: Mothe Chandeniers Axonometric 


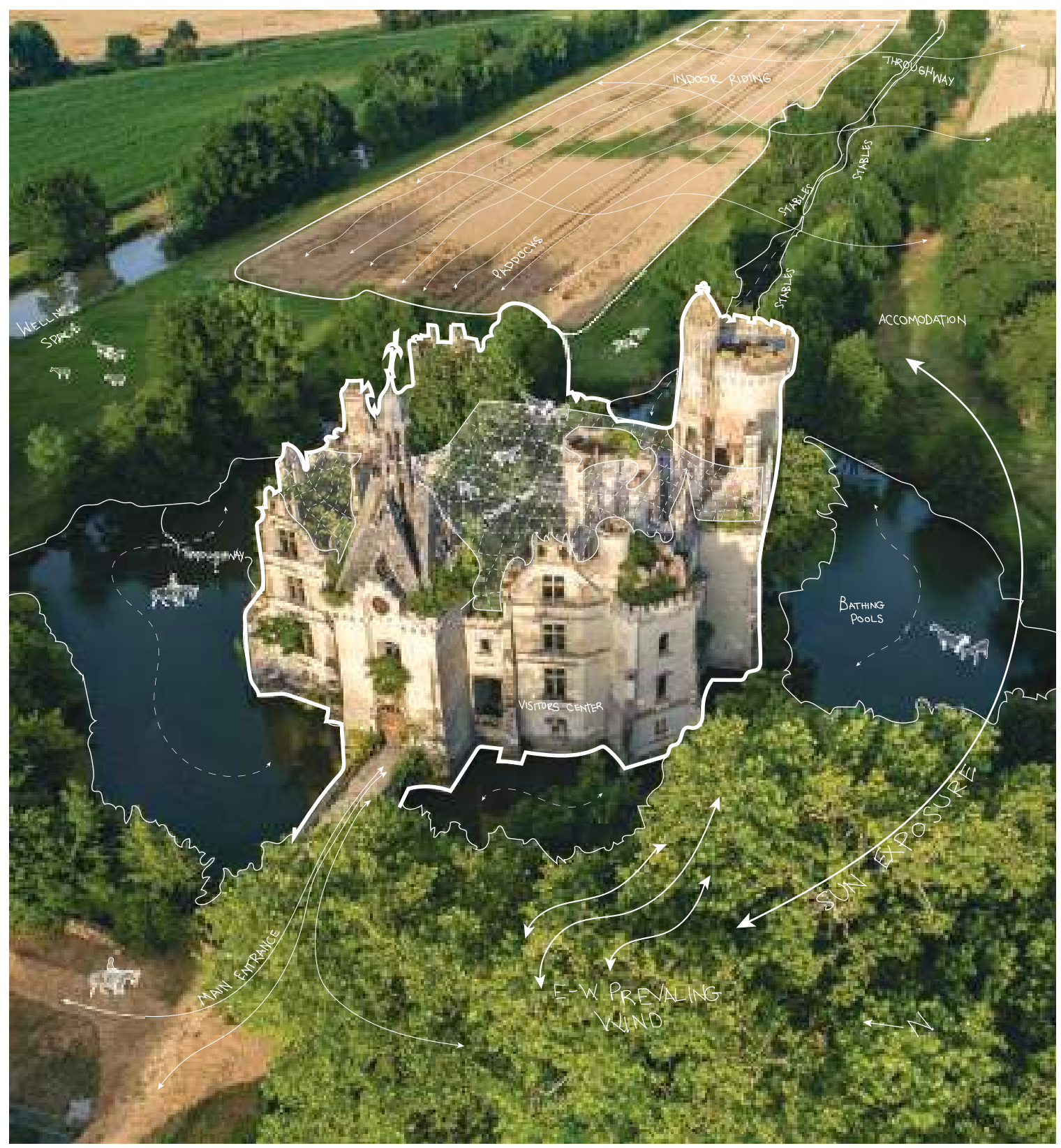

Figure 49: Mothe Chandeniers Sketch by Stephanie Agar 


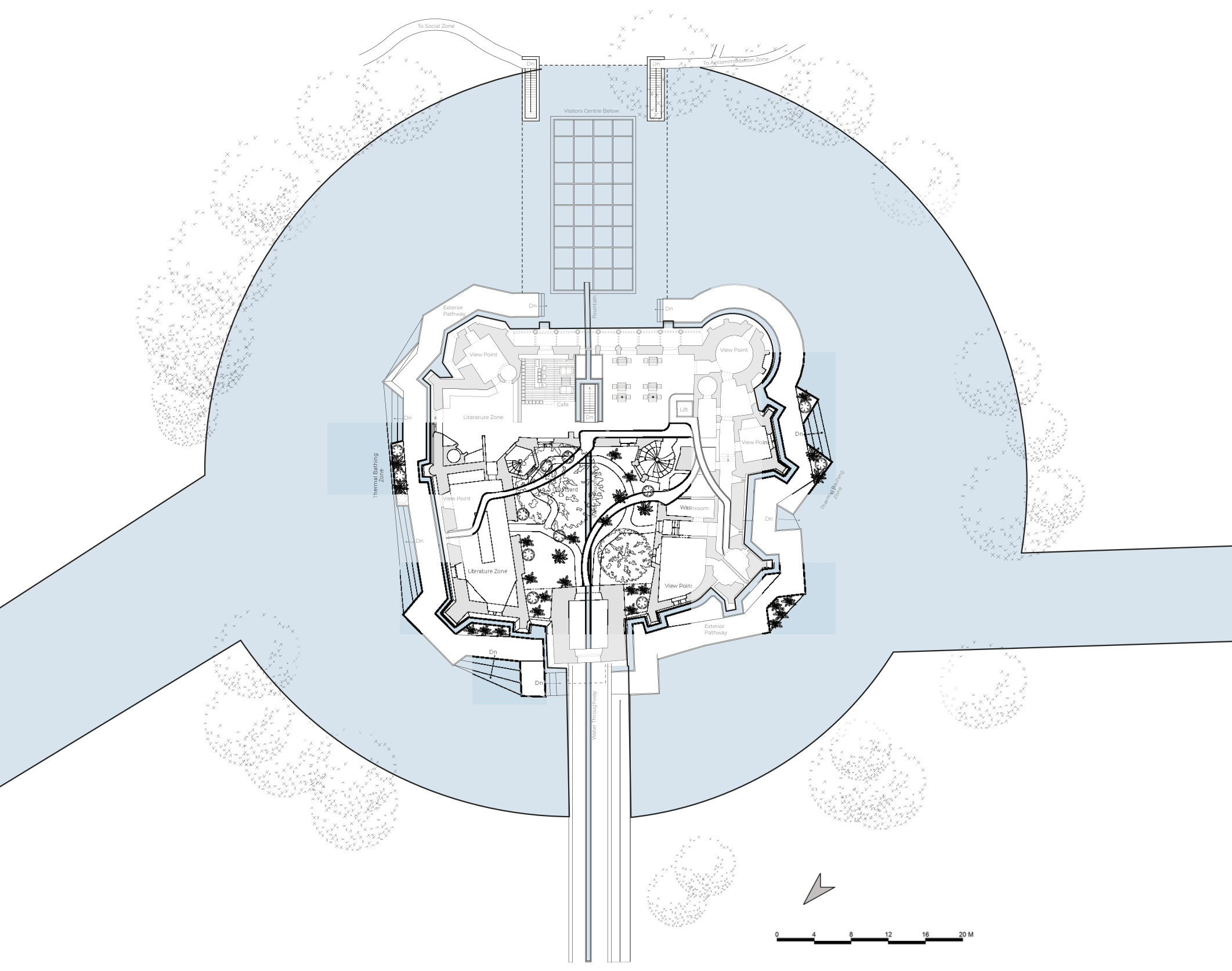

Figure 50: Mothe Chandeniers Ruins Proposed Floor Plan 


\section{Proposed Strategy}

The proposed design takes special consideration of how a space operates by enhancing the ecological elements on site in order to make a horse's unnatural environment more natural. The site is organized in a cyclical manner with six destination zones. Using the Bagua map illustrated on page 72 , the site is sectioned off into different zoned programs that connect with a network of pathways. Figure 51 illustrates the six zones. The independent zones each have their own benefits but work together to achieve a final result; a positive progression of one's inner/outer state.

Architectural strategies include orientating and manipulating the site to create an advantageous design. This may be through burming the earth against the perimeter of the architecture to conceal it within the landscape, working with prevailing winds, or understanding the sun exposure. The strategy focuses on the scale of the project, as it could easily get out of hand and take over the entire site. Conversely,the design may be too confined and limited to a small space causing claustrophobia. The scale of the site, a human and their limitations, and most importantly the horse are all contributing factors.

Water is symbolic of the rich agricultural landscape that surrounds the site. The existing band of water severing the middle of the site acts as a central axis to the existing ruins. The design proposes an extension of this prominent feature by threading water through the castle and the proposed additions. The manipulated landscape and the perforated trails within it guide visitors through the entire site as they embark on their journey. At first glance, the steep inclines in the landscape conceals the embedded architecture. This allows for a romanticized view of the ruins, from any position on the site. Yet, the trails are still accessible to all thanks to the equestrian program on the site.

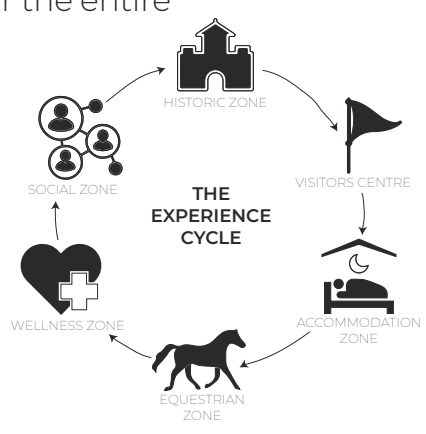

Figure 51: Mothe Chandeniers Program Cycle by Stephanie Agar

Equus As Client: A Biocentric Retreat 


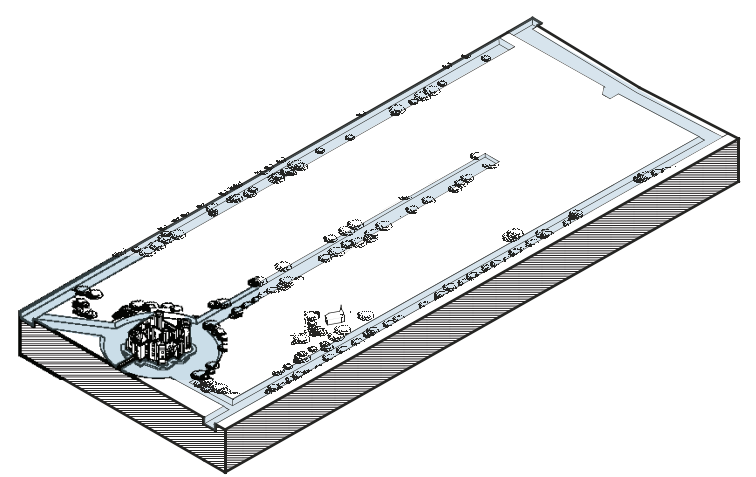

CONSERVE ACCESSIBILITY

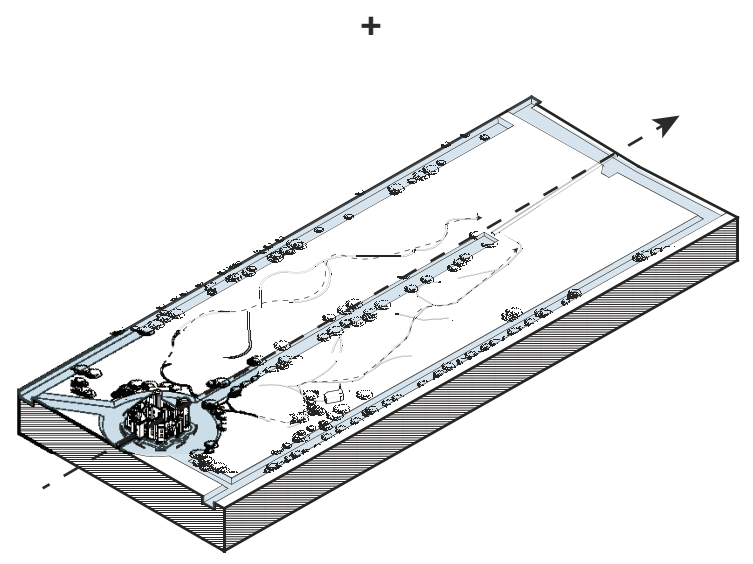

\section{EXTEND / GUIDE}

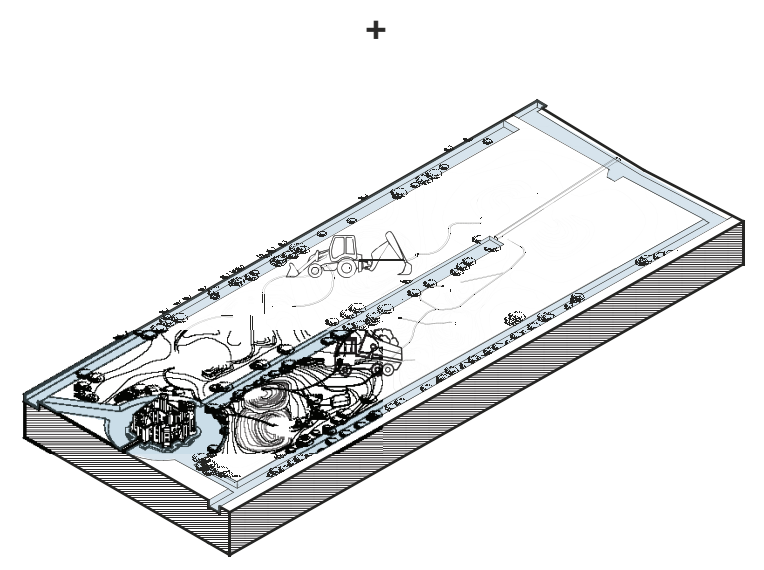

EXTRACT / RETAIN
The project focuses on creating a site that gives way to nature. The architecture does not take away from the existing, it compliments it and provides further potential for it's growth. For example, the mesh trails are provided purely for framework during floods, while grass and ivy vegetation are able to grow through it. In the courtyard of the ruins one is able to see hanging ivy growing intricately through the suspended mesh bridges.

The natural and built landscape act as a platform to experience the earth and it's vegetation. This is a sensory experience as the gardens engage one's touch, taste, smell and sight. For example, the lemon and orange trees produce an aroma that attracts the visitors and horses for their taste and aromas. The fire pits in the social zone also act as aromatherapy.

Material selections vary depending on the aspiring experience in each zone. Overall the materials resemble earth tones and nature as they incorporate water, fire and earth into the material palette.

Figure 52: Strategy by Stephanie Agar 


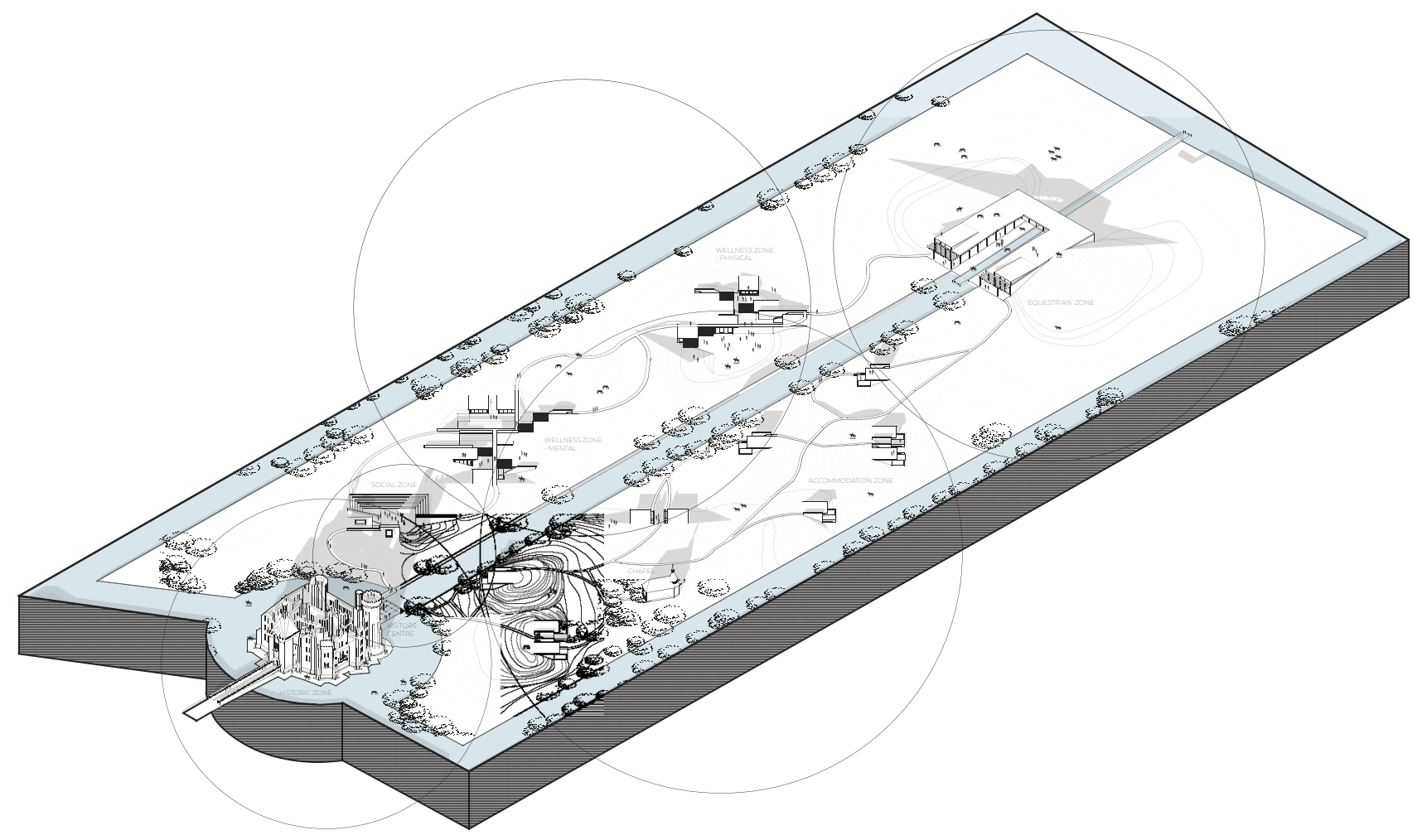

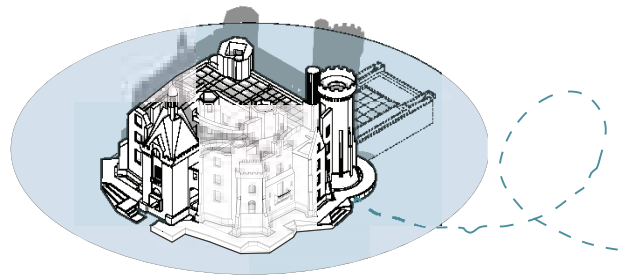

1. HISTORIC ZONE

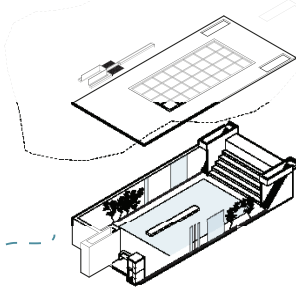

2. VISITORS CENTRE

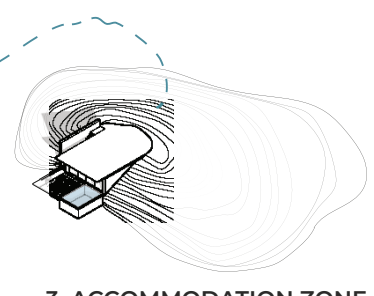

3. ACCOMMODATION ZONE

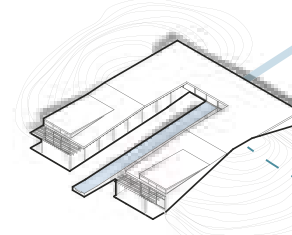

4. HIPPOTHERAPY ZONE

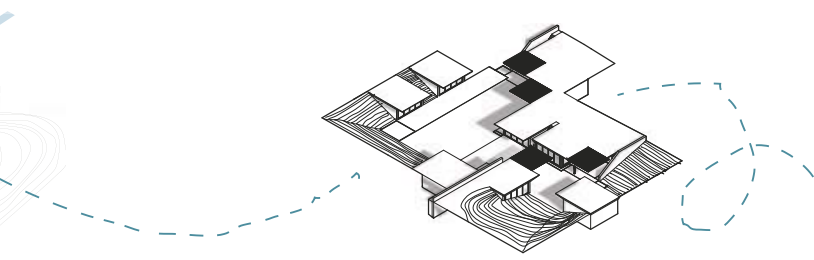

5. WELLNESS ZONE

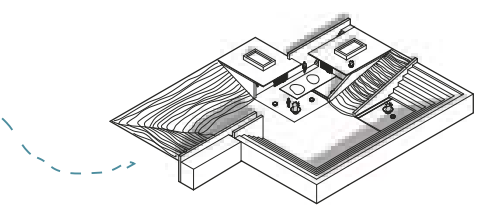

6. SOCIAL ZONE

Figure 53: Mothe Chandeniers Exploded Axonometric by Stephanie Agar 


\section{"A horse, a horse, my kingdom for a horse.}

-Shakespeare in Richard III 


\section{Historic Zone}

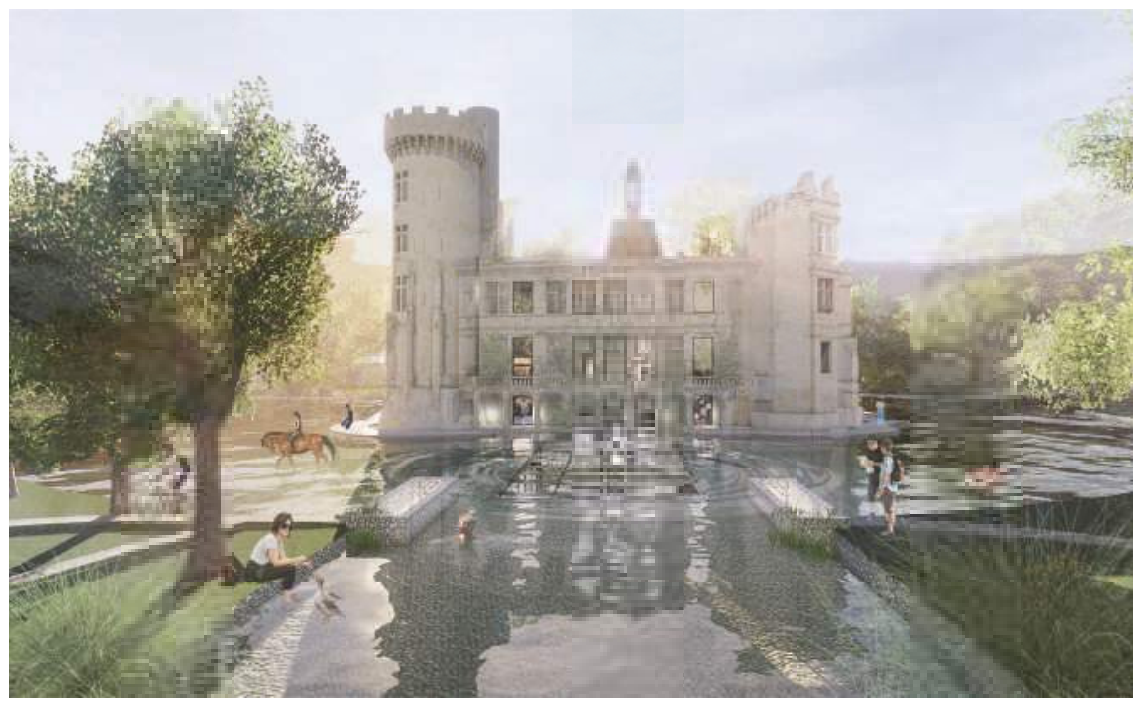

Figure 55: Mothe Chandeniers Rear Exterior Render

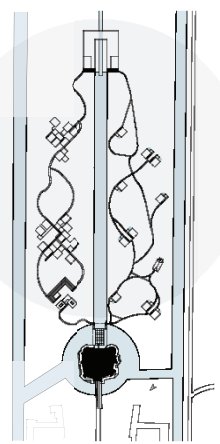

Figure 56: Historic Key Plan

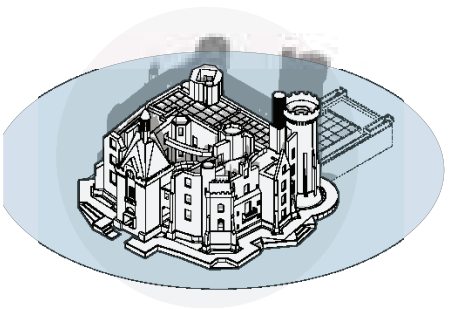

Figure 57: Historic Axonometric

The first space visitors will inhabit is the historic zone. Within this area resides the Mothe Chandeniers fortress ruins and it's surrounding moats and channels. This multi-wythe stone building was once seen as a safe space where intellectuals would gather and explore its many layers of corridors and rooms. Today there is a paradox in this castle, as the density and weight of the building encapsulates its 'safe' reputation, there is an ever-growing porosity as the building's structure crumbles and opens up to its surroundings. The proposed design seeks to preserve the delicate balance of safety and porosity in the building. As visitors enter, they are guided by a water stream which runs from the front property line, over the moat's bridge, and into the building. This is the water axis that will be reoccurring throughout the project, providing guidance and a sense of tranquility. The castle is currently roofless with only nature as it's canopy. The intervention proposes a rooftop with a hollow central courtyard that allows the existing vegetation to continue to grow. Within the ruins and the courtyard are a series of perforated elevated metal pathways which allow the existing natural elements to weave and wrap through them. 


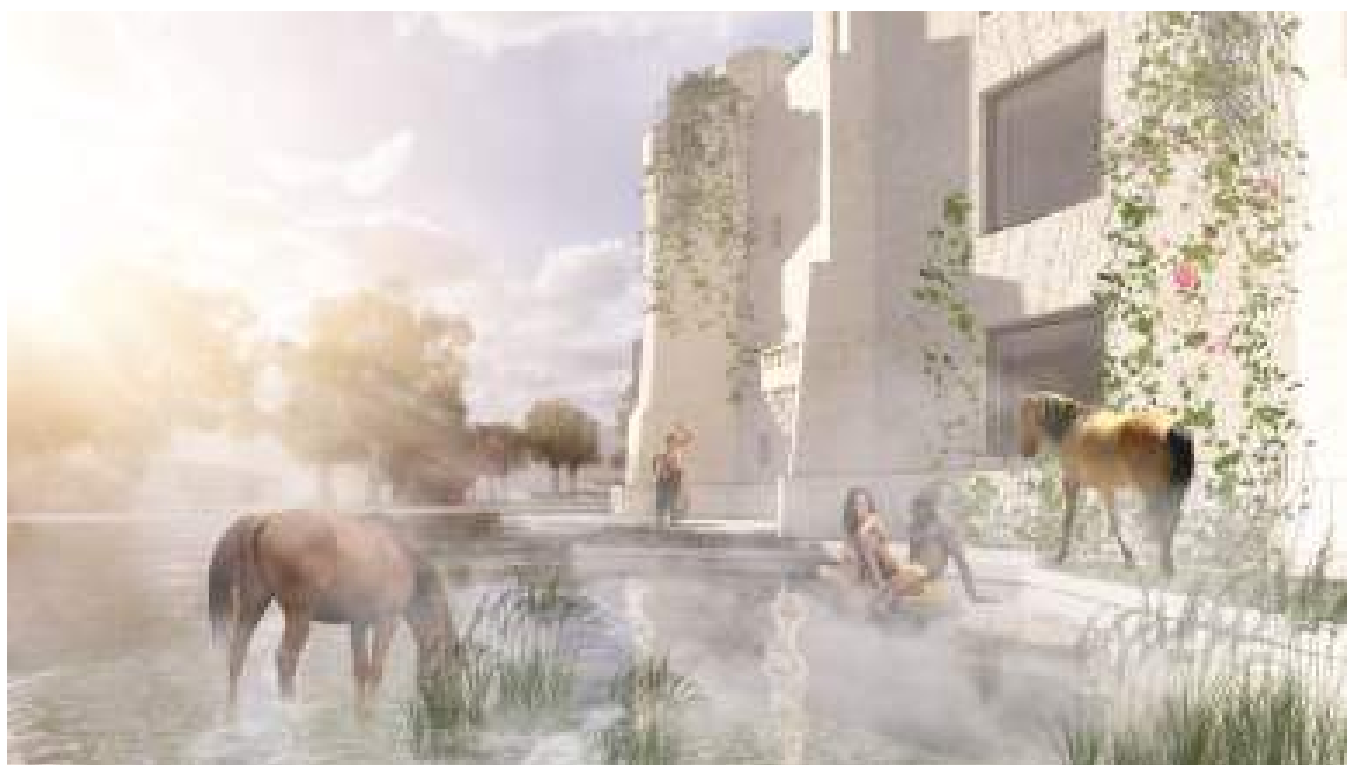

Figure 58: Thermal Bath

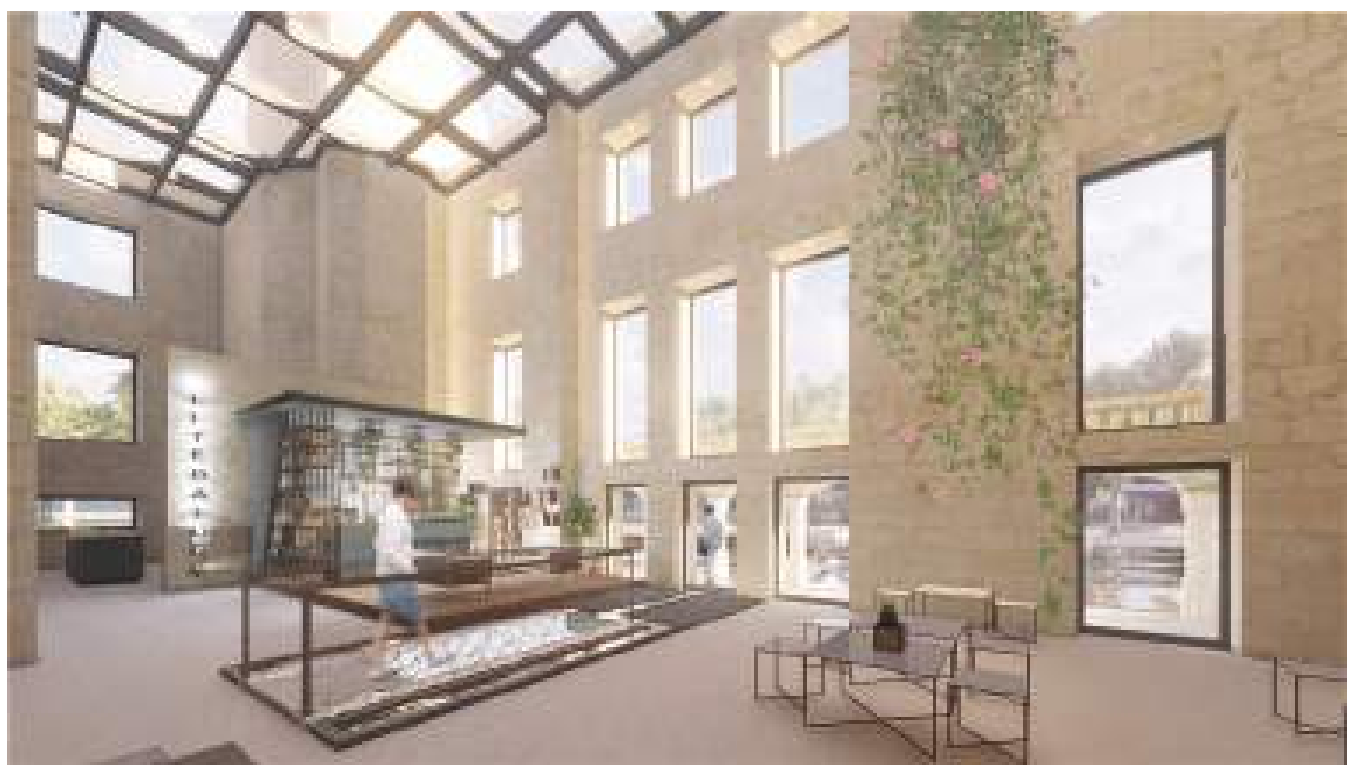

Figure 59: Cafe Render 


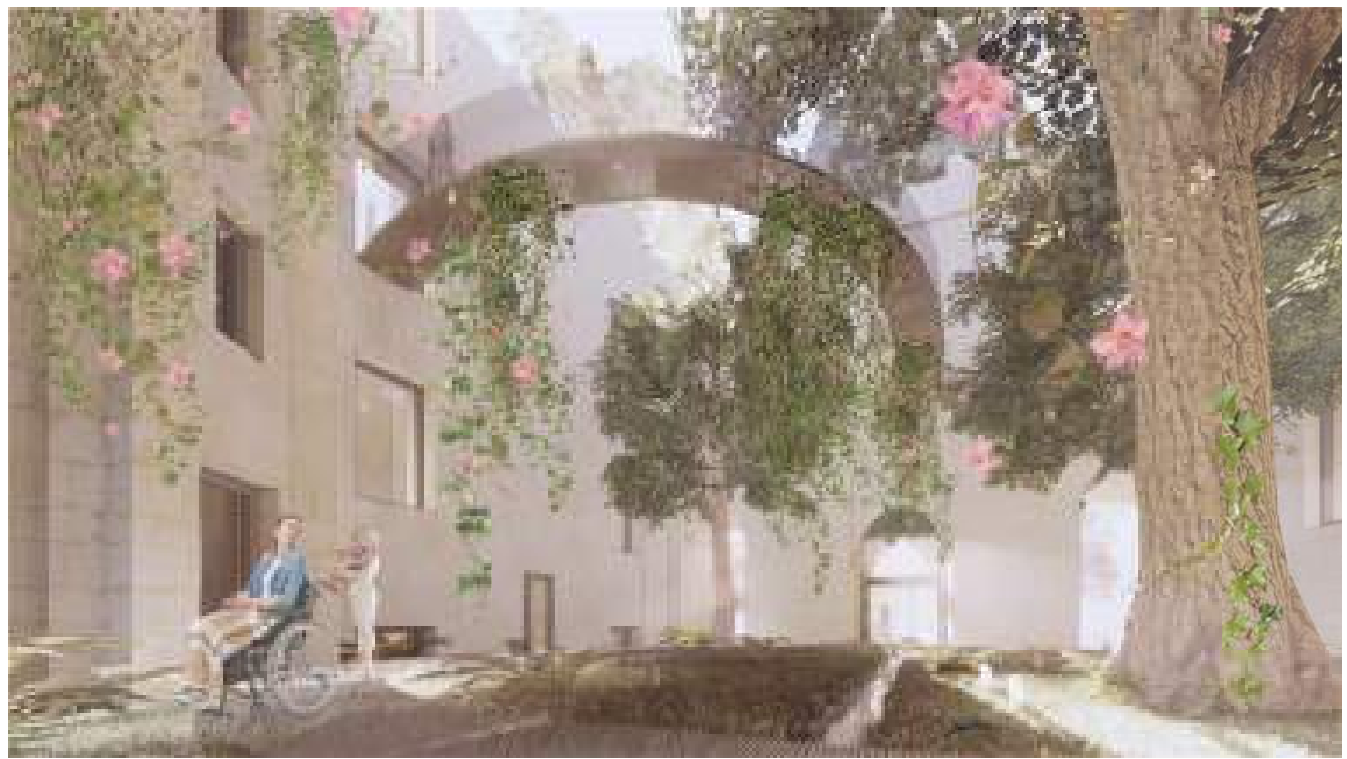

Figure 60: Mothe Chandeniers Courtyard Render

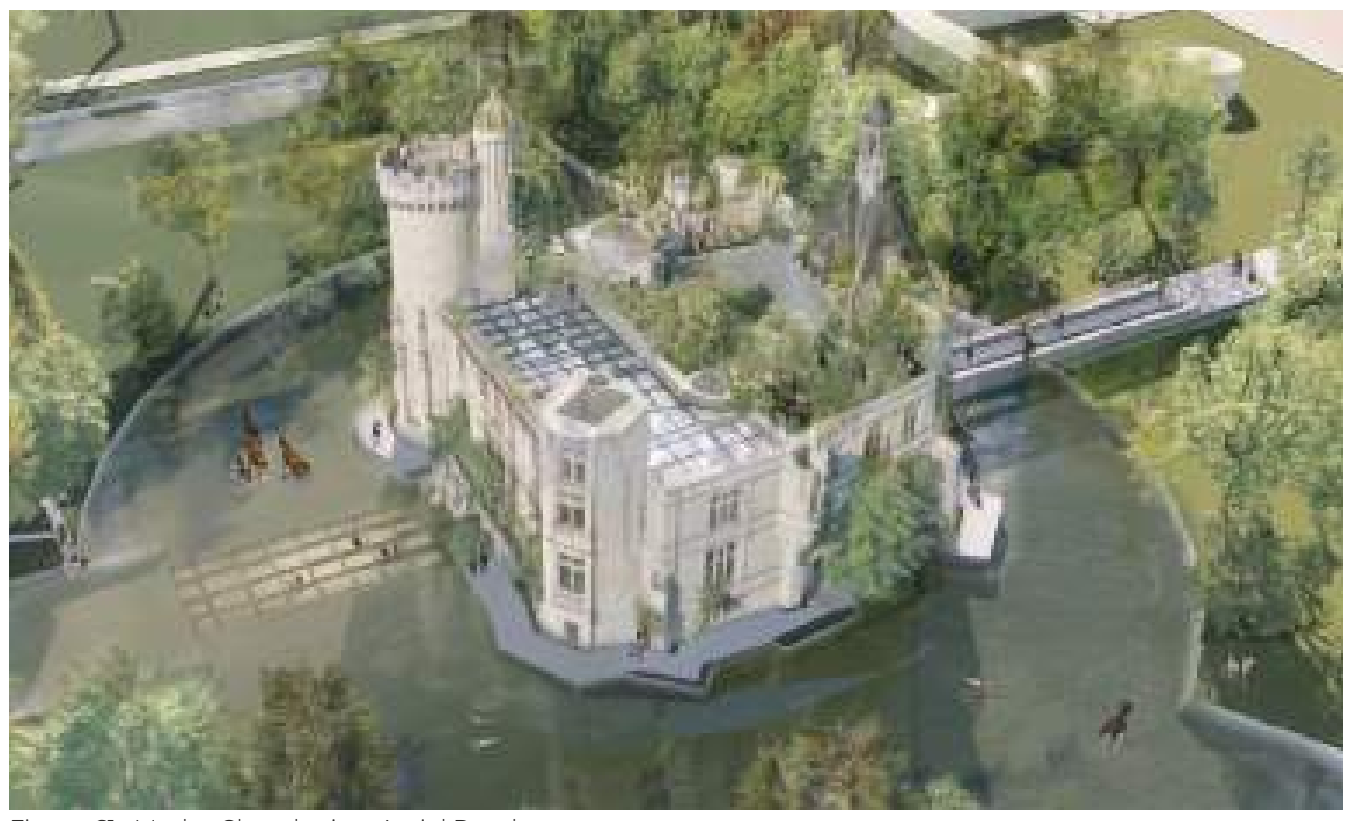

Figure 61: Mothe Chandeniers Aerial Render 


\section{Visitors Centre}

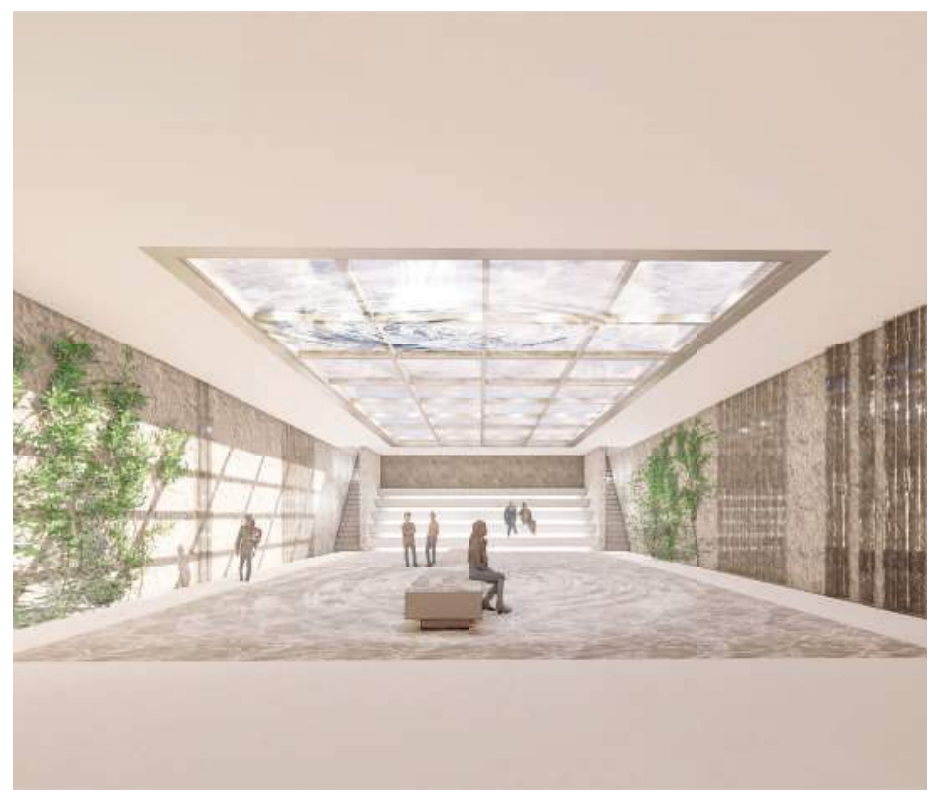

Figure 62: Underwater Visitors Centre Render

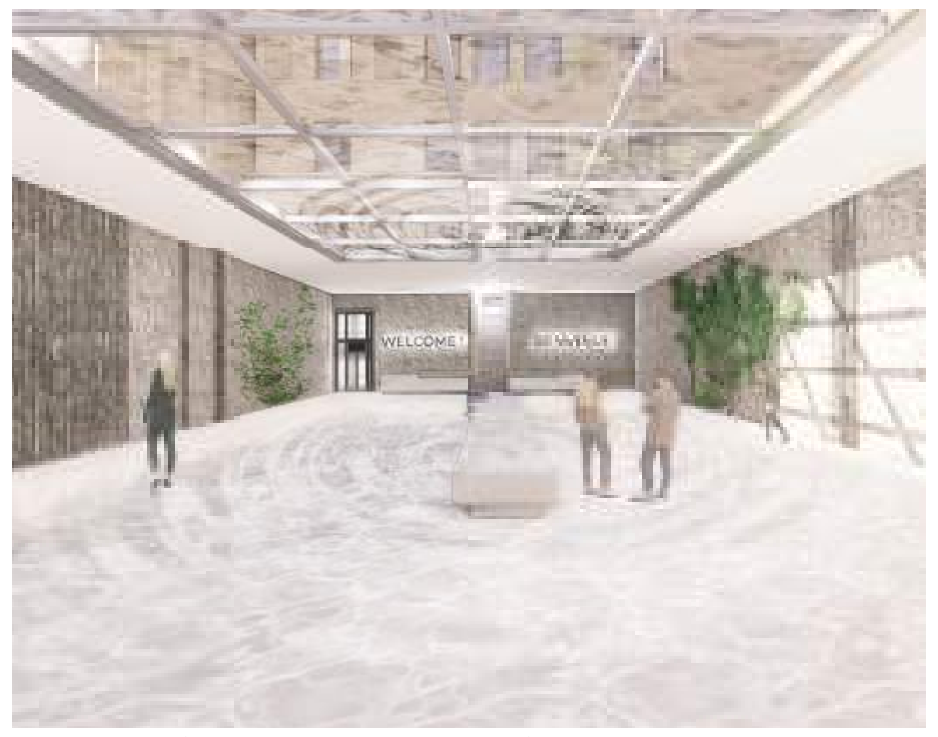

Figure 63: Underwater Visitors Centre Render 2

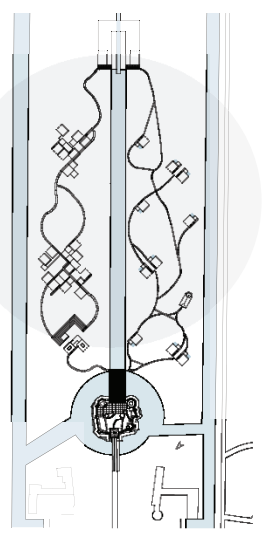

Figure 64: Visitors Centre Key Plan

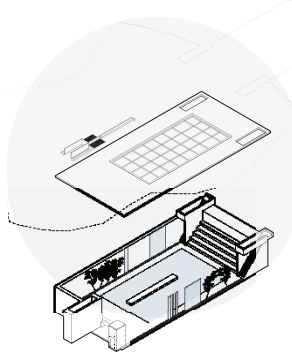

Figure 65: Visitors Center Axonometric

The second zone, the visitors' center is a space dedicated to human needs. Located adjacent to the castle, under the moat, the visitors center is at an unusual grade level, even for humans. As its under the moat, it produces a surreal, calming space. The glass roof creates an airy atmosphere as the water reflections pour onto the ground. The objective of the visitors center is to create a tranquility which initiates the visitors to a hyper-sensitive retreat. 
Level 8 - Lookout Tower D

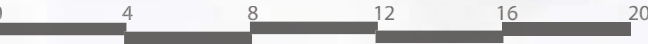

Level 7 - Lookout Tower C

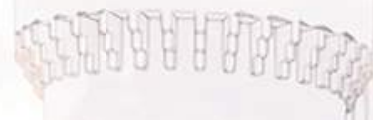

Level 6 - Lookout Tower B

Level 5 - Lookout Tower A

Level 4 - Rooftop Mezzanine

Level 3 - Suspended Trails

evel 2 - Suspended Trails

Level 1 - Interior Courty
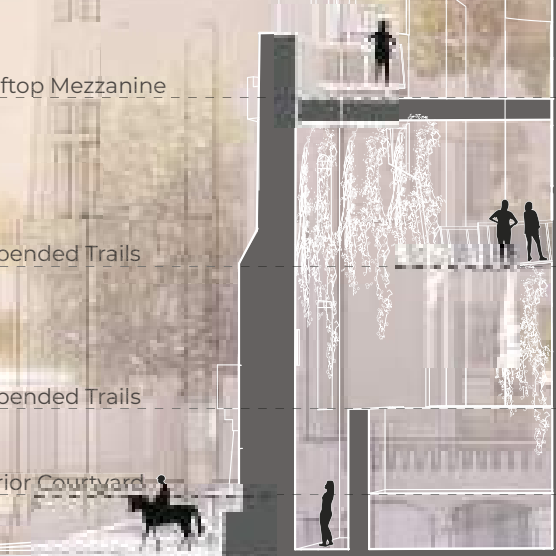

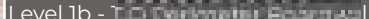

Existing Ruins@ Grade
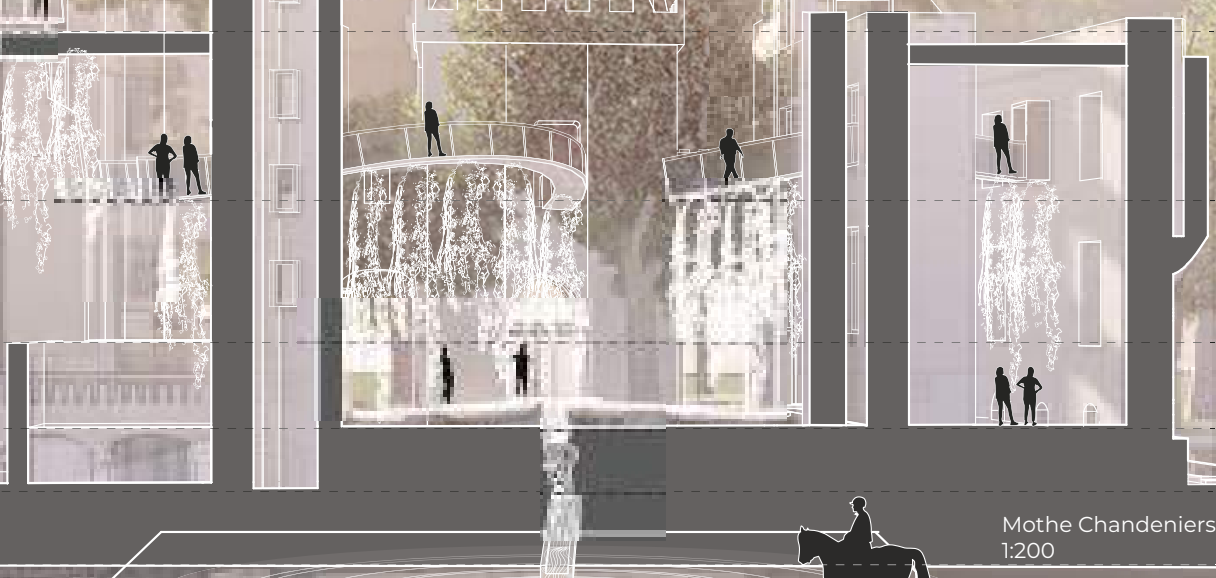

Level 0 - T.O Visitors Centre

Level - Visitors Centre

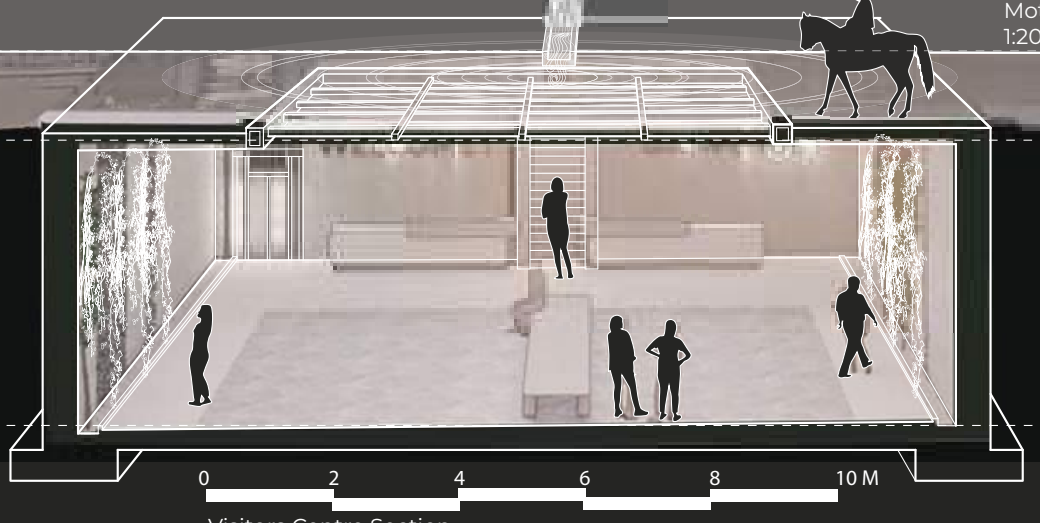

Mothe Chandeniers Section $1: 200$

Visito
1:100

Figure 66: Visitors Centre \& Castle Ruins Section Render 


\section{"A successful equestrian design requires a balance to the de- mands of the site, the goals of the owner, and the needs of the horse but with the needs of the horse remaining a priority."m16}

-Author Unknown 


\section{Accommodation Zone}

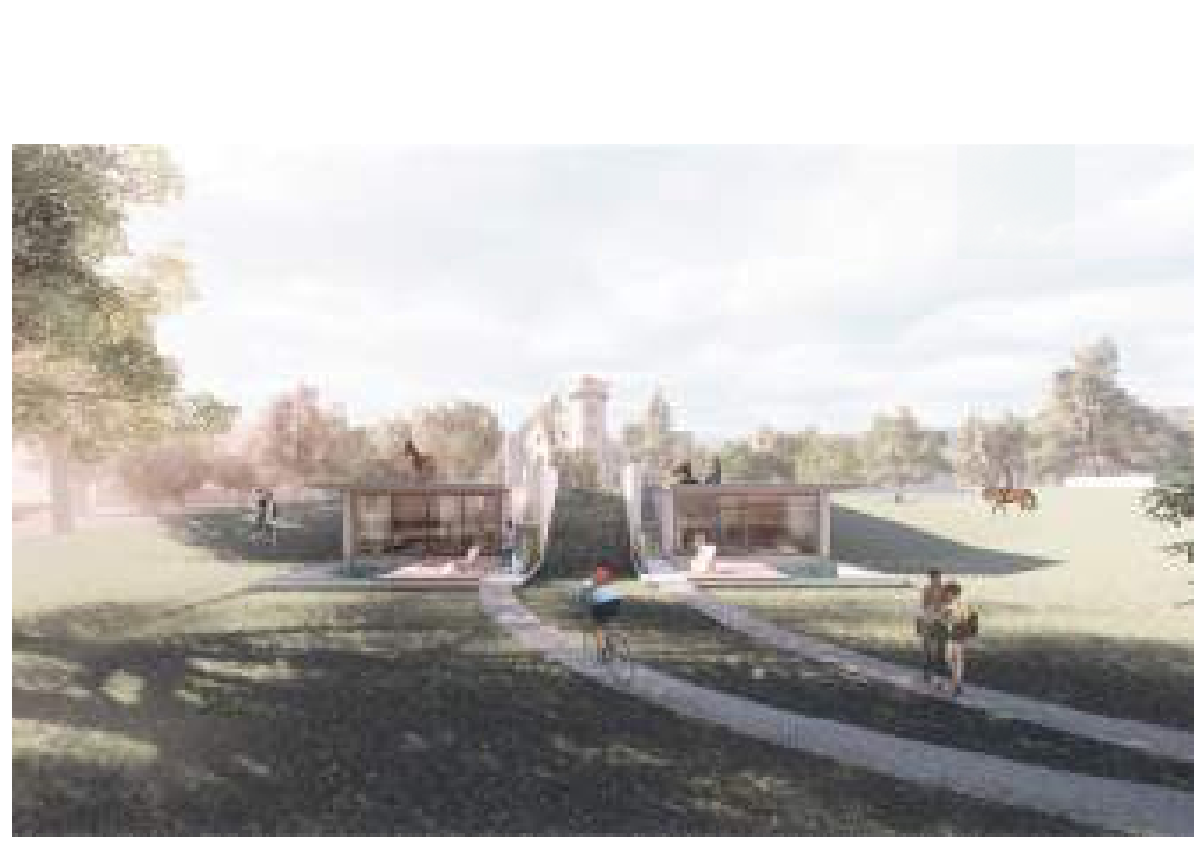

Figure 67: Accommodation Exterior Render

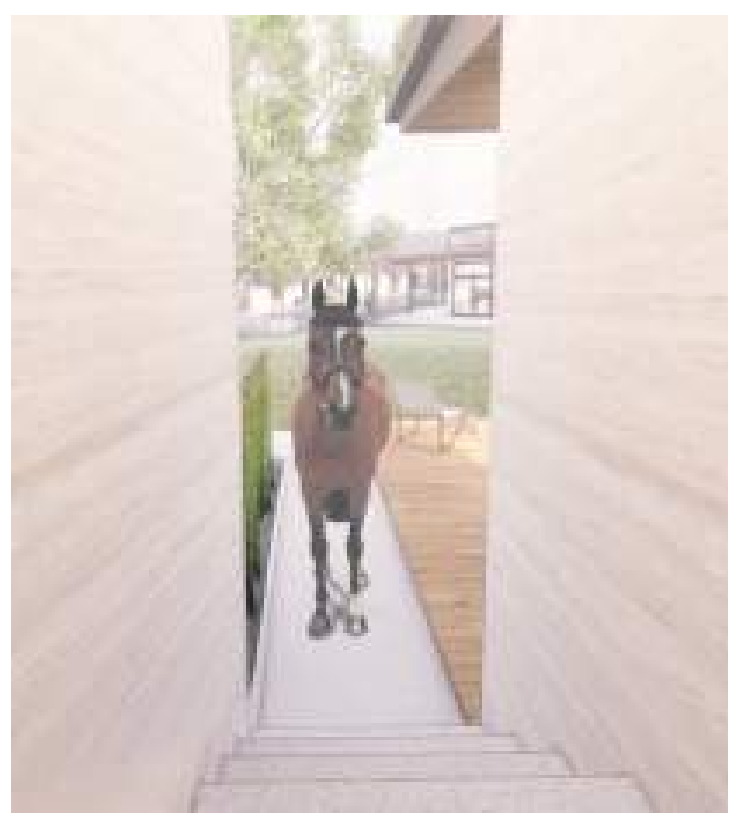

Figure 70: Accommodation Exterior Render

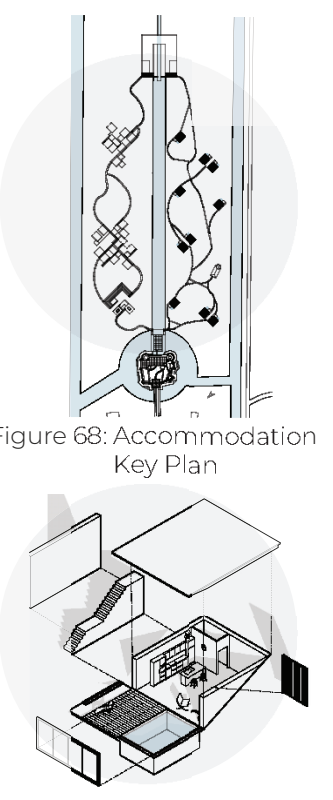

Figure 69: Accommodation Exploded Axo

Located true South on the property, the accommodation zone has a villa module that is replicated throughout this area. Each module is burmed halfway around it's rear perimeter walls. This allows for a gradual slope in the earth on the exterior ramping up to the roof of the module; it forms a man-made hill and when replicated it creates a picturesque rolling topography. From the horse's point of view, it is an free and open space to canter with minor variations in the earth. This space is where co-habitation takes place and the visitors are able to watch the horses from afar. The retreat visitors have not yet passed through the equestrian zone to interact with the horses, however, if a horse feels confident enough, it is able to interact with the visitors in the accommodation zone. 


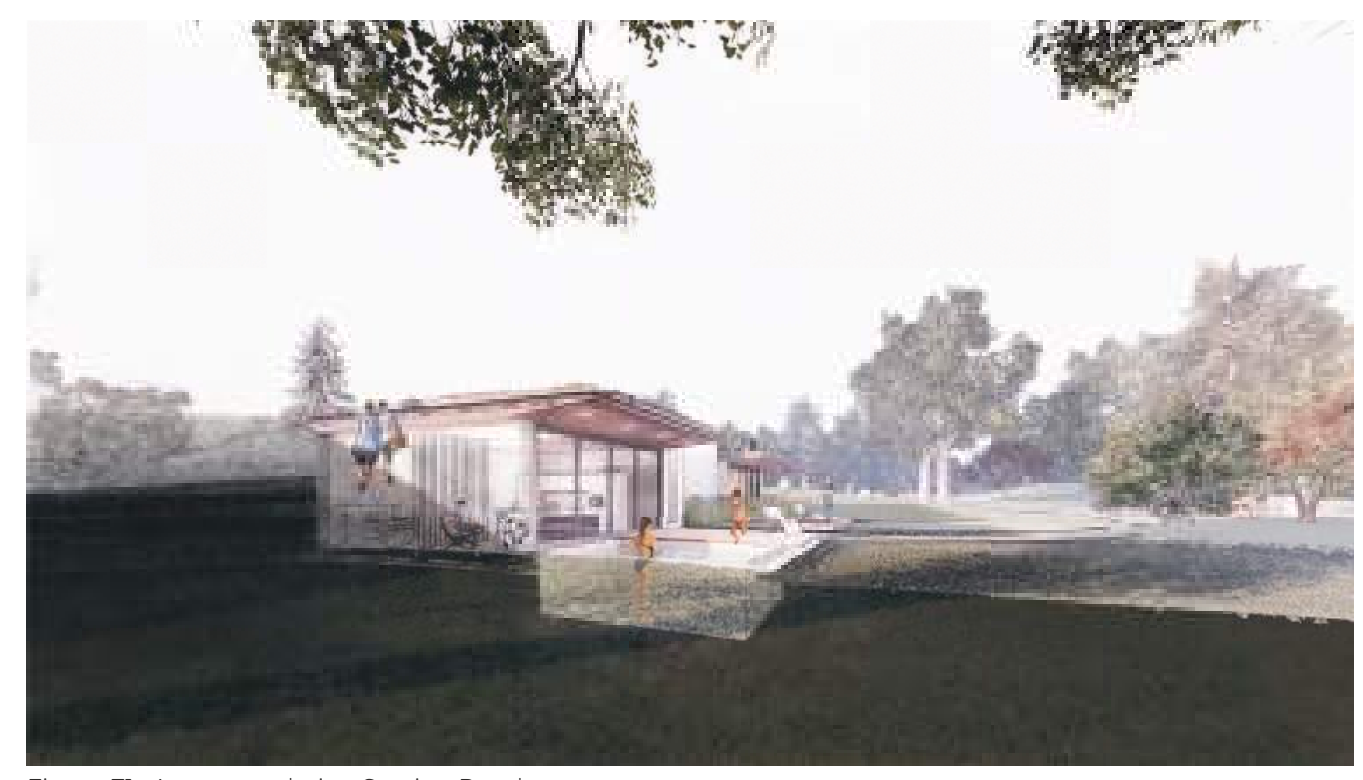

Figure 71: Accommodation Section Render

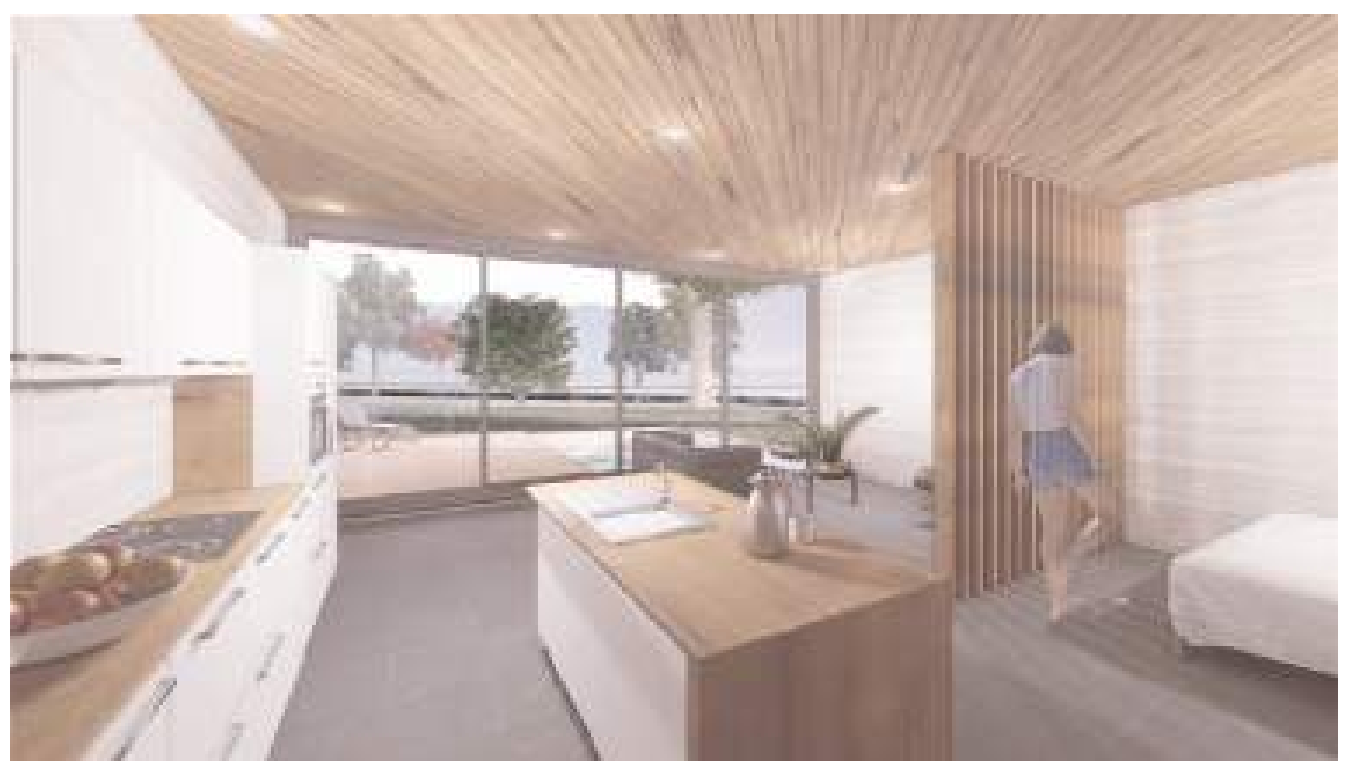

Figure 72: Accommodation Interior Render 


\section{Equestrian Zone}

The stable design is arguably the most important aspect of this project. The stable is a moment where the horses seek safety, comfort and socialize with one another. It is the zone where visitors seeking hippotherapy meet their equine therapists. It is a space that generally may seem largely unnatural and frightening for both species. With the proper design, the stable is able to organically entice the human and horse into meeting in one confined yet generous space in order to form a healing bond. As hypersensitive creatures, horses require many threshold spaces that gradually filter out the light and chaos of the exterior world. At the same time, an open concept space ensures that the horse's mind is at ease and able to see its surroundings. Horses are extremely inquisitive creatures who often escape out of their stalls to romp around the barns. Details in the location of the stalls and their adjacent spaces must be thoroughly considered to ensure safety for both the humans and horses.

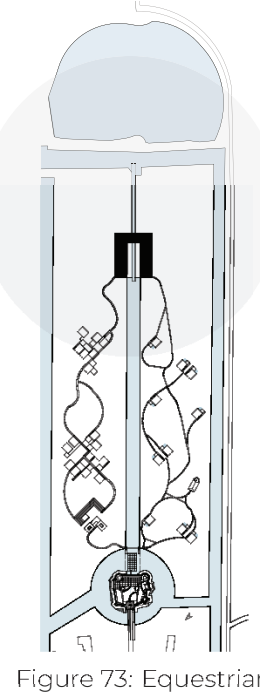

Figure 73: Equestria
Key Plan

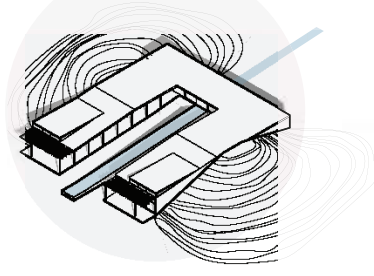

Figure 74: Equestrian Axonometric

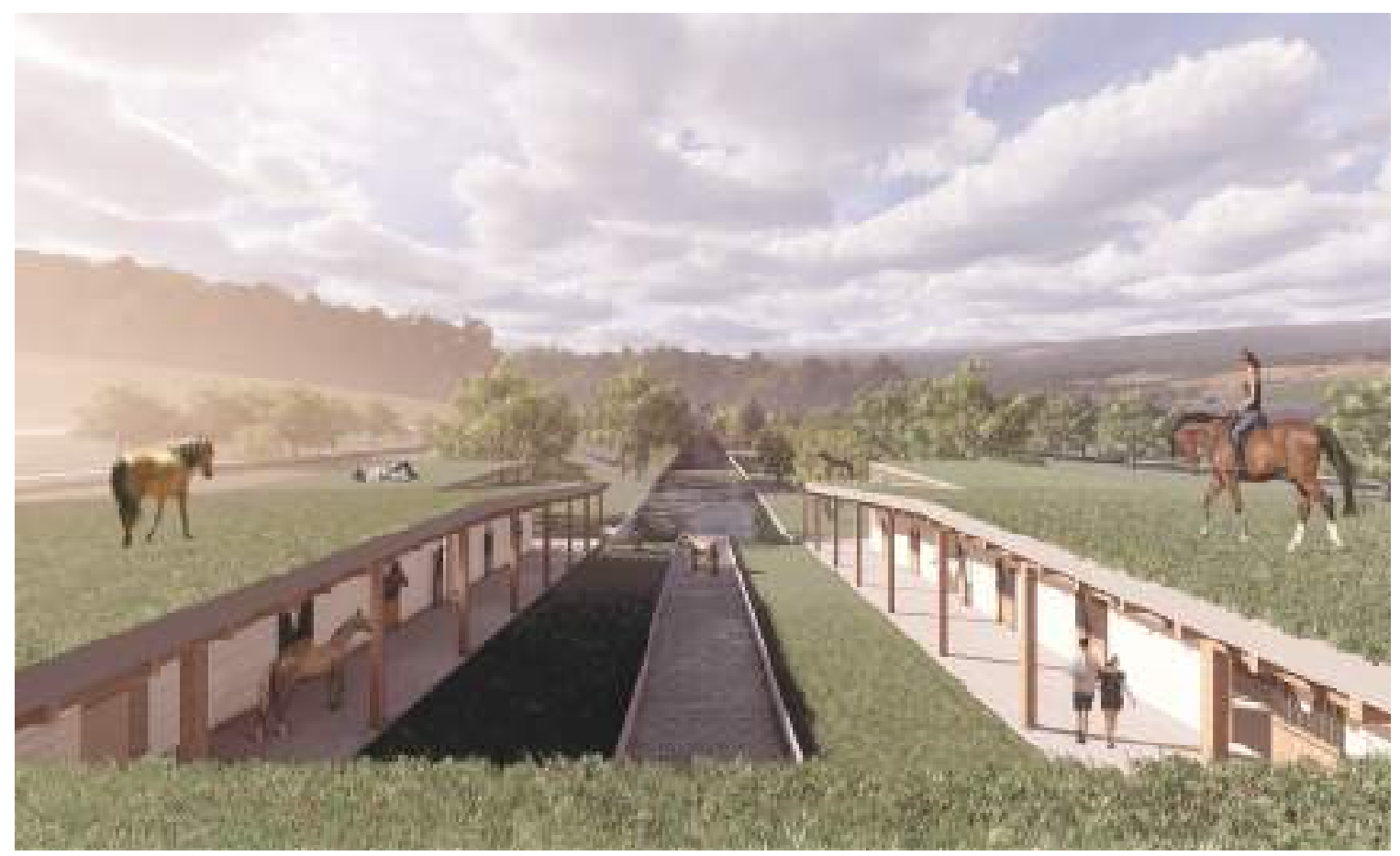

Figure 75: Equestrian Rooftop Render 


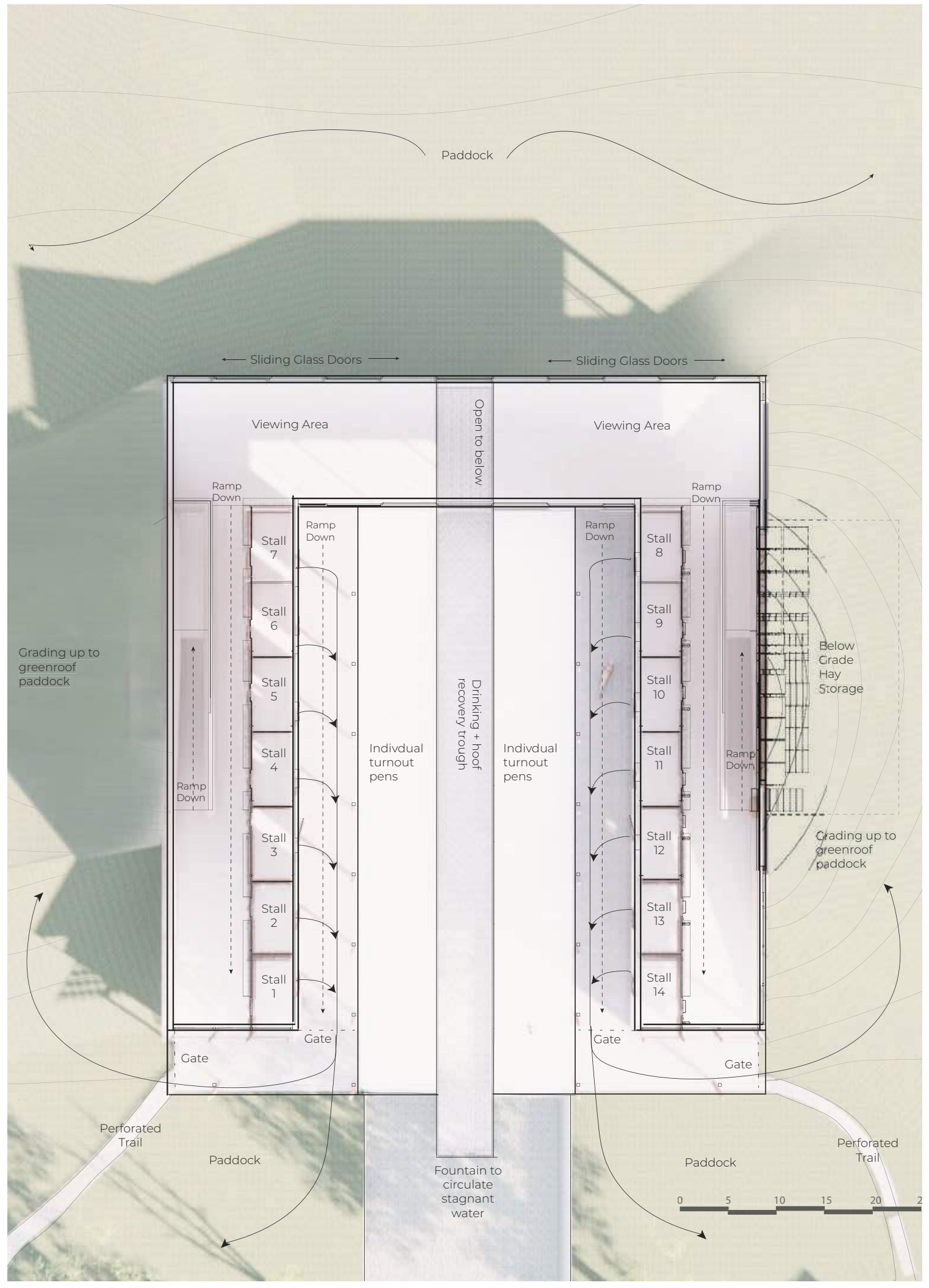

Figure 76: Equestrian Floor Plan 

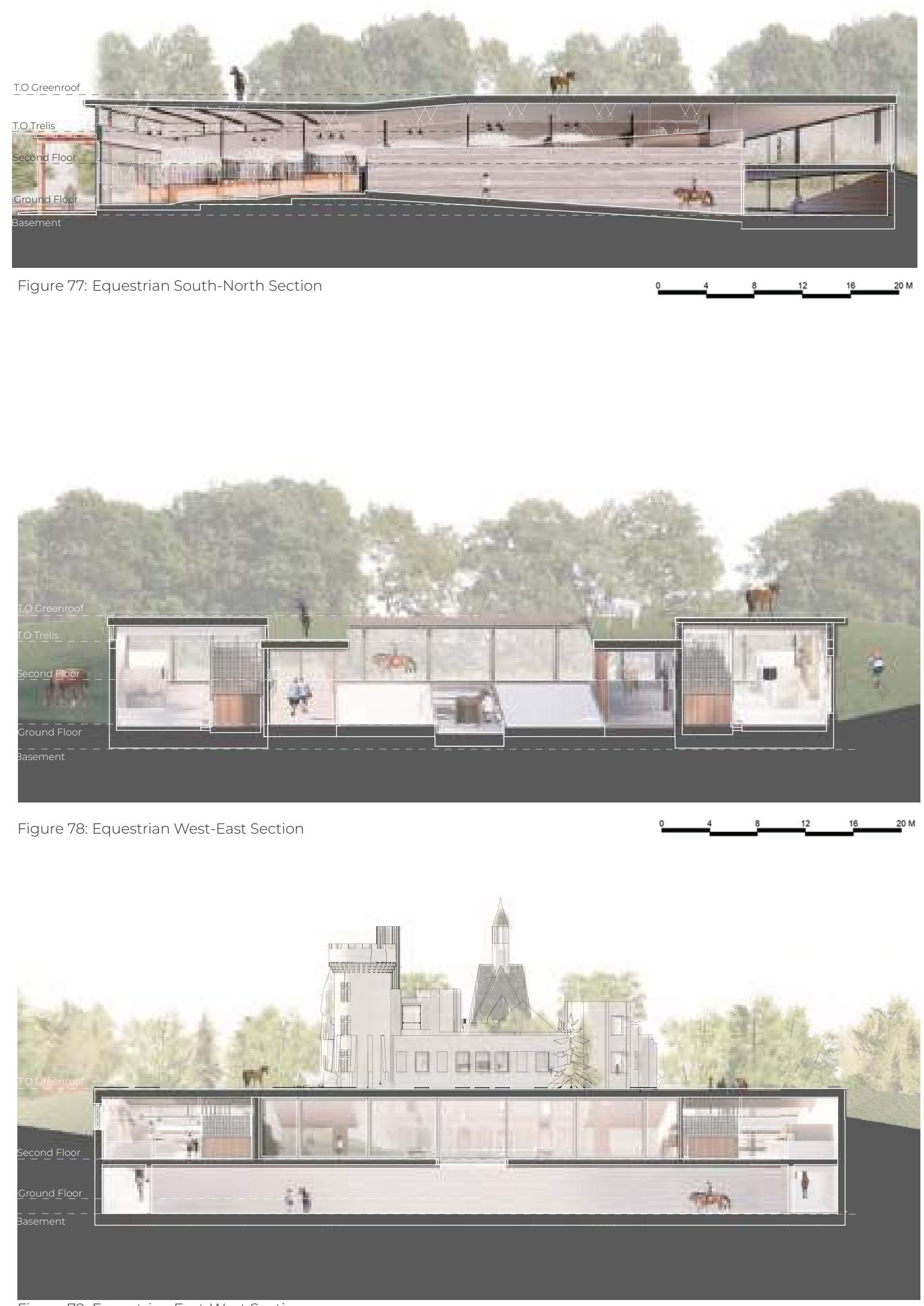

Figure 79: Equestrian East-West Section

Equus As Client: A Biocentric Retreat 

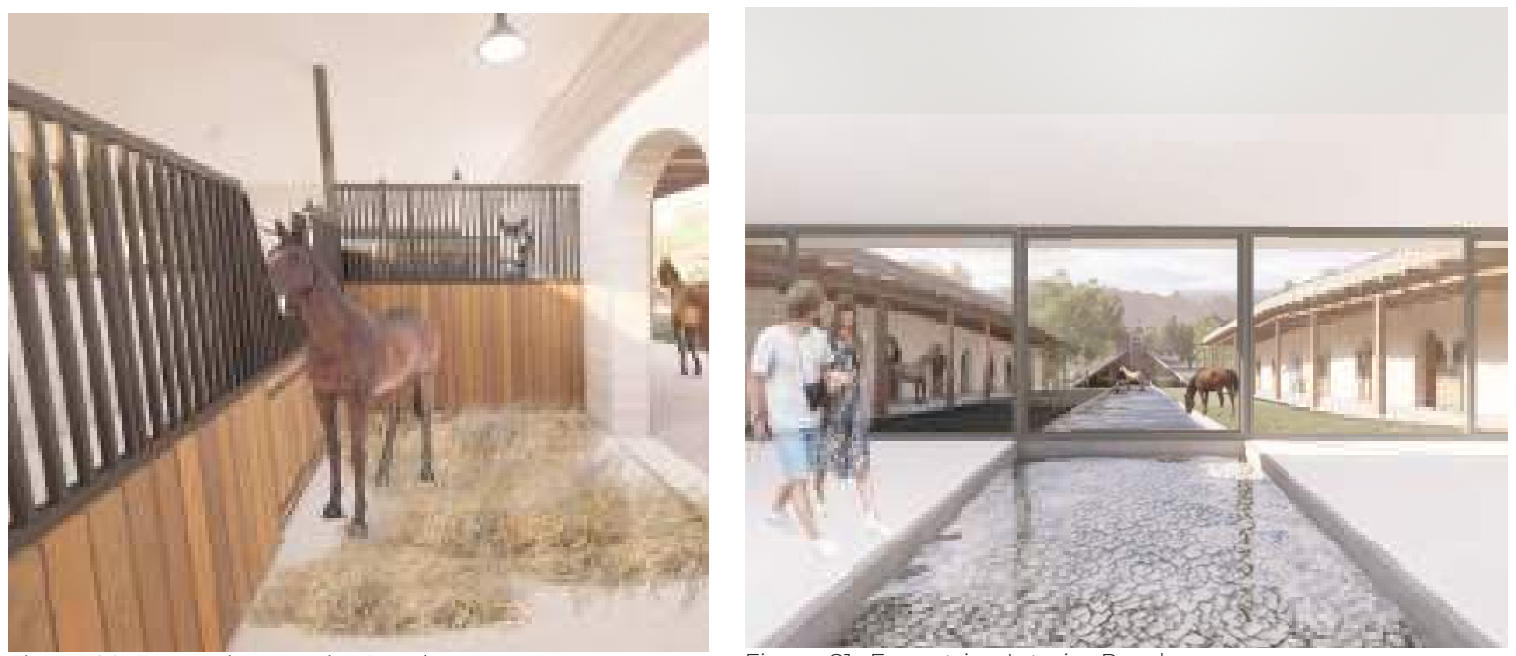

Figure 80: Equestrian Interior Render

Figure 81: Equestrian Interior Render

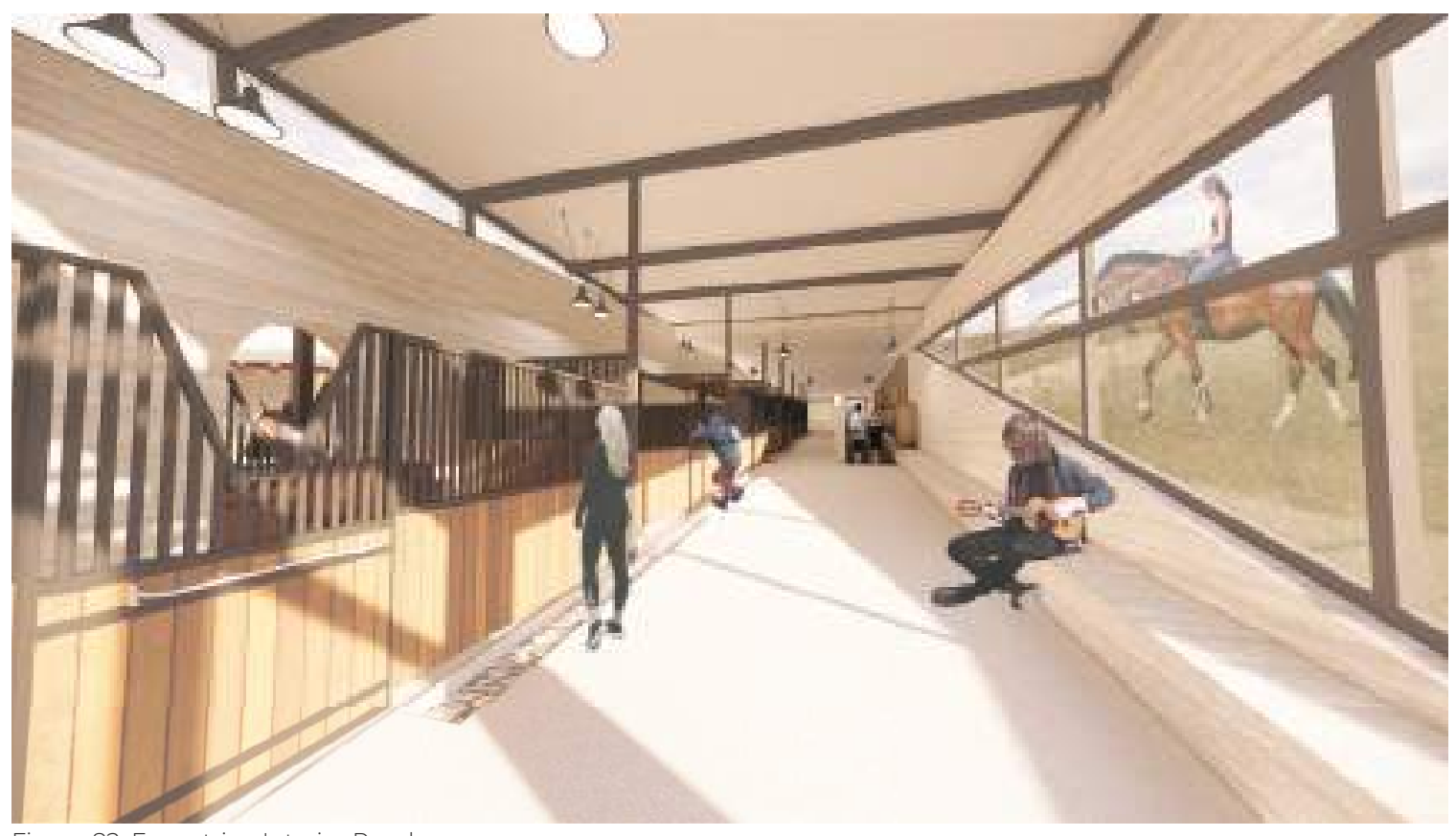

Figure 82: Equestrian Interior Render 
"I am convinced that a good building must be capable of absorbing the traces of human life and taking on a specific richness... I think of the patina of age on materials, of innumerable small scratches on surfaces, of varnish that has grown dull and brittle, and of edges polished by use."

-Peter Zumthor 


\section{Wellness Zone}

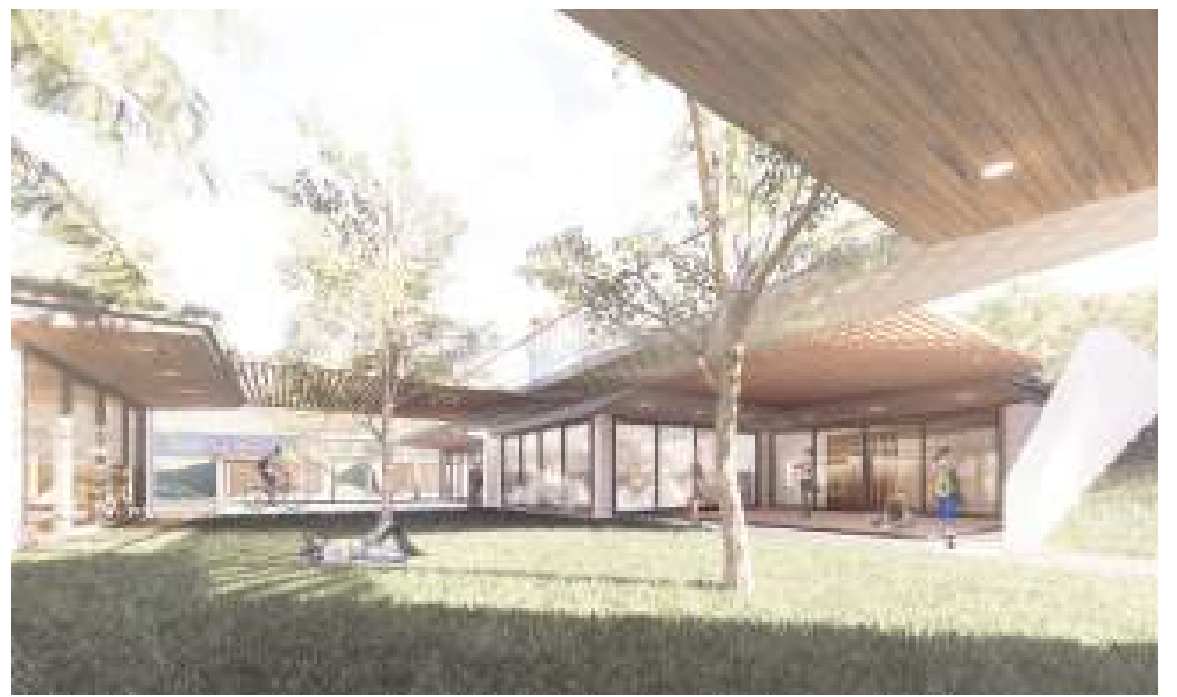

Figure 83: Wellness Below Grade Render

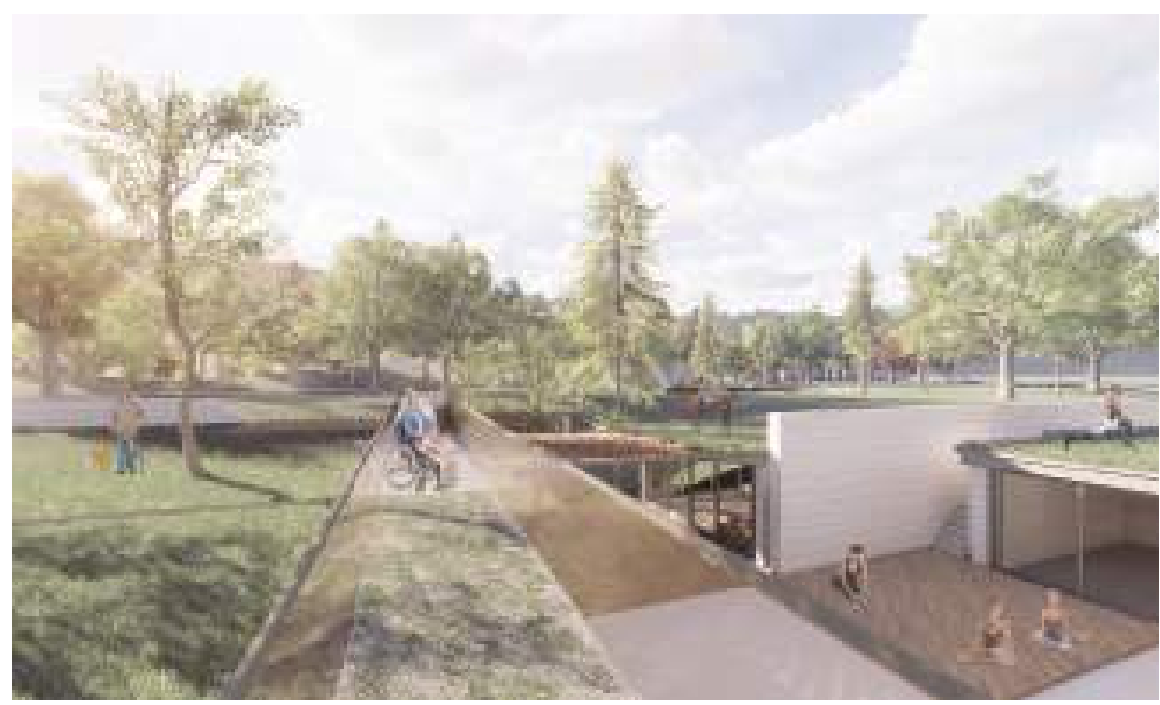

Figure 84: Wellness at Grade Render

The wellness zone is conceived as a two-phase space; part physical rehabilitation and part mental mindfulness. Similar to the accommodation zone, the wellness zone is compromised of modules. Each nestled into excavated spaces in the true north portion of the property. All excavated soil is used to burm the villas in the accommodation zone. 


\section{Social Zone}

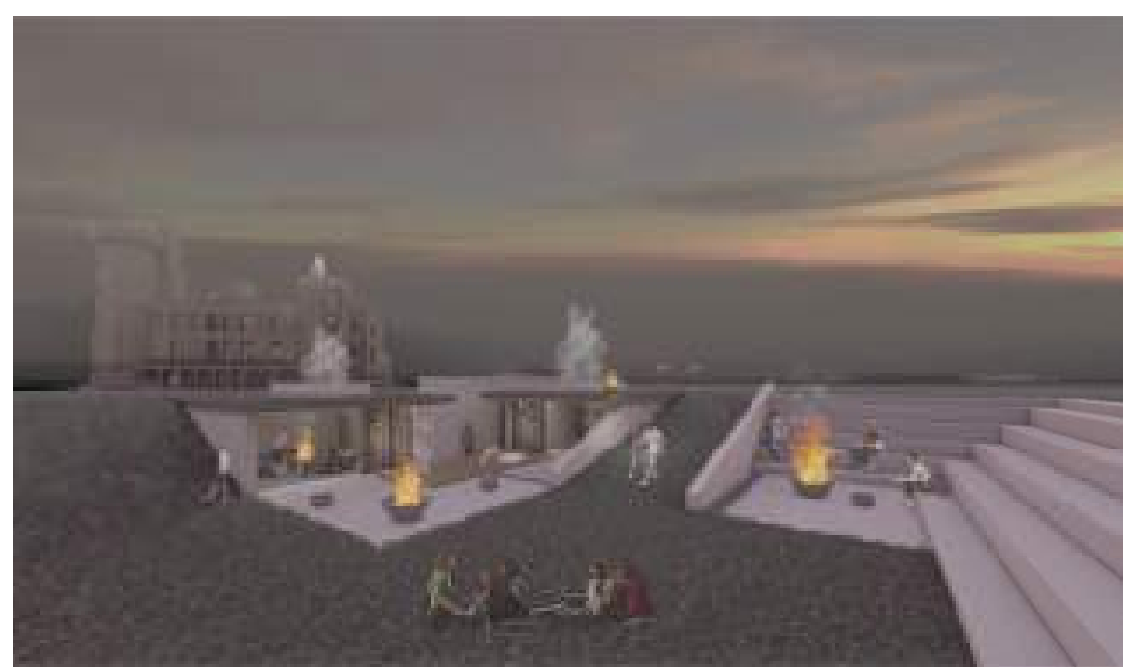

Figure 87: Social Exterior Seating Render

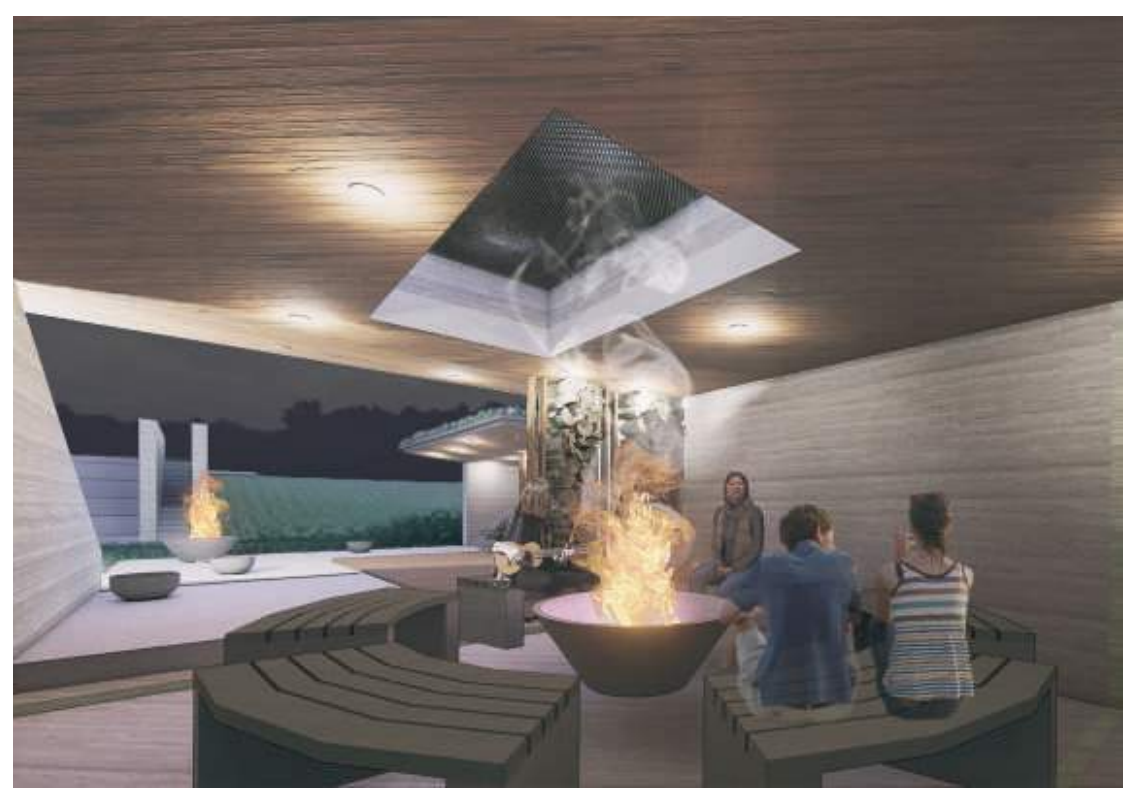

Figure 88: Social Fire pit Hub Render

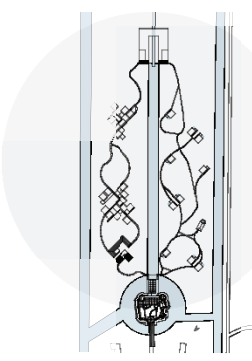

Figure 89: Social Key Plan

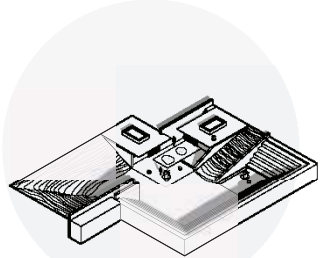

Figure 90: Social Axonometric

As the final zone in the cycle, the social zone is a place for celebration and entertainment. The aroma of the oil infused fires gathers both the humans and the horses into the alcoves of the social zone. The modules are placed in an excavated space on the site so that at grade level the horizon appears as a calming fog running across the horizon. This space gives a nod to the historical outdoor theatre and its famous aromatic lemon and orange trees. 


\section{Co-Habitation vs Interaction}

Spaces within the site allow for shared and independent spaces between horses and humans. In order to harmonize as an ecology, there needs to be a balance between the two. In a biocentric design, all subjects inhabiting the space are able to make their own decisions with no external force. Co-existing paths at different topographic levels allow for outlook viewing platforms. The perforated paths allow for accessibility for all conditions. Spaces such as the villas and the ruins are heav- ily influenced by human needs and desires, however certain details in the architecture accommodate horses. For example, the operable windows are placed and swing in a way to allow a curious horse to 'visit'. The gardens in the wellness and social zones act as gathering spaces as their aroma and built environment attracts all subjects. The objective is to use the built environment to encourage subjects to interact or co-exist.

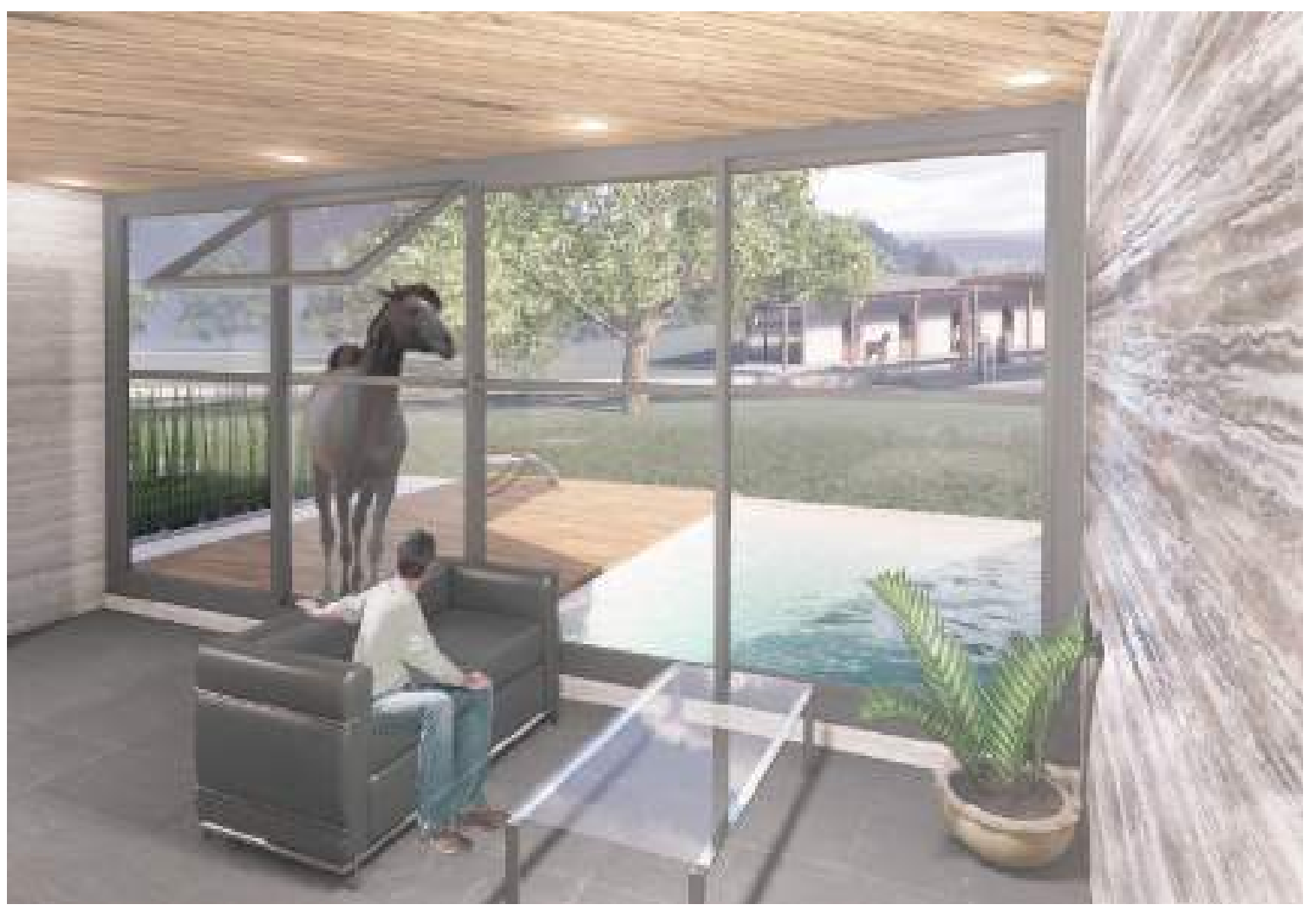

Figure 91: Co-habitation Pathway Render 


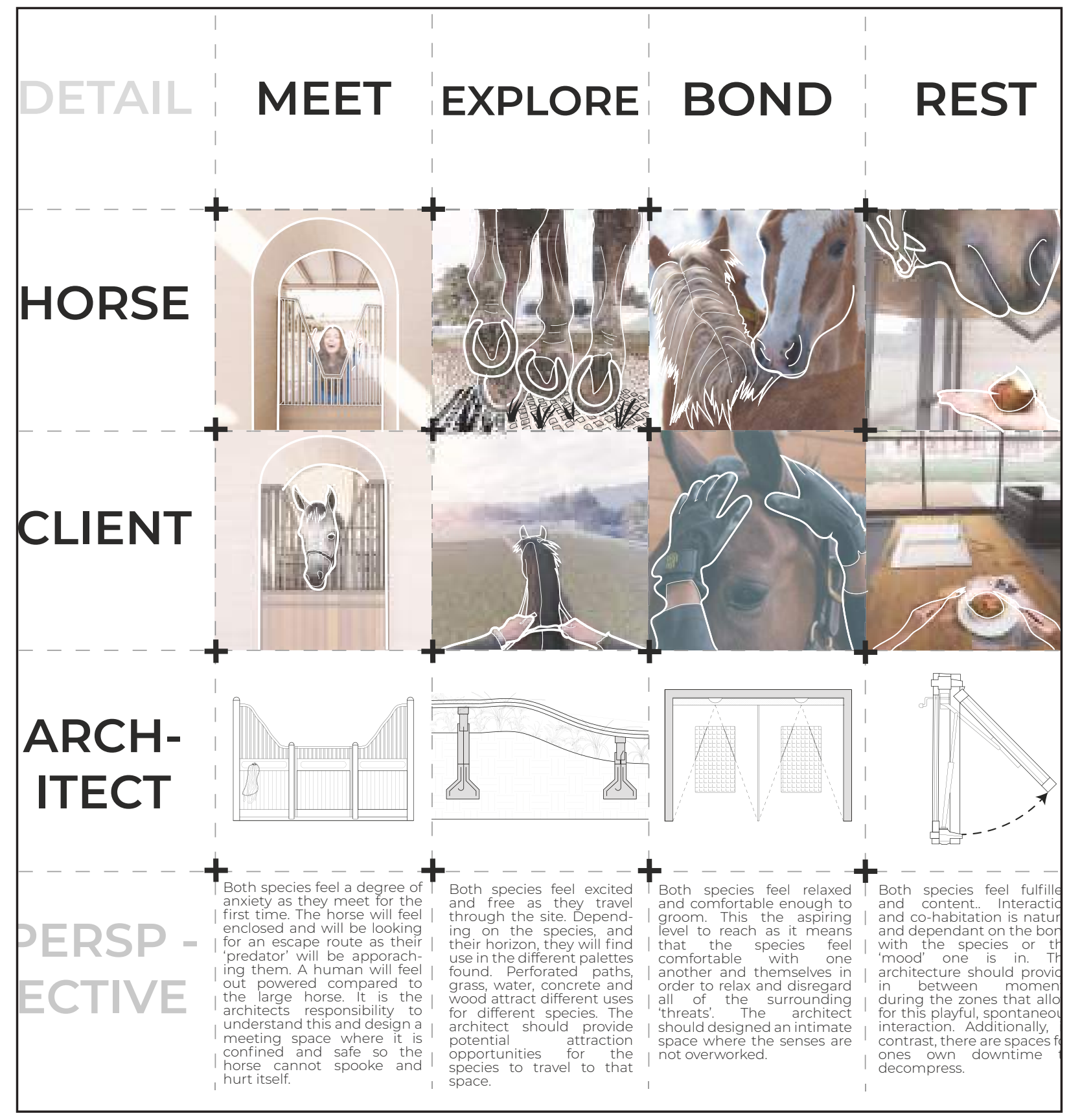

Figure 92: Multi-Perspective Catalogue 


\section{Physical Site Model}
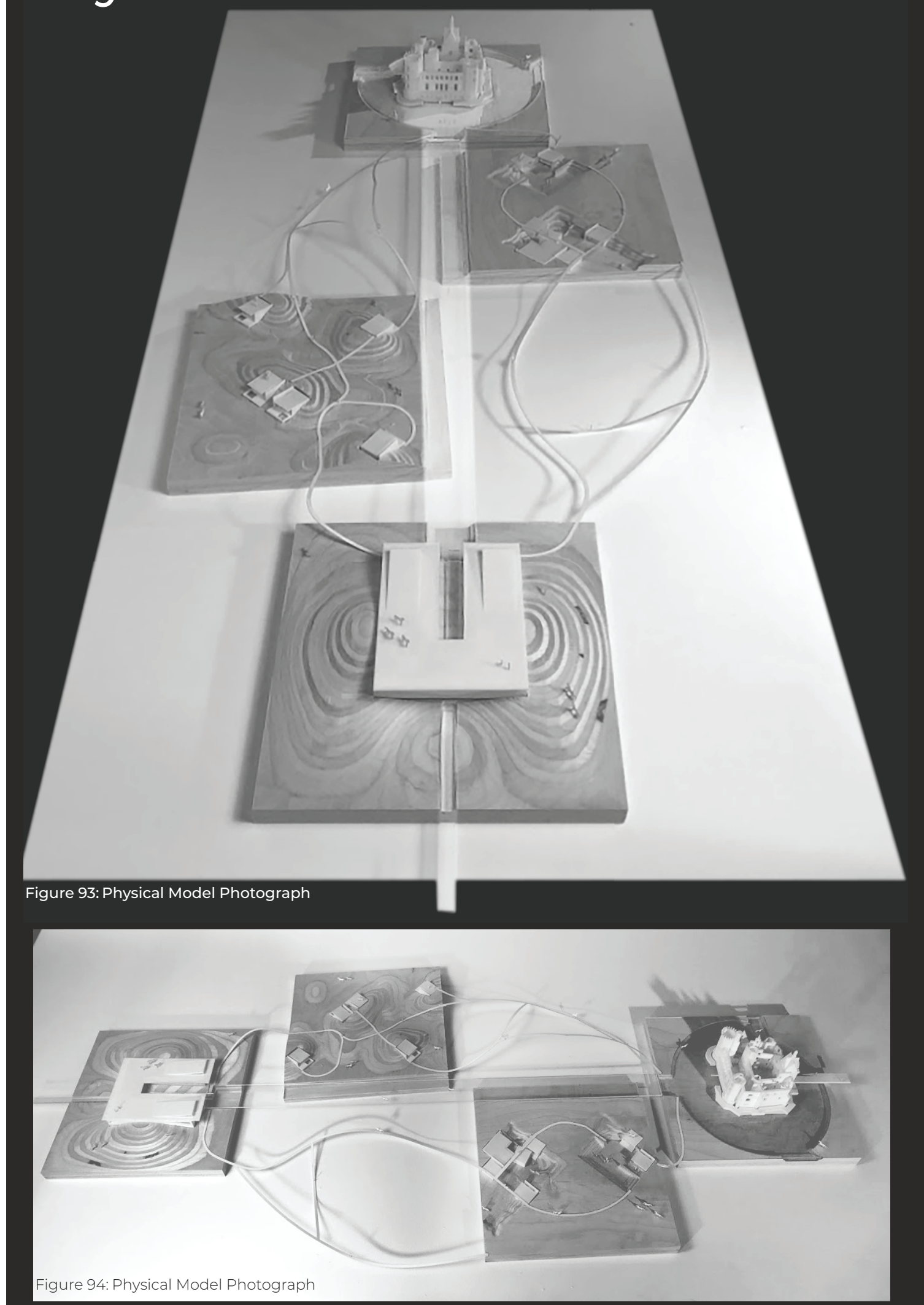


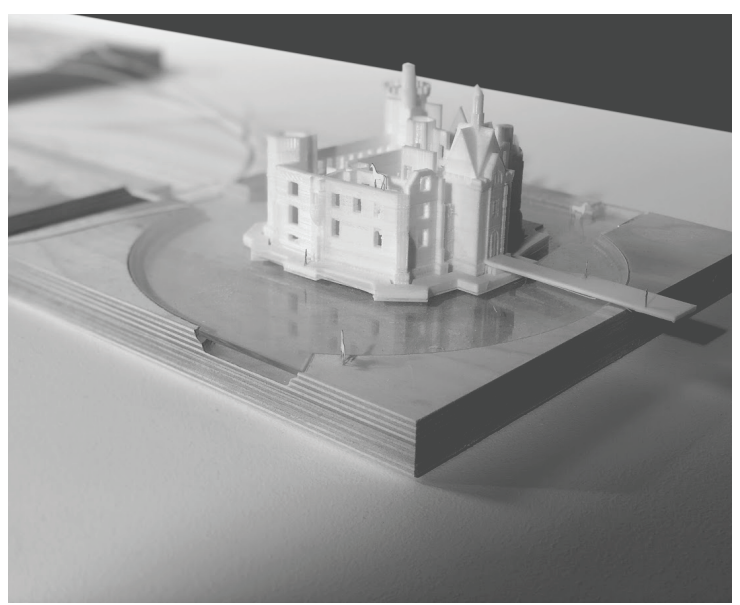

Figure 95: Physical Model Photograph

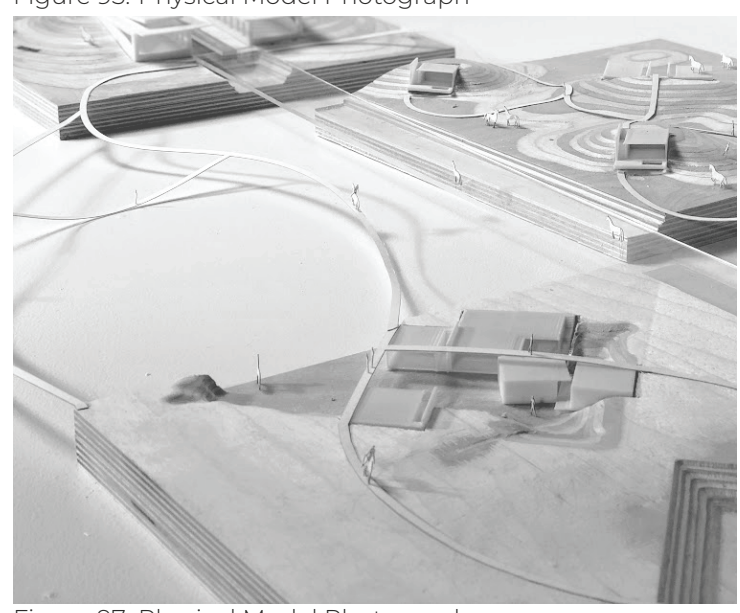

Figure 97: Physical Model Photograph

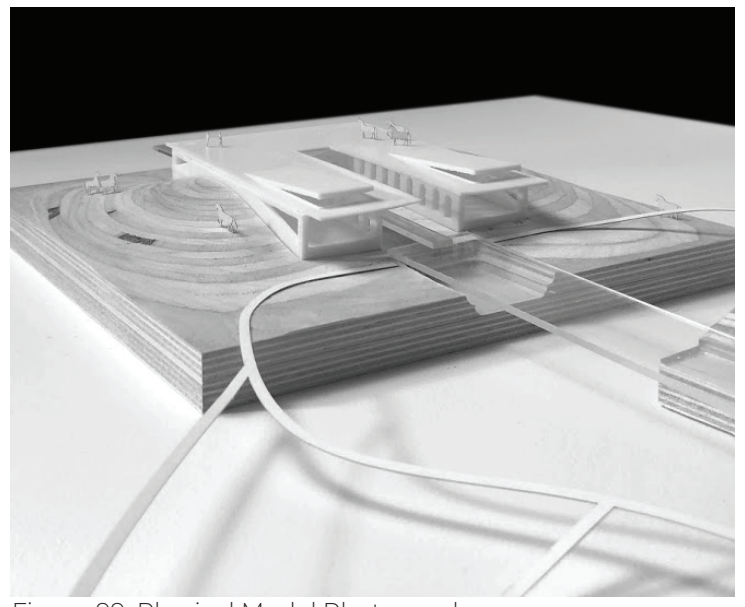

Figure 99: Physical Model Photograph

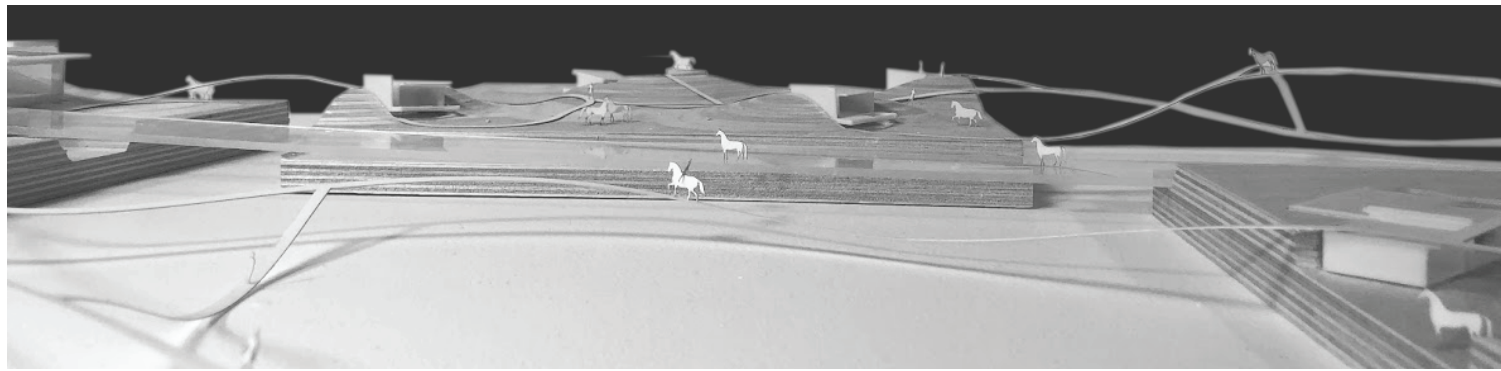

Figure 101: Physical Model Photograph

Equus As Client: A Biocentric Retreat

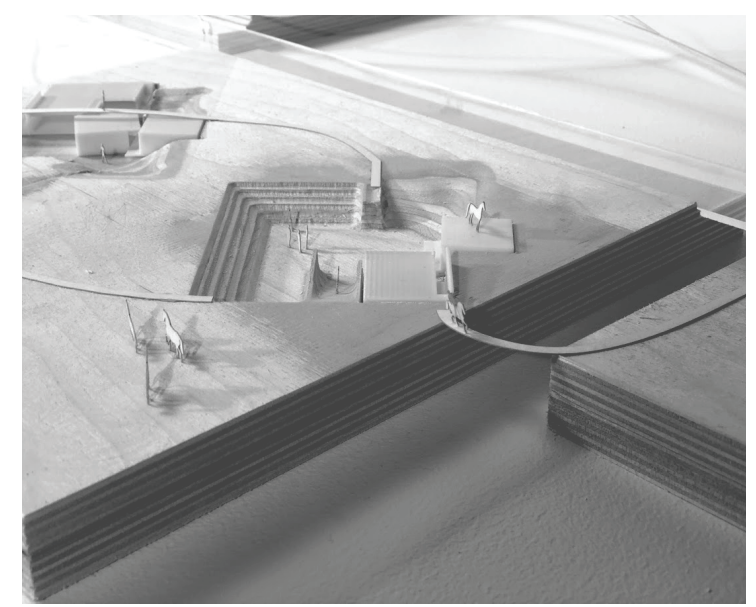

Figure 96: Physical Model Photograph

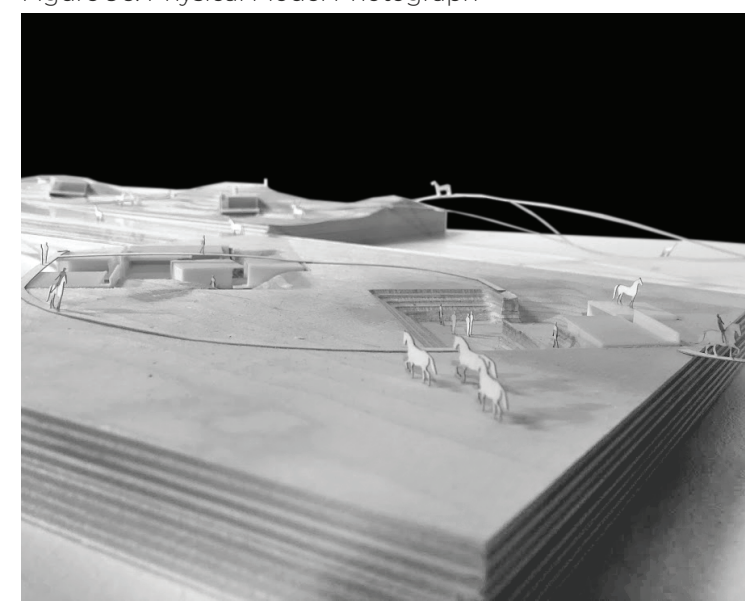

Figure 98: Physical Model Photograph

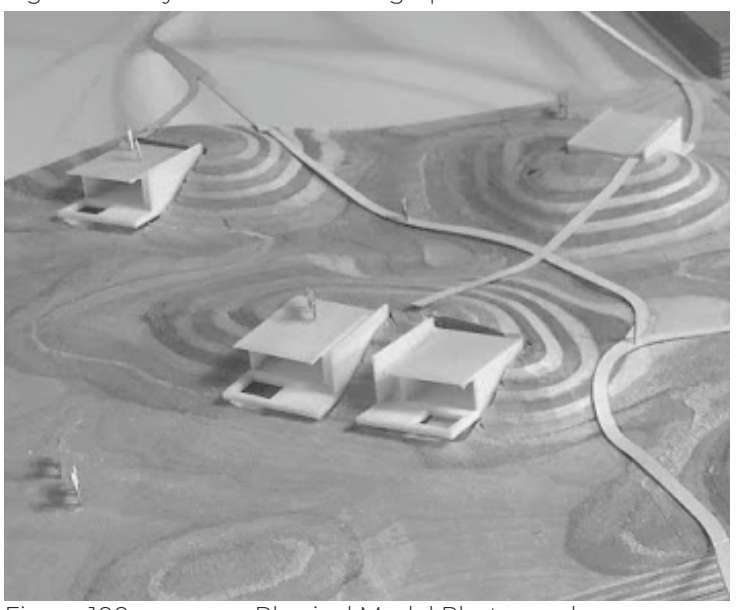

Figure 100 


\section{Anamorphic Image Experiments}

The anamorphic images are an exploration which attempts to emulate the horses 350 degree perspective of the design. Using a cylindrical mirror, one can see a panoramic rendering

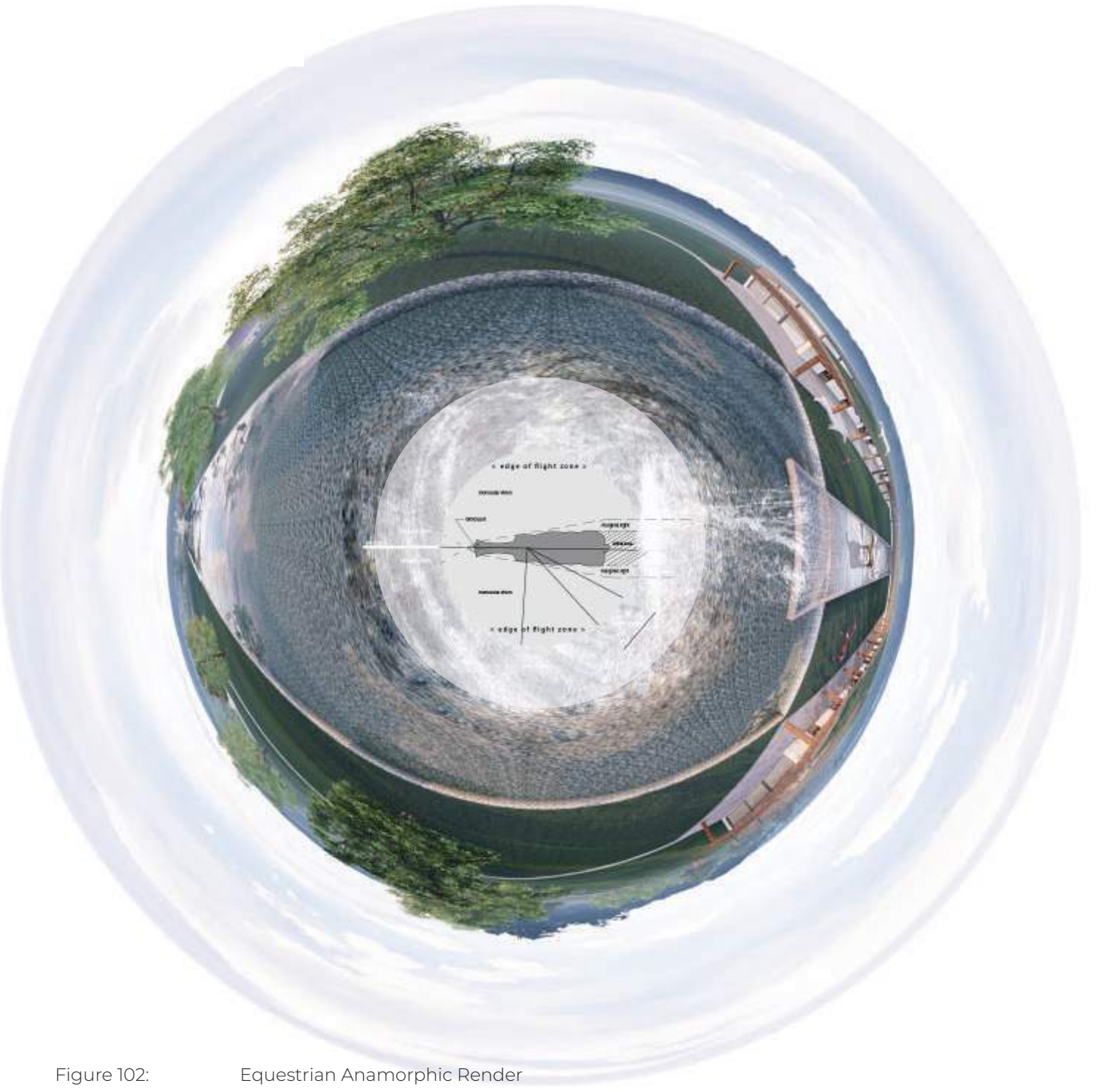




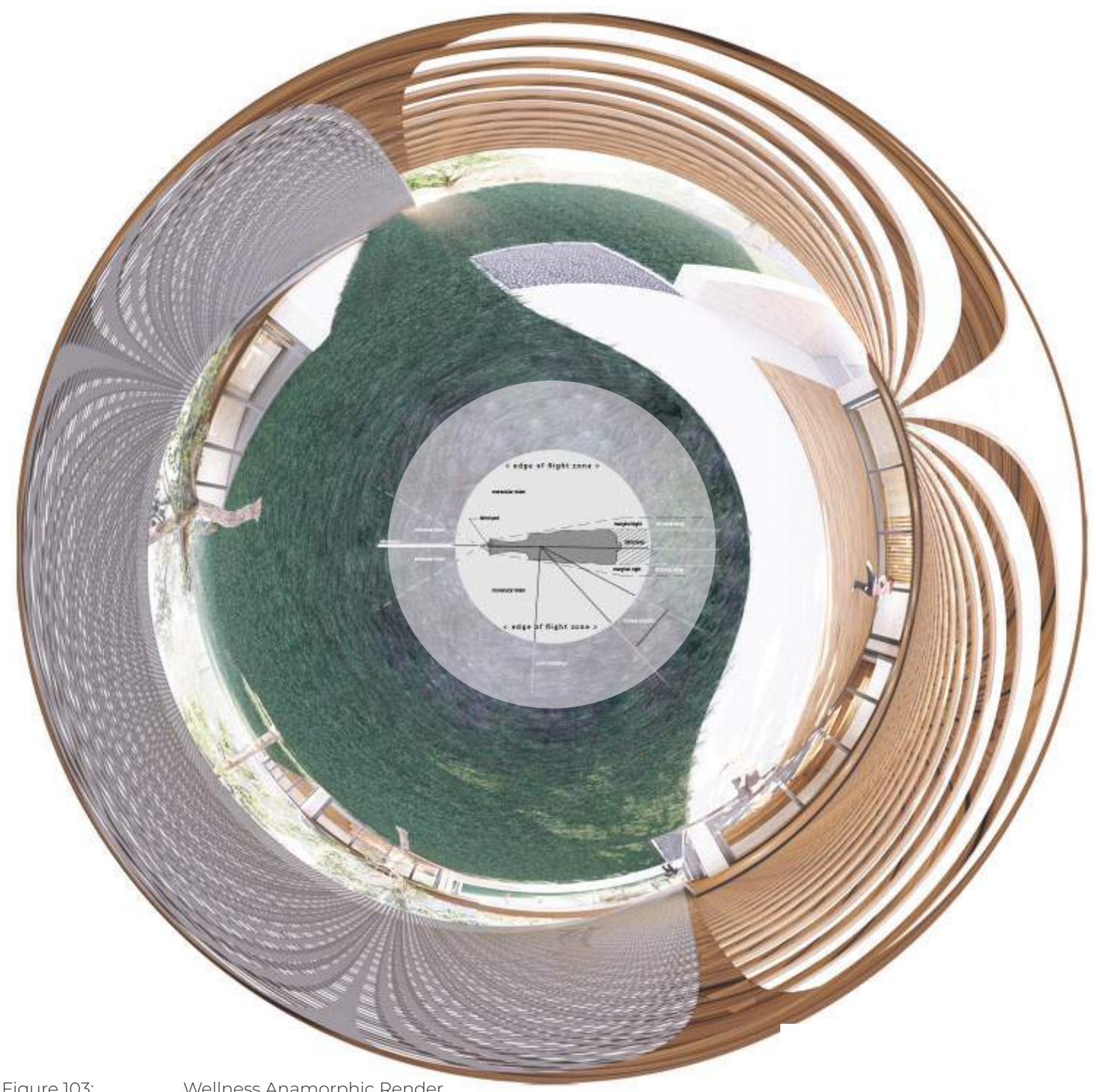

Figure 103:

Wellness Anamorphic Render 


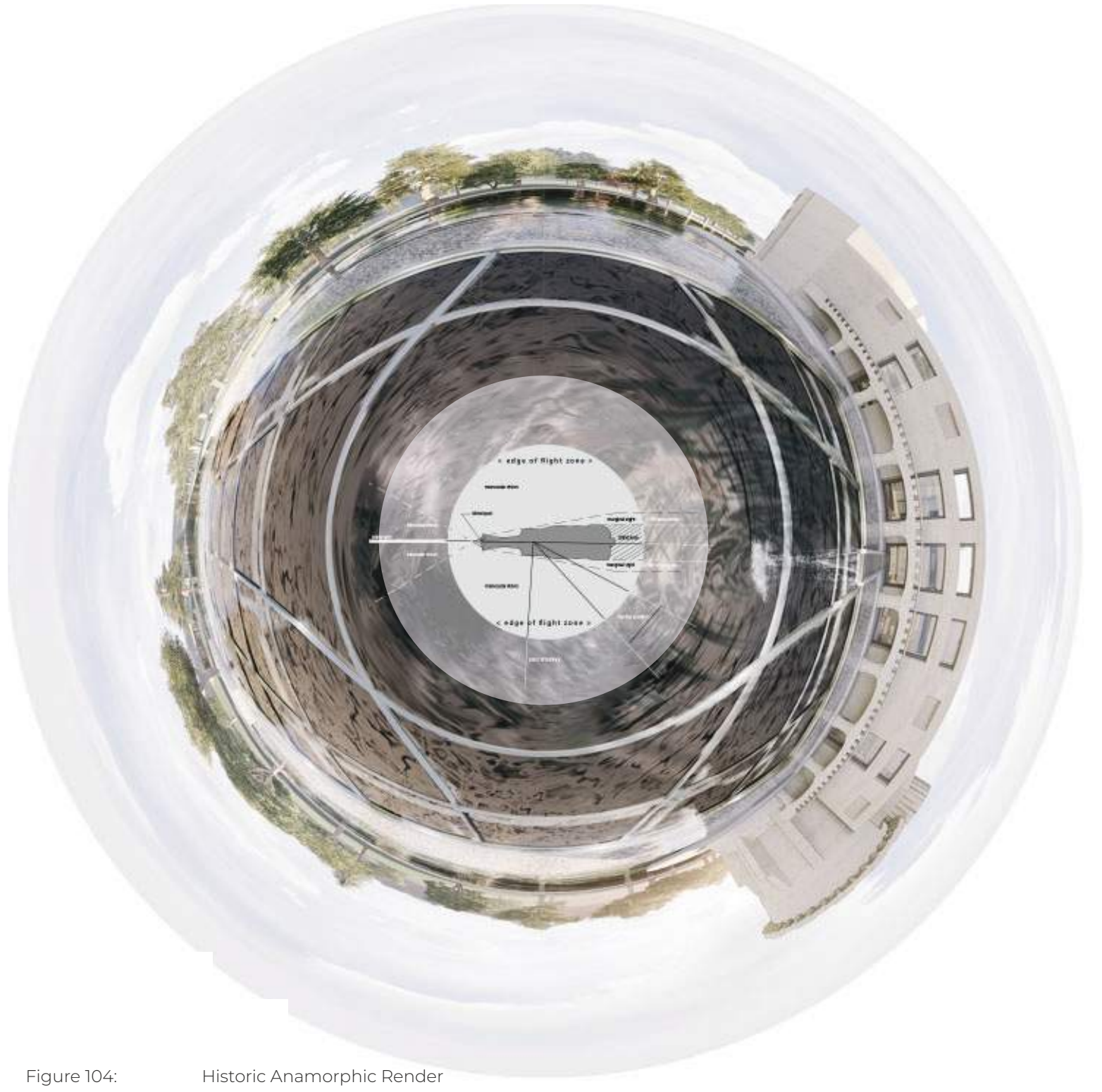

Equus As Client: A Biocentric Retreat 


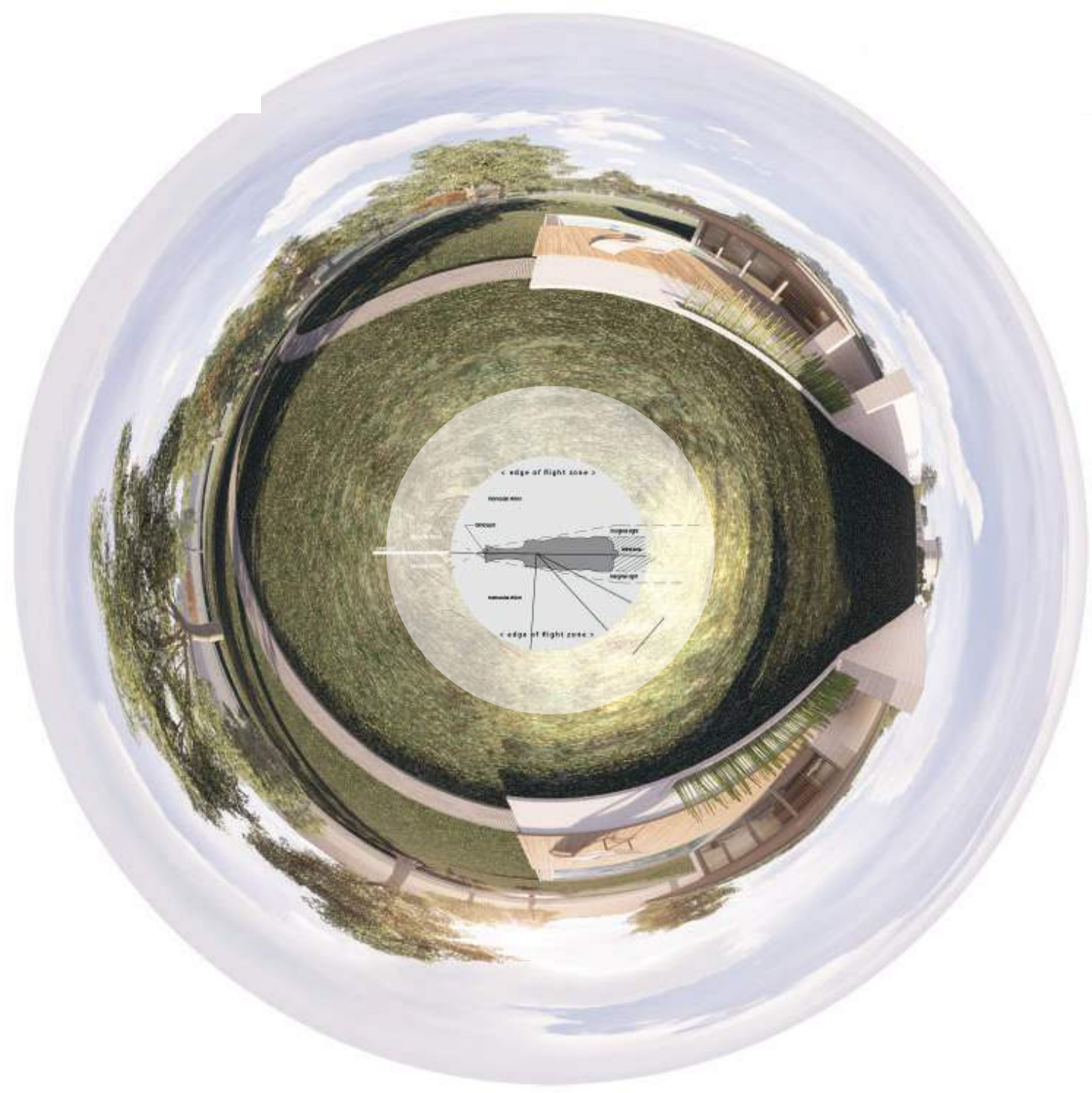

Figure 105:

Equestrian Anamorphic Render 


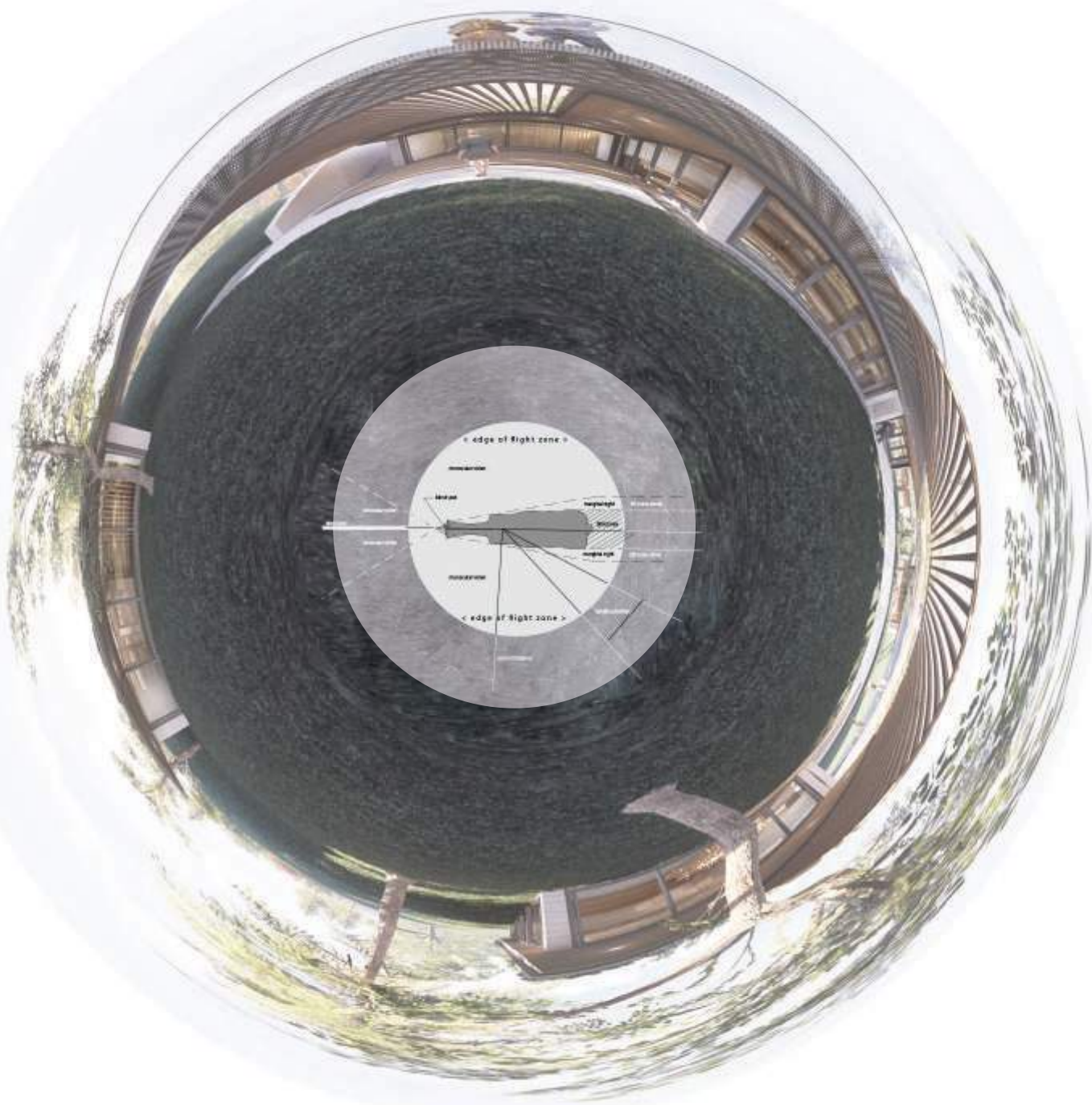

Figure 106:

Wellness Anamorphic Render 2 


\section{Post Script}

Horses have been a human's faithful companion and workmate throughout history. Anyone who has had an experience with a horse understands that they are very special creatures. Their hypervigilance and social skills are why they are so dearly admired by humans. From a horse's perspective these two traits are what makes them survive. From a scientific perspective, it's what makes them such great therapists. This ability to anticipate and reflect what one sees requires "mirror neurons". This creates the traits of hypervigilance and social skills in a horse. This hypersensitivity is akin to the symptoms people have when suffering with PTSD. Hypersensitive horses and hypersensitive humans both require therapy from one another. Often, hippotherapy centres are designed like most typical equestrian stables; from a humans perspective. By contrast, using a biocentric design, the proposed architecture is designed for all species inhabiting it. This gives new potential design ideas that will create a better harmony and balance throughout the built environment. This thesis, hopes to develop one's thinking when designing architecture. There is an added experiential architectural engagement in biocentric design that can not transfer to anthropocentric design; it is the other-centered, sensorial, energy flowing experience that one has when inhabiting the biocentric design. 


\section{Endnotes}

$1 \quad$ Jakob von Uexküll, A Foray into the Worlds of Animals and Humans: with A Theory of Meaning (University of Minnesota Press, 2010) 10.

2 Miezan Van Zyl, and Elwyn Hartley Edwards, The Horse Encyclopedia (DK/Penguin Random House, 2016) 53.

3 Tim Hayes and Robert Redford, Riding Home: The Power of Horses to Heal (St. Martins Griffin, 2016) 23.

$4 \quad$ Jakob von Uexküll, A Foray into the Worlds of Animals and Humans: with A Theory of Meaning (University of Minnesota Press, 2010).

$5 \quad$ Ibid 42

$6 \quad$ "From Social Butterfly to Engaged Citizen : Urban Informatics, Social Media, Ubiquitous Com puting, and Mobile Technology to Support Citizen Engagement" , edited by Marcus Foth, et al., (MIT Press, 2011) https://ebookcentral-proquest-com.proxy.library.carleton.ca/lib/oculcarleton-ebooks/ detail.action?docID=3339346 (accessed 19/02/24) 420

Ibid 421.

Ibid 425

Jakob von Uexküll, A Foray into the Worlds of Animals and Humans: with A Theory of Meaning (University of Minnesota Press, 2010) 42.

10 "From Social Butterfly to Engaged Citizen : Urban Informatics, Social Media, Ubiquitous Com puting, and Mobile Technology to Support Citizen Engagement", edited by Marcus Foth, et al., (MIT Press, 2011) https://ebookcentral-proquest-com.proxy.library.carleton.ca/lib/oculcarleton-ebooks/ detail.action?docID=3339346 (accessed 19/02/24) 421-35

11 Jakob von Uexküll, A Foray into the Worlds of Animals and Humans: with A Theory of Meaning (University of Minnesota Press, 2010) 76. Ibid 80.

13 Tim Hayes and Robert Redford, Riding Home: The Power of Horses to Heal (St. Martins Griffin, 2016) 10-73.

14 Jakob von Uexküll, A Foray into the Worlds of Animals and Humans: with A Theory of Meaning (University of Minnesota Press, 2010) 96.

15 "From Social Butterfly to Engaged Citizen : Urban Informatics, Social Media, Ubiquitous Com puting, and Mobile Technology to Support Citizen Engagement", edited by Marcus Foth, et al., (MIT Press, 2011) https://ebookcentral-proquest-com.proxy.library.carleton.ca/lib/oculcarleton-ebooks/ detail.action?docID=3339346 (accessed 19/02/24) 421-35

16 Jakob von Uexküll, A Foray into the Worlds of Animals and Humans: with A Theory of Meaning (University of Minnesota Press, 2010) 23.

17 "From Social Butterfly to Engaged Citizen : Urban Informatics, Social Media, Ubiquitous Com puting, and Mobile Technology to Support Citizen Engagement", edited by Marcus Foth, et al., (MIT Press, 2011) https://ebookcentral-proquest-com.proxy.library.carleton.ca/lib/oculcarleton-ebooks/ detail.action?docID=3339346 (accessed 19/02/24) 421-35

18 Jakob von Uexküll, A Foray into the Worlds of Animals and Humans: with A Theory of Meaning (University of Minnesota Press, 2010) 21. 


\section{Endnotes}

Ronald T Curran and Elaine Scarry, "Dreaming by the Book" (World Literature Today, vol. 74, no. 4, 2000) 908

David Abrams, "The Spell of the Sensuous: Perception and Language in a More-than-Human World" (Vintage Books, 2017) ix.

Ibid $x$.

Ibid 4.

Ibid 6.

"From Social Butterfly to Engaged Citizen : Urban Informatics, Social Media, Ubiquitous Com puting, and Mobile Technology to Support Citizen Engagement", edited by Marcus Foth, et al., (MIT Press, 2011) https://ebookcentral-proquest-com.proxy.library.carleton.ca/lib/oculcarleton-ebooks/ detail.action?docID=3339346 (accessed 19/02/24) 421-35

Ibid 431.

Ibid 425 .

Ibid 420 .

Ibid 444 .

Ibid 433 .

Tim Hayes and Robert Redford, Riding Home: The Power of Horses to Heal (St. Martins Griffin, 2016) 10.

Ronald T Curran and Elaine Scarry, "Dreaming by the Book" (World Literature Today, vol. 74, no. 4, 2000) 908.

C. Woebken, and K. Okada, "Animal Superpowers", (online project documentation 2008) http:// www. woebken.net/animalsuperpowers.htm (accessed 18/11/20).

Ibid.

"From Social Butterfly to Engaged Citizen : Urban Informatics, Social Media, Ubiquitous Com puting, and Mobile Technology to Support Citizen Engagement" , edited by Marcus Foth, et al., (MIT Press, 2011) https://ebookcentral-proquest-com.proxy.library.carleton.ca/lib/oculcarleton-ebooks/ detail.action?docID=3339346 (accessed 19/02/24) 430

Ibid 431.

Ibid 425 .

David T Suzuki, "The Sacred Balance: Rediscovering Our Place in Nature” (Allen \& Unwin, 2008) 49. John Blackburn, and Beth Herman, "Healthy Stables by Design: A Common Sense Approach to the Health and Safety of Horses" (Images Publishing ,2013) 23

Miezan Van Zyl, and Elwyn Hartley Edwards, The Horse Encyclopedia (DK/Penguin Random House, 2016) 70.

John Blackburn, and Beth Herman, "Healthy Stables by Design: A Common Sense Approach to the Health and Safety of Horses" (Images Publishing ,2013) 48.

Ibid 20.

Steve Lowell "Roman Chariots, Railroad Tracks, Milspecs and Urban Legends." (Defense Standardiza tion Program Journal, Aug. 2011) 1-3.

Miezan Van Zyl, and Elwyn Hartley Edwards, The Horse Encyclopedia (DK/Penguin Random House, 2016) 23.

Ibid 36.

Ibid 38.

Equus As Client: A Biocentric Retreat 


\section{Endnotes}

Ibid 38.

Ibid 39.

Ibid 40 .

David T Suzuki, "The Sacred Balance: Rediscovering Our Place in Nature" (Allen \& Unwin, 2008) 46 Jakob von Uexküll, A Foray into the Worlds of Animals and Humans: with A Theory of Meaning (University of Minnesota Press, 2010).

Tim Hayes and Robert Redford, Riding Home: The Power of Horses to Heal (St. Martins Griffin, 2016) 23.

Hayes, Tim, and Robert Redford. Riding Home: The Power of Horses to Heal. St. Martins Griffin, 2016. p. 27

Ibid. p. 23

John Blackburn, and Beth Herman, "Healthy Stables by Design: A Common Sense Approach to the Health and Safety of Horses" (Images Publishing, 2013) 54.

Hayes, Tim, and Robert Redford. Riding Home: The Power of Horses to Heal. St. Martins Griffin, 2016. p. 30

John Blackburn, and Beth Herman, "Healthy Stables by Design: A Common Sense Approach to the Health and Safety of Horses" (Images Publishing ,2013) 12

Tim Hayes and Robert Redford, Riding Home: The Power of Horses to Heal (St. Martins Griffin, 2016) 35.

Ibid. p. 27

Ibid. p. 32

Ibid. p. 34

Ibid. p. 35

Ronald T Curran and Elaine Scarry, "Dreaming by the Book" (World Literature Today, vol. 74, no. 4, 2000) 908

Tim Hayes and Robert Redford, Riding Home: The Power of Horses to Heal (St. Martins Griffin, 2016) 35.

Ibid. p. 33

Jakob von Uexküll, A Foray into the Worlds of Animals and Humans: with A Theory of Meaning (University of Minnesota Press, 2010).

Tim Hayes and Robert Redford, Riding Home: The Power of Horses to Heal (St. Martins Griffin, 2016) 56.

Ibid 56

Ibid 76

Ibid 40-50

John Blackburn, and Beth Herman, "Healthy Stables by Design: A Common Sense Approach to the Health and Safety of Horses" (Images Publishing ,2013) 32

Tim Hayes and Robert Redford, Riding Home: The Power of Horses to Heal (St. Martins Griffin, 2016) 26.

Ibid 27.

John Blackburn, and Beth Herman, "Healthy Stables by Design: A Common Sense Approach to the Health and Safety of Horses" (Images Publishing ,2013) 21 


\section{Endnotes}

$74 \quad$ Prime Stables. "A Complete History of Horse Stables Through The Ages." www.primestables.co.uk/ equestrian-buildings/a-complete-history-of-horse-stables-through-the-ages/ (accessed 18/09/06)

Ibid

Ibid

Ibid

Ibid

Ibid

John Blackburn, and Beth Herman, "Healthy Stables by Design: A Common Sense Approach to the Health and Safety of Horses" (Images Publishing ,2013) 11

Ibid 12.

Ibid 15.

Miezan Van Zyl, and Elwyn Hartley Edwards, The Horse Encyclopedia (DK/Penguin Random House, 2016) 47.

David T.Suzuki and Ian Hanington, "Just Cool It!: the Climate Crisis and What We Can Do: a Post-Paris Agreement Game Plan" (Greystone Books, 2017) 145

Young Architects Competitions, "Common Ruins" (2018) www.youngarchitectscompetitions.com/ competition/common-ruins\#competition (accessed 18/10/12).

Tim Hayes and Robert Redford, Riding Home: The Power of Horses to Heal (St. Martins Griffin, 2016) $111-112$.

John Blackburn, and Beth Herman, "Healthy Stables by Design: A Common Sense Approach to the Health and Safety of Horses" (Images Publishing ,2013) 21.

Cooke, Julia. "How to Make Architecture More Animal-Friendly." Curbed, Curbed, 10 May 2016, www. curbed.com/2016/5/10/11640046/making-architecture-better-for-animals.

Tim Hayes and Robert Redford, Riding Home: The Power of Horses to Heal (St. Martins Griffin, 2016) 4 Ibid 60

Ibid 56

Ibid 60 .

Ibid 20.

David T.Suzuki and Ian Hanington, "Just Cool It!: the Climate Crisis and What We Can Do: a Post-Paris Agreement Game Plan" (Greystone Books, 2017) 148

Lee, Patina. "The Evolution of French Architecture." Widewalls, Dec. 2016, www.widewalls.ch/ french-architecture/.

Booth, Norman K. Foundations of Landscape Architecture: Integrating Form and Space Using the Language of Site Design. Wiley, 2012, pg. 61-69

lbid.

Ibid.

John Blackburn, and Beth Herman, "Healthy Stables by Design: A Common Sense Approach to the Health and Safety of Horses" (Images Publishing ,2013) 22.

Young Architects Competitions, "Common Ruins" (2018) www.youngarchitectscompetitions.com/ competition/common-ruins\#competition (accessed 18/10/12).

Ibid.

Ibid 


\section{Endnotes}

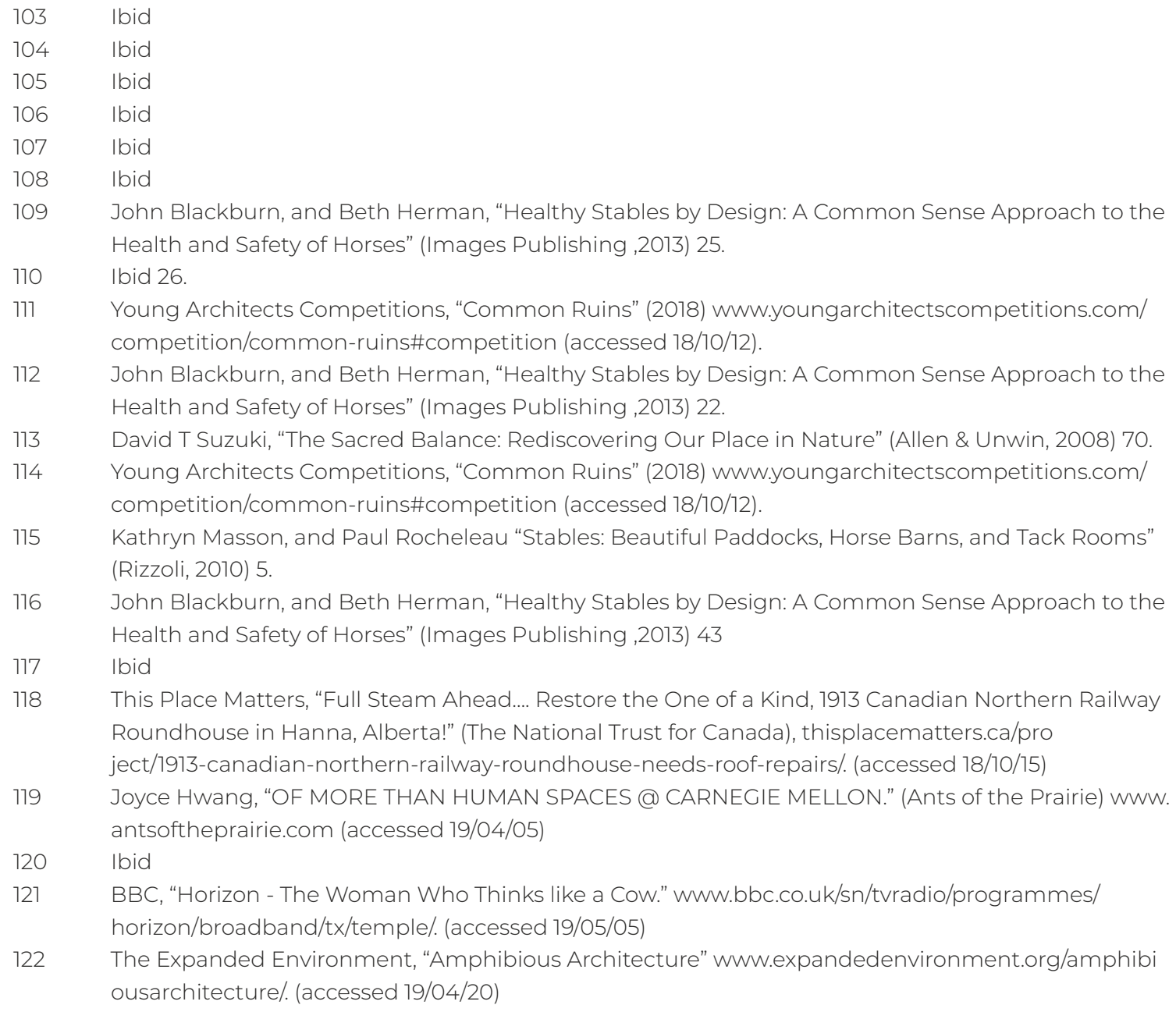




\section{Works Cited}

Abram, David. The Spell of the Sensuous: Perception and Language in a More-than-Human World. Vintage Books, 2017.

"Amphibious Architecture." The Expanded Environment, www.expandedenvironment.org/am phibiousarchitecture/. (accessed 19/04/20)

Blackburn, John, and Beth Herman. Healthy Stables by Design: A Common Sense Approach to the Health and Safety of Horses. Images Publishing., 2013.

Booth, Norman K. Foundations of Landscape Architecture: Integrating Form and Space Using the Language of Site Design. Wiley, 2012.

Bramble, Cate. Architects Guide to Feng Shui: Exploding the Myth. Routledge, 2016.

Cooke, Julia. "How to Make Architecture More Animal-Friendly." Curbed, Curbed, 10 May 2016, mww.curbed.com/2016/5/10/11640046/making-architecture-better-for-animals.

Curran, Ronald T., and Scarry, Elaine. "Dreaming by the Book." World Literature Today, vol. 74, no. 4, 2000, p. 908., doi:10.2307/40156303.

From Social Butterfly to Engaged Citizen : Urban Informatics, Social Media, Ubiquitous Comput ing, and Mobile Technology to Support Citizen Engagement, edited by Mar cus Foth, et al., MIT Press, 2017. ProQuest Ebook Central, https://ebookcen tral-proquest-com.proxy.library.carleton.ca/lib/oculcarleton-ebooks/detail.action 


\section{Works Cited Continued}

Grandin, Temple. "About Temple Grandin." Welcome to Temple Grandin's Official Autism Website, unw.templegrandin.com/templehome.html. (accessed 19/05/03)

Hayes, Tim, and Redford. Robert. Riding Home: The Power of Horses to Heal. St. Martins Griffin, 2016.

Haraway, Donna Jeanne. When Species Meet. University of Minnesota Press.

"Horizon - The Woman Who Thinks like a Cow." BBC, BBC, www.bbc.co.uk/sn/tvradio/pro grammes/horizon/broadband/tx/temple/. (accessed 19/05/03)

Hwang, Joyce. "OF MORE THAN HUMAN SPACES @ CARNEGIE MELLON." Ants of the Prairie, wuw.antsoftheprairie.com/. (accessed 19/02/74)

Lee, Patina. "The Evolution of French Architecture." Widewalls, Dec. 2016, wnw.widewalls.ch/ french-architecture/.

Lowell, Steve. "Roman Chariots, Railroad Tracks, Milspecs and Urban Legends." Defense Stan dardization Program Journal, Aug. 2017.

Masson, Kathryn, and Paul Rocheleau. Stables: Beautiful Paddocks, Horse Barns, and Tack Rooms. Rizzoli, 2010.1

Pallasmaa, Juhani. The Eyes of the Skin. Wiley.

Prime Stables. "A Complete History of Horse Stables Through The Ages." Prime Stables, 4 Sept. 2018, www.primestables.co.uk/equestrian-buildings/a-complete-history-of-horsestables-through-the-ages/. (accessed 18/10/20). 


\title{
Works Cited Continued
}

\author{
Shaffer, Peter. Equus. Scribner, 2005. \\ Suzuki, David T., et al. The Sacred Balance: Rediscovering Our Place in Nature. Allen \& Unwin, \\ 2008. \\ Suzuki, David, and lan Hanington. Just Cool It!: the Climate Crisis and What We Can Do: a \\ Post-Paris Agreement Game Plan. Greystone Books,2017. \\ Terrazas, Beatriz. "Feng Shui Stable." Chicago Tribune, 28 Sept. 1999, www.chicagotribune.com/ \\ news/ct-xpm-1999-09-28-9909290026-story.html. (accessed 18/12/10). \\ Uexküll Jakob von. A Foray into the Worlds of Animals and Humans: with A Theory of Meaning. \\ University of Minnesota Press, 2010. \\ Woebken, C., and K. Okada. 2008. Animal Superpowers online project documentation. http:// \\ wuw.woebken.net/animalsuperpowers.htm. (accessed 19/01/20). \\ Wolch, Jennifer, and Owens, Marcus. "Animals in Contemporary Architecture and Design." Hum \\ animalia, 2017, wmw.depauw.edu/humanimalia/issue 16/wolch-owens.html\#disalvo. \\ Woolf, Virginia. Mrs. Dalloway..B. Tauchnitz, 1929. \\ "Young Architects Competitions." Common Ruins, Young Architects Competitions, www.youngar \\ chitectscompetitions.com/competition/comon-ruins\#competition. \\ Zyl, Miezan Van, and Elwyn Hartley Edwards. The Horse Encyclopedia. DK/Penguin Random \\ House, 2016.
}




\section{List of Figures}

\author{
Page iii \\ Figures 2-4: "Under-horse by Andrius \\ Burba" Photographs. 2017. <https://mm. \\ boredpanda.com/under-horse-i-photo- \\ graph-horses-from-underneath/?utm_ \\ source=google\&utm_medium=organic\&utm_ \\ campaign=organic> (accessed 17/19/2018).
}

\section{Page 25}

Figure 21: "Fear - Claustrophobia by Nicholas Oen" Photograph. 2018. < https://oss.adm ntu.edu.sg/oenw0001/fear-claustrophobia> (accessed 17/23/2018).

Figure 22: "Gross Country" Photograph. 2012. < http://blogrodeio.blogspot.com/2012/07/sertanejo-bruto.html> (accessed 17/23/2018)

Figure 23: "Lonely Barn by Donna Catterick" Photograph. 2011. <https://alwaysbackroads wordpress.com/2017/11/07/lonely-barn> (accessed 17/23/2018).

Figure 24: "The Light Inside the Barn by Wayne Tilcock" Photograph. 2011. https://ww.flickr.com/photos/42105057@ N02/6127541248> (accessed 17/23/2018).

\section{Page 34}

Figure 28: Healthy Stables by Design Diagram Blackburn, John, and Beth Herman. Healthy Stables by Design: A Common Sense Approach to the Health and Safety of Horses. Images Publishing., 2013.

\section{Page 46}

Figure 32: "Axis and Avenues at Versailles"Booth, Norman K. Foundations of Landscape Architecture: Integrating Form and Space Using the Language of Site Design. Wiley, 2012. (accessed 03/05/2019).

\section{Page 47}

Figure 33: "Agriculture Rows"Photograph. http://spice4life.co.za/lets_talk_business/africa-in-need-of-sustainable-agricultural-production/ > (accessed 03/05/2019)

Figure 34: "Rows of poplar trees in the countryside, Tuscany Italy"Photograph. < https:// mw.123rf.com/photo_78153682_rows-of-poplar-trees-in-the-countryside-tuscany-italy. html> (accessed 03/05/2019).

Figure 35: "Bryce Canyon"Photograph 2009. < https:/Mmw.valleephotos.com/Travel/ Bryce-Canyon/> (accessed 03/05/2019).

\section{Page 52}

Figures 36-42: "Common Ruins by Young Architects Competitons" Photographs. 2018 $<$ https://mmw.youngarchitectscompetitions. com/competition/common-ruins\#competition> (accessed 12/2/2018). 


\title{
List of Figures
}

\author{
Page 102 \\ Figure 108: "Hanna roundhouse reunion \\ celebrates railroad history" Calgary Herald. \\ News Article. 2015. < https://calgaryherald. \\ com/news/local-news/hanna-roundhouse-re- \\ union-celebrates-railroad-history> (accessed \\ 11/10/2018)
}

Figure 109: "Full Steam Ahead.... Restore the One of a Kind, 1913 Canadian Northern Railway Roundhouse in Hanna, Alberta!" This Place Matters. Photograph. 2018. < https://this placematters.ca/project/1913-canadian-northern-railway-roundhouse-needs-roof-repairs/> (accessed 17/10/2018).

\section{Page 106}

Figures 113-114: Bat Tower Drawings. Ants of the Prairie. < http://mw.antsoftheprairie.com> (accessed 03/05/2019)

Figures 115-116: Co-Habitat Drawings. Ants of the Prairie. < http://mw. antsoftheprairie.com> (accessed 03/05/2019)

\section{Page 107}

Figure 117: Working With Farm Animals. Book Cover Page, Author Temple Grandin. <httos://www.amazon.com/Temple-Grandins-Guide-Working-Animals/dp/1612127444 > (accessed 03/05/2019)

Figure 118: Amphibious Architecture. Photograph and Diagram by Natalie Jeremijenko \& Chris Woebken. <https://wnw.depauw.edu/ humanimalia/issue\%2016/wolch-owens.html > (accessed 03/05/2019) 


\section{Appendix A}

\section{Site Study: Canada}

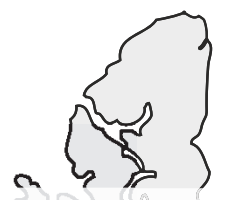

A brief site study of Canada explores the expansion of hippotherapy centers from Europe to North America. Canada has the proper market for hippotherapy centers, especially in Alberta, Saskatchewan and Ontario where there is ample pasteurized land, farmers, and horses. As seen on Figure 31: Canada's Horse Statistics, accredited hippotherapy centers a spread throughout Canada, with the monopoly in Ontario.17

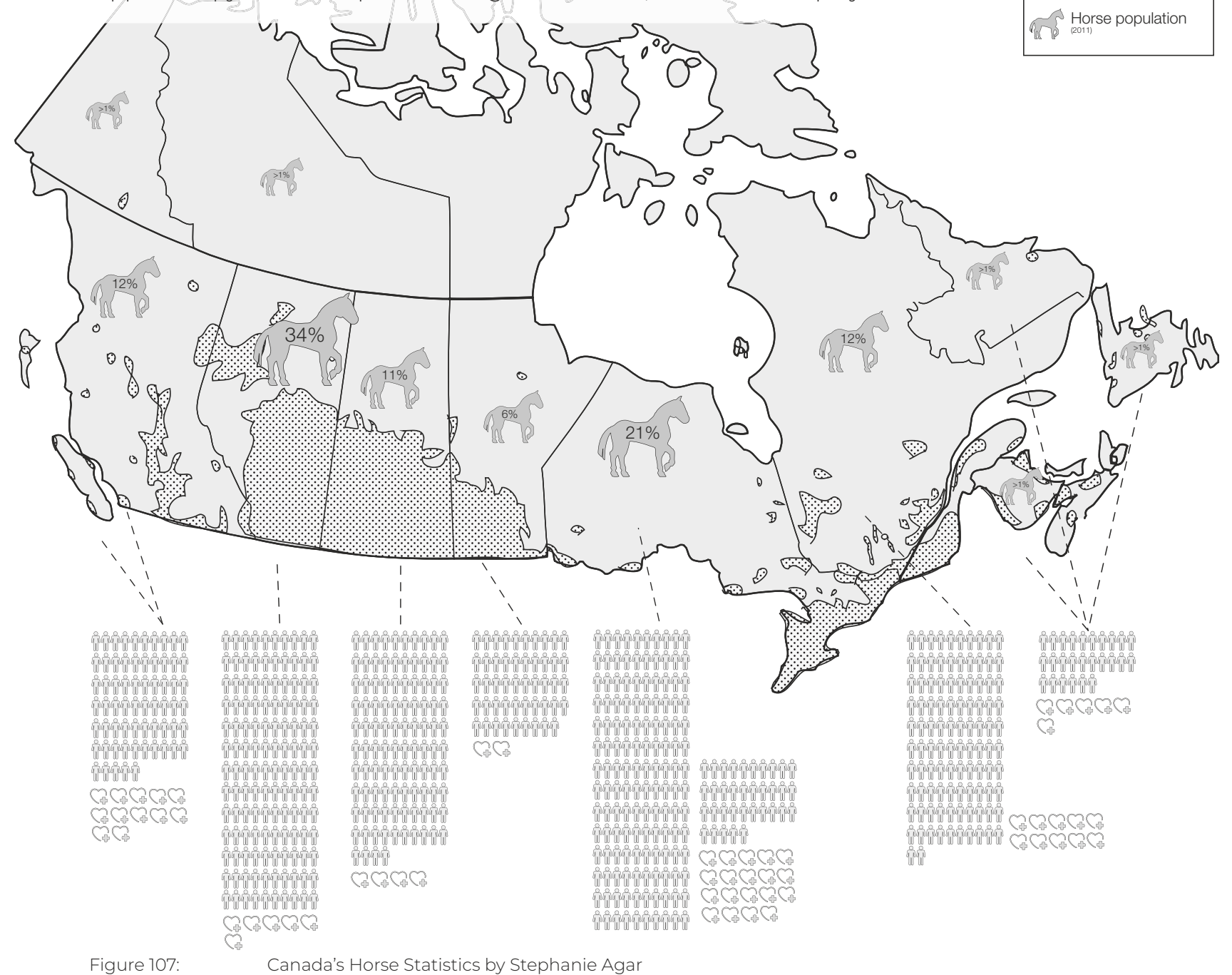




\section{Hanna Roundhouse, Alberta}

$\begin{array}{ll}\text { Constructed: } & 1913 \\ \text { Previous Program: } & \begin{array}{l}\text { Canadian National Railway } \\ \text { roundhouse }\end{array} \\ \text { Construction Type: } & \text { Multi wythe brick and wood } \\ \text { Town: } & \text { Hanna } \\ \text { Region: } & \text { Southern Alberta, } \\ & \text { Special Area No. } 2 \\ \text { Last Use: } & \text { 1961 } \\ \text { Condition: } & \text { Abandoned } \\ \text { Events: } & \text { Five stall addition in 1921 } \\ & \text { Roundhouse Restoration Project }\end{array}$

"This roundhouse was built by Canadian Northern Railway in 1973 to support the settlement of Western Canada. People were brought to Alberta by the railway to settle and farm Western Canada. Farmers and immigrants were employed by the railway, constructing bridges and railroad tracks, and every position available with the railroad. As a result, money was earned by workers to help them and their families survive life on the prairie. Many of those workers stayed with the railroad for 30-50 years of service, and some workers lost their lives building or working for the railroad. The Town of Hanna was selected a Canadian Northern Railway Divisional Point, servicing steam engines from 1913 until CNR decommissioned the roundhouse in 1967 and doors were closed. Settling Western Canada was a very important "mission" for the railway and the Canadian government. Farmers were needed to grow food to support Eastern Canada, as well as themselves. The Railway provided employment for all, skilled and unskilled men, and as a result, people came West to find work and many small towns were created along the railway." "7s

-This Place Matters Website Funding
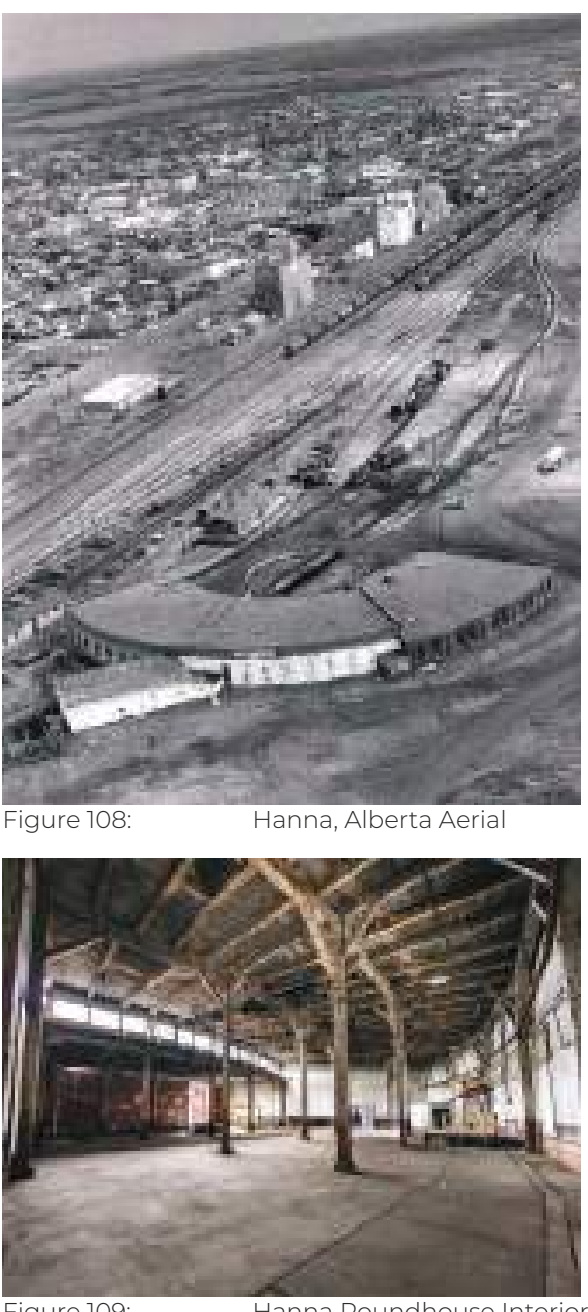

Figure 109:

Hanna Roundhouse Interior

Equus As Client: A Biocentric Retreat 


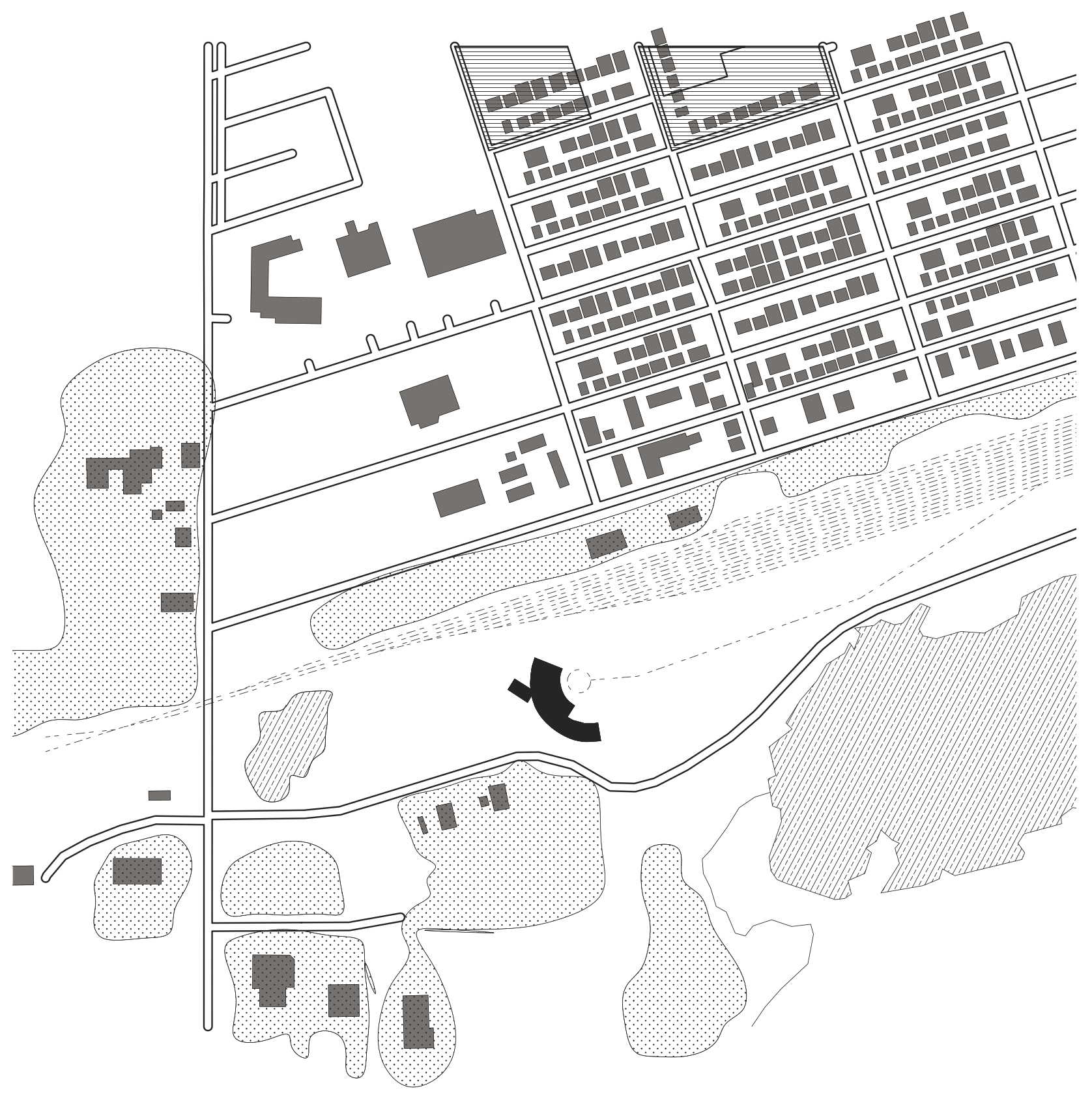

Figure 110: Hanna, Alberta Site Plan by Stephanie Agar 


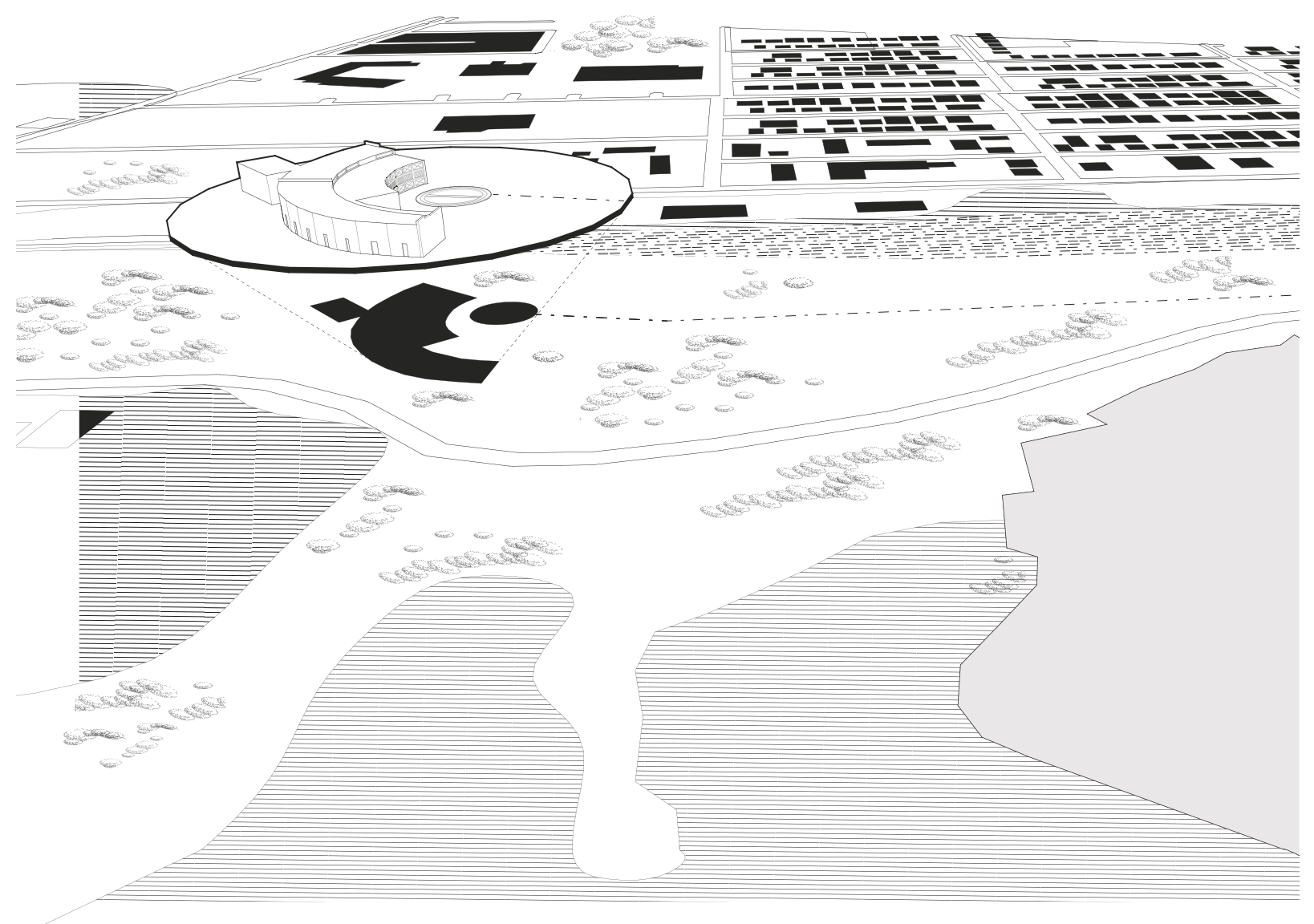

Figure 111: Hanna, Alberta Axonometric Drawing by Stephanie Agar 


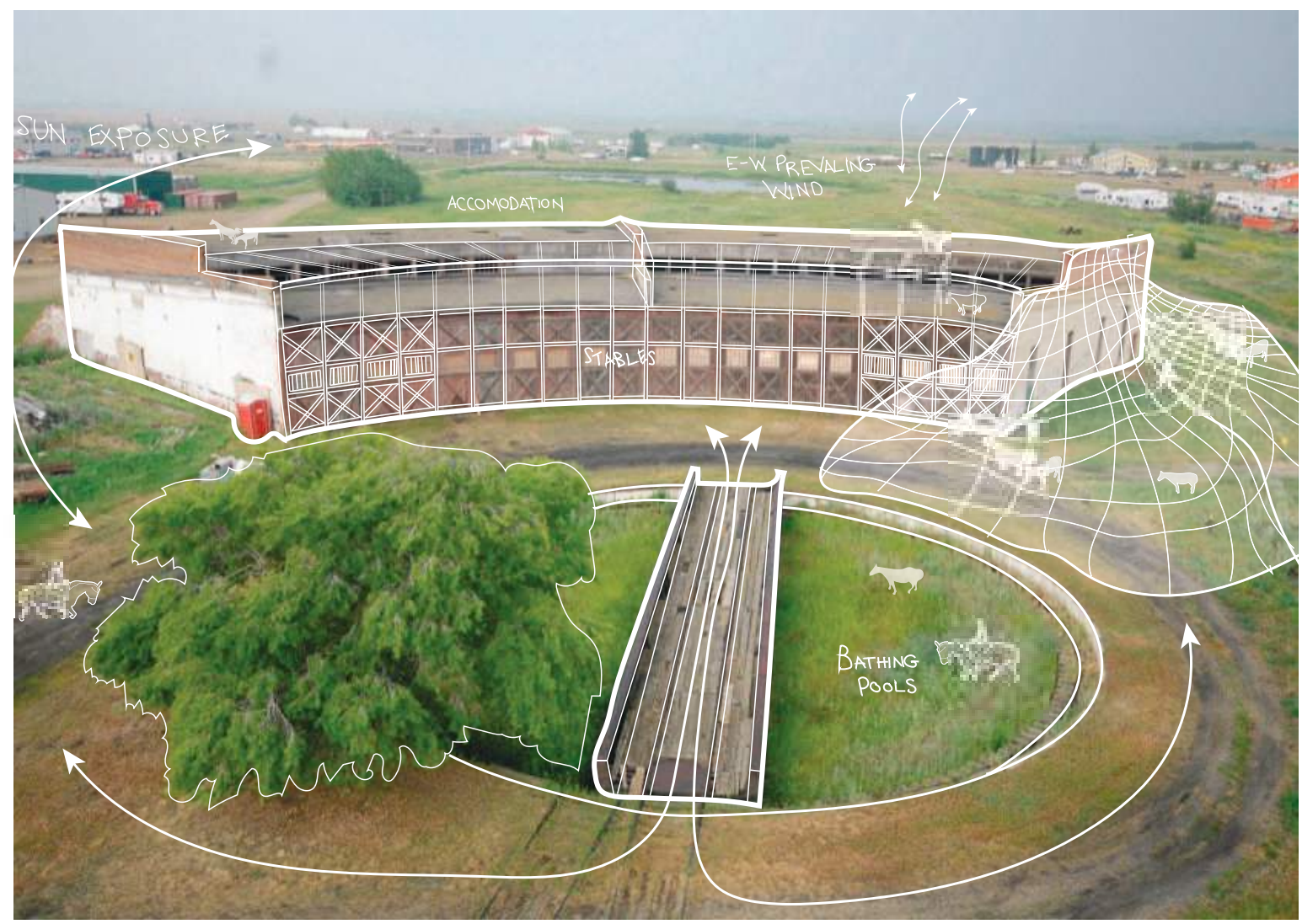

Figure 112: Hanna, Alberta Sketch by Stephanie Agar 


\section{Appendix B}

\section{Precedent Biocentric Projects}

Griffis Sculpture Park, East Otto, NY : Ashford Hollow Foundation by Ants of the Prairie, 2010

"BATTOWER is the first built prototype in a series of bat habitation projects which explore strategies for increasing public awareness of bats as a critical component of our ecosystem. Bats are effective as natural pesticides, pollinators, and mosquito abatement. Yet they are often considered as a kind of urban pest, and are frequently exterminated by human-run 'pest control' services. Their very survival is also being challenged by White Nose Syndrome, a disease which has inexplicably been wiping out large bat populations in northeastern United States.

In an attempt to bring visibility to bats, BAT TOWER challenges notions of the typical off-the-shelf bat house. Rather than innocuously fading into the background, the tower stands as a prominently visible outdoor sculpture. Drawing from the idea of a vertical cave, the installation has a heavy and intense presence, contrasting the lightness and invisibility associated with do-ityourself bat house constructions.

BAT TOWER is sited and designed to attract and facilitate bat inhabitation. Located adjacent to a lake, the site boasts an abundance of mosquitoes and other bat-attracting insects. Chives, oregano and other bat-attracting herbs are planted within the base of the tower. To help facilitate entry, the project's ribbed construction includes a series of 'landing pads' near the top of the tower. A pattern of grooves on both vertical and horizontal surfaces allows bats to more easily climb into the tower and cling to its 'ceilings.' To provide a suitably warm interior for bat roosting, dark wood panels cover the tower's inhabitation zone in order to absorb sunlight." 119

Co-Habitat , A Room for London Competition, by Ants of the Prairie 2010

"A Rooftop Habitation for humans and animals: Guests of CO-HABITAT are situated between and along a series of urban wildlife habitation structures, designed particularly to attract and accommodate birds and bats. As natural pollinators and 'pesticides,' these animals would stimulate the growth of rooftop crops and other vegetation over time. With potential opportunities to see birds nesting or bats hunting for mosquitoes (consequently providing a natural means of mosquito-abatement for humans), CO-HABITAT is an experience for recreational enthusiasts of urban nature and scientists alike. From the project's interior spaces, human inhabitants will become extra-aware of their surrounding environment through vision. The project proposes a wall system comprised of mirrored-louvers that would mediate selected views toward the city. The effects of these mirrors would draw attention to the urban context by fragmenting the skyline, as well as creating visual repetitions, for example situations where one sees the same iconic building reflected multiple times. Additionally the presence of bats and birds, as they fly in and out of their nesting sheds, would be visually intensified through this system of reflections." 120

Equus As Client: A Biocentric Retreat

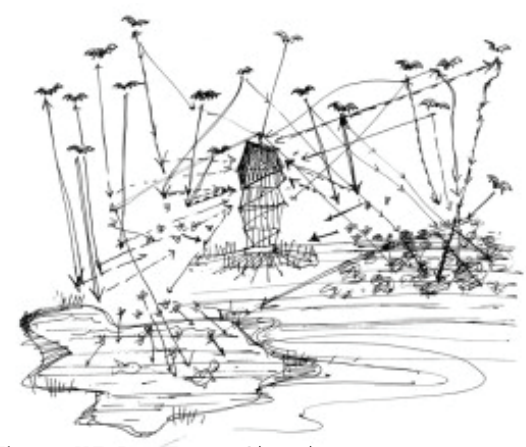

Figure 113: Bat Tower Sketch

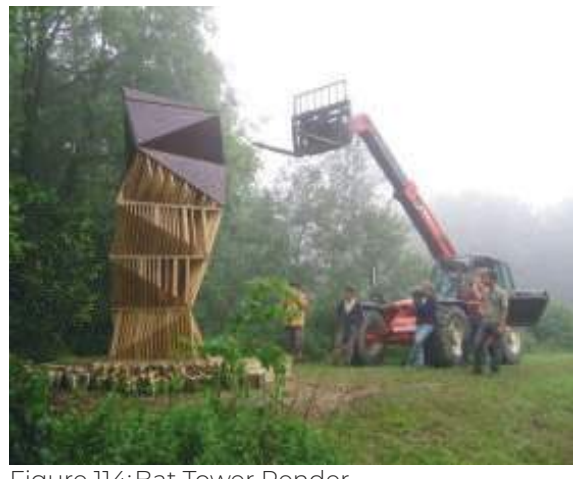

Figure 114: Bat Tower Render

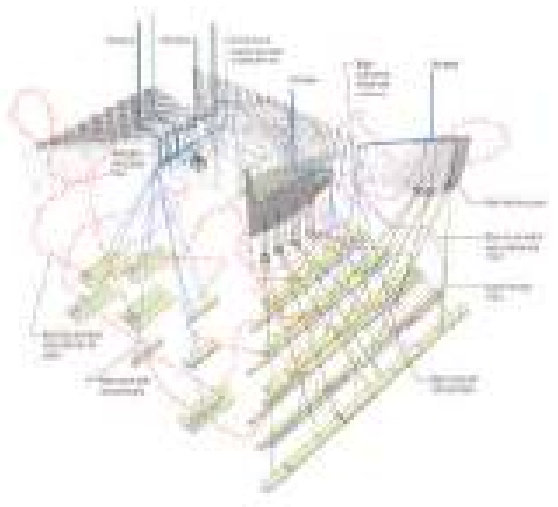

Figure 115: Co-habitat Diagram

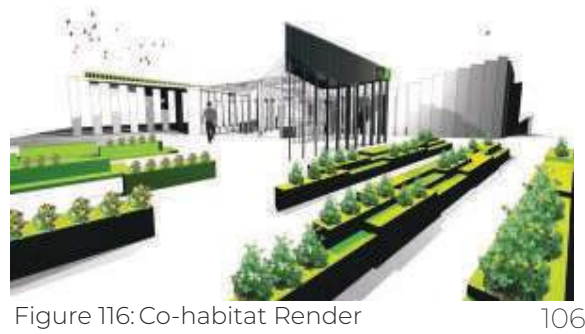


"Dr Temple Grandin has a unique ability to understand the animal mind - and she's convinced her skill is down to her autistic brain.

Temple believes she experiences life like an animal. Her emotions are much simpler than most people's and she feels constantly anxious. It's this struggle with overwhelming anxiety that led her to discover just how much she has in common with animals and, in particular, cows.

Using her ability to observe the world through an animal's eye, she has been able to make an enormous impact on animal welfare. Her greatest achievement has been in the area of slaughterhouses - she has fundamentally changed the way animals are held and slaughtered.

Today she's an associate professor of animal science, a best-selling author and the most famous autistic woman on the planet." 127

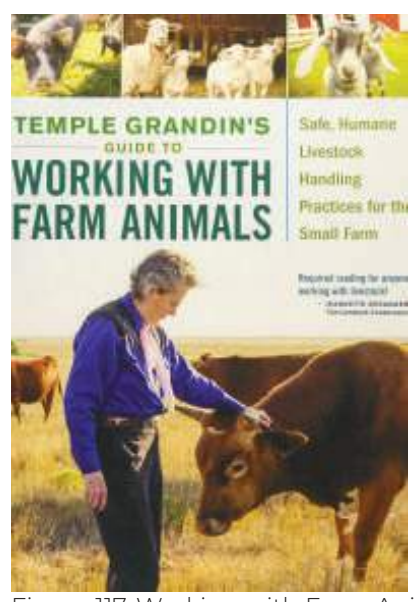

Figure 117: Working with Farm Animals Book Cover

\section{Amphibious Architecture by Natalie Jeremijenko and Chris Woebken}

"The now completed Amphibious Architecture project seeks to captivate participants by immersing them into the ebbs and flows of aquatic ecosystems - areas that are generally under-explored and under-engaged in the public realm. Installed in the East and Bronx Rivers in New York City, the glowing flotilla consists of sensors below the water and lights above. The sensors monitor water quality and fish presence, and the lights react to the information being collected by their gatherer counterparts below the water. Anyone can text message the sensors to receive real time information about the status of the river. This urge to make the invisible visible to the public is compelling, overlapping a myriad of social and ecological networks throughout the city.

The team further describes the aim of the project as such:

Instead of treating the rivers with a "do-not-disturb" approach, the project encourages curiosity and engagement. Instead of treating the water as a reflective surface to mirror our own image and our own architecture, the project establishes a two-way interface between environments of land and water." 22

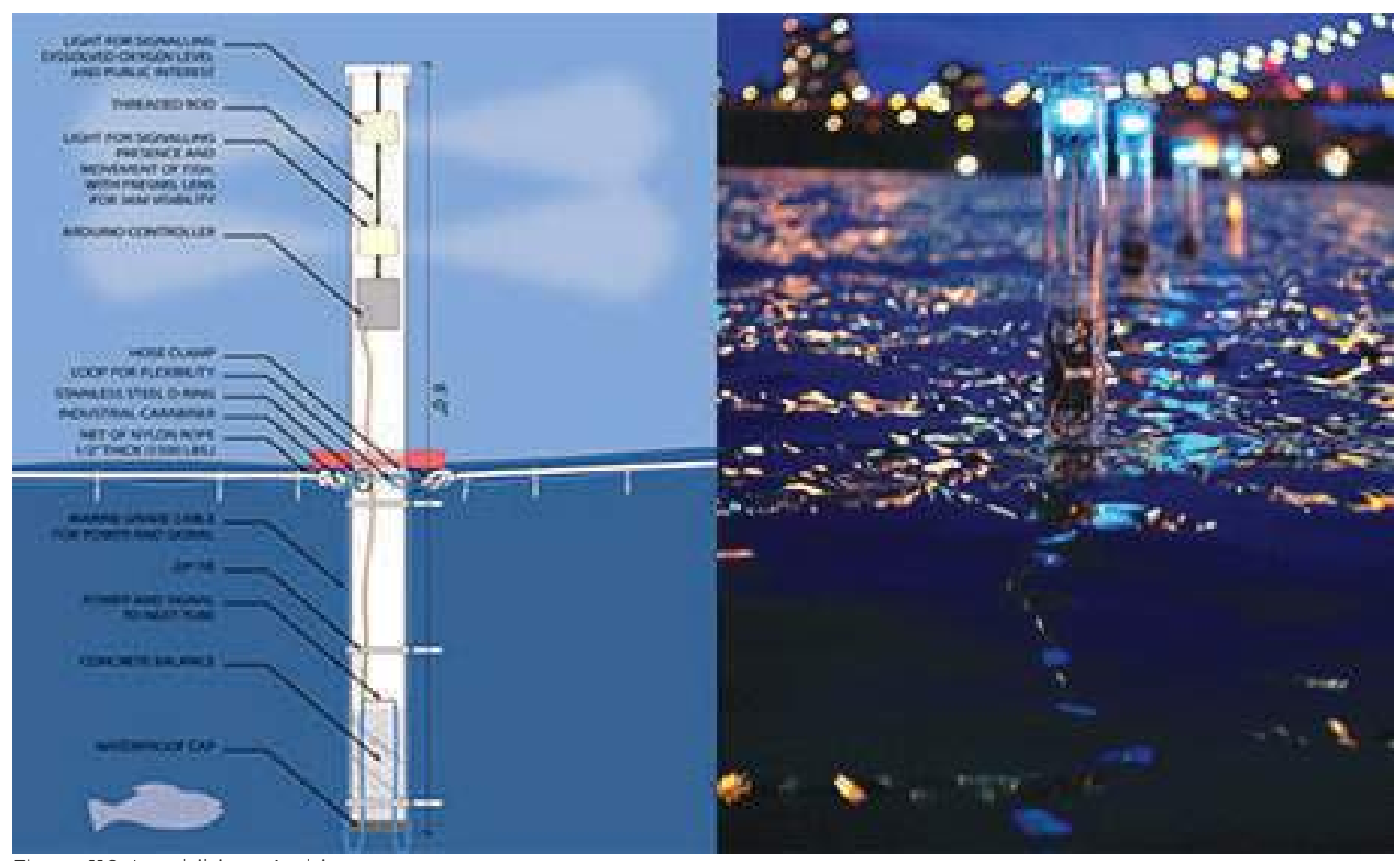

Figure 118: Amphibious Architecture

Equus As Client: A Biocentric Retreat 
Equus As Client: A Biocentric Retreat by Stephanie Agar

2019 